\title{
The 2018 version of the gene table of monogenic neuromuscular disorders (nuclear genome)
}

\author{
Gisèle Bonne ${ }^{\mathrm{a}, *}$, François Rivier ${ }^{\mathrm{b}}$, Dalil Hamroun ${ }^{\mathrm{c}}$ \\ a'Sorbonne Universités, UPMC Univ Paris 06, INSERM UMRS974, Centre de Recherche en Myologie, Institut de Myologie, G.H. Pitié-Salpêtrière, Paris, France \\ ${ }^{\mathrm{b}}$ Neuropédiatrie \& CR Maladies Neuromusculaires, CHU de Montpellier, U1046 INSERM, UMR9214 CNRS, Université de Montpellier, France \\ ${ }^{\circ}$ CHRU de Montpellier, Direction de la Recherche et de l'Innovation, Hôpital La Colombière, 39 Avenue Charles Flahault, Montpellier 34295, France
}

\section{General features}

This table is published annually in the December issue. Its purpose is to provide the reader of Neuromuscular Disorders with an updated list of monogenic muscle diseases due to a primary defect residing in the nuclear genome. It comprises diseases in which the causative gene is known or at least localized on a chromosome, if not yet identified. Diseases for which the locus has not been mapped or which are due to defects involving mitochondrial genes are not included. ${ }^{1}$

As in past years the diseases are classified into 16 groups:

1. Muscular dystrophies;

2. Congenital muscular dystrophies;

3. Congenital myopathies;

4. Distal myopathies;

5. Other myopathies;

6. Myotonic syndromes;

7. Ion channel muscle diseases;

8. Malignant hyperthermias;

9. Metabolic myopathies;

10. Hereditary cardiomyopathies, subdivided into

$10 \mathrm{~A}$ (non-arrhythmogenic) and

10B (arrhythmogenic);

11. Congenital myasthenic syndromes;

12. Motor neurone diseases;

13. Hereditary ataxias;

14. Hereditary motor and sensory neuropathies;

15. Hereditary paraplegias;

16. Other neuromuscular disorders.

\footnotetext{
* Corresponding author. Sorbonne Universités, UPMC Univ Paris 06, INSERM UMRS974, Centre de Recherche en Myologie, Paris, France. Fax: +33142165700.

E-mail address: g.bonne@institut-myologie.org (G. Bonne).

${ }^{1}$ For diseases caused by mitochondrial genome mutations see: MITOMAP A human mitochondrial genome database. A compendium of polymorphisms and mutations of the human mitochondrial DNA http://www.mitomap.org/ MITOMAP.
}

In each group every entry corresponds to a clinical entity and has an item number. ${ }^{2} \mathrm{~A}$ given gene may be involved in several different clinical entities (phenotypic heterogeneity such as in LMNA defects) and conversely a given clinical entity may be produced by a defect in several possible alternative genes (genotypic heterogeneity such as in CMT). In some diseases both kinds of heterogeneity may occur. As a consequence a gene or a disease may be cited in several places of the table.

\section{The two versions of the gene table ${ }^{3}$}

The annual printed version below is abridged and does not contain the Arrhythmogenic Hereditary Cardiomyopathies (Group 10-B), Hereditary Ataxias (Group 13), and Hereditary Paraplegias (Group 15). The list of references is restricted to new key references corresponding to the items added or implemented since the preceding year.

The full online version contains the complete data of the 16 groups and the cumulative list of key references since 1991. It is freely accessible at http://www.musclegenetable.fr. It is designed to cope with the complexity described above. In this version the data are cross-referenced and linked to PubMed and to major databases related to molecular medicine (Leiden Muscular Dystrophy, OMIM, NCBI, Genatlas, Orphanet, GeneCards). It contains several query tools allowing one to perform a variety of interrogations. This computerized version of the table is now surpassing the printed version which cannot accommodate the ever increasing volume and complexity of data. The statistics tool instantly provides the latest list of genes, proteins, phenotypes and cumulative bibliographic key references. Each list can be displayed, printed and exported in Excel format.

\footnotetext{
2 The assigned item number is provisional and may change in the next annual version.

3 The history and development of both versions of the table are presented in the 2013 publication (Kaplan JC and Hamroun D. The 2013 version of the gene table of neuromuscular disorders. Neuromuscul Disord. 22 (12), 1108-1135.)
} 
Overview of the new data in the 2018 printed version of the gene table

There are 35 new items, marked by background shading. Altogether they comprise $\mathbf{2 8}$ additional genes and $\mathbf{8}$ additional phenotypic variants caused by a gene already listed in the 2017 version (see box).

New in the 2017 printed version of the gene table 28 genes added:

AIFM1 (item \# 16.34)

CALR3 (item \# 10.20)

CNTNAP1 (item \# 16.15)

DSG2 (item \# 10.59)

ERBB4 (item \# 12.57)

FASTKD2 (item \# 16.36)

FLAD1 (item \# 9.30)

$H R A S$ (item \# 3.50)

INPP5K (item \# 2.49)

LAMA5 (item \# 11.35)

$M Y M K$ (item \# 3.51)

MYO18B (item \# 3.49)

$M Y P N$ (item \# 3.11 and item \# 10.23)

NEFH (item \# 14.66)

PMP2 (item \# 14. 11)

POGLUT1 (item \# 1.46)

PRDM1 (item \# 10.68)

PTRH2 (item \# 16.37)

RAF1 (item \# 10.70)

SGPL1 (item \# 14.80)

SLC18A3 (item \# 11.27)

SLC25A46 (item \# 12.73)

SPTBN4 (item \# 3.47)

TMEM65 (item \# 16.35)

TUBA4A (item \# 12.60)

VAMP1 (item \# 11.34 and item \#15.66)

WARS (item \# 12.23)

$Z A K$ (item \# 3.48)

8 additional phenotypic variants caused by mutation in a gene already listed in the gene table

\section{SMCHDI}

(item \# 1.11 allelic to BAMS (OMIM \#603457))

$D A G 1$ (item \# 2.37)

GYG1 (item \# 9.12)

$\angle D B 3$ (item \# 10.25)

TCAP (item \# 10.26)

$B A G 3$ (item \# 10.64 and 14.67)

VCP (item \# 14.61)

\section{1 new gene for a previously identified locus}

SIGMAR1 (item \#12.6, allelic to item \# 12.54)

40 new key references

\section{Contact}

Users of the gene table are kindly requested to send any comments on the printed and/or the online version to g.bonne@institut-myologie.org.

\section{Acknowledgements}

We are extremely thankful to Jean-Claude Kaplan for his constant trust and support in giving us the opportunity to take over the maintenance of the "Muscle Gene Table" he initiated in 1991. We sincerely wish him an enjoyable retirement from the Gene Table, knowing he will keep a kindly eye on it. We sincerely thank Tanya Stojkovic for her careful review of entries in group 14.

We acknowledge the help of Myobase, a bibliographic alert system of the AFM (Asscociation Française contre les Myopathies), URL: http://www.myobase.org/

We are extremely appreciative of the invaluable assistance provided by Jane Miller at all stages of elaboration and editing of this table. 


\section{Gene table of monogenic neuromuscular disorders (nuclear genome only)}

A computerized version of the table is freely accessible at $h t t p: / / w w w . m u s c l e g e n e t a b l e . f r /$

Shaded background indicates newly added items.

\begin{tabular}{|c|c|c|c|c|c|c|c|c|}
\hline DISEASE NAME & $\begin{array}{l}\text { Item } \\
\text { line } \\
\text { in this } \\
\text { group }\end{array}$ & Inheritance & $\begin{array}{l}\text { Locus or } \\
\text { disease } \\
\text { symbol and } \\
\text { OMIM } \\
\text { number }\end{array}$ & Chromosome & $\begin{array}{l}\text { Gene symbol } \\
\text { and OMIM } \\
\text { number }\end{array}$ & $\begin{array}{l}\text { Protein } \\
\text { (mitochondrial } \\
\text { proteins indicated } \\
\text { by symbol }[M] \text { ) }\end{array}$ & $\begin{array}{l}\text { Key } \\
\text { references }\end{array}$ & $\begin{array}{l}\text { Other allelic disease(s) } \\
\text { (group in this table) }\end{array}$ \\
\hline
\end{tabular}

\section{GROUP 1. MUSCULAR DYSTROPHIES}

Duchenne muscular dystrophy; $1.1 \quad$ XR

Becker muscular dystrophy

DMD

Emery-Dreifuss muscular

dystrophy, X-linked, type 1

$1.2 \quad \mathrm{XR}$

310200

DMD

300377

300376

EDMD1

310300

$\mathrm{Xq} 28$

EMD

300384

Emery-Dreifuss muscular

dystrophy, X-linked, type 2

$1.3 \quad \mathrm{XR}$

Emery-Dreifuss muscular

dystrophy, autosomal dominant

1.4

$1.4 \quad \mathrm{AD}$

\section{EDMD6}

300696

$\mathrm{Xq} 27.2$

EDMD2

181350

300163

1q21.2 LMNA

150330
Emery-Dreifuss muscular

dystrophy, autosomal recessive

$1.5 \quad \mathrm{AR}$

AR

EDMD3

181350 1q21.2

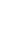

LMNA

150330
Nesprin-1 related muscular dystrophy

Nesprin-2 related muscular

dystrophy

LUMA-related muscular dystrophy

LAP1B-related muscular dystrophy
1.6 $\mathrm{AD}$

612998

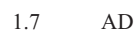

$1.8 \quad \mathrm{AD}$

$1.9 \quad \mathrm{AR}$

612999

614302
EDMD4 6q25 $\quad$ SYNE1

EDMD5

$14 \mathrm{q} 23$

SYNE2

608442

EDMD7

1q25.2
Four and a half LIM domain 1

$\operatorname{Lamin} \mathrm{A} / \mathrm{C}$
$\operatorname{Lamin} \mathrm{A} / \mathrm{C}$
Monaco et al. (1986)

Burghes et al. (1987)

Koenig et al. $(1987,1988)$

Hoffman et al. $(1987,1988)$

Hodgson et al. (1986)

Romeo et al. (1988)

Bione et al. (1994, 1995)

Klauck et al. (1995)

Nigro et al. (1995)

Gueneau et al. (2009)

Bonne et al. (1999)

Worman and Bonne (2007)

Raffaele di Barletta et al. (2000) Worman and Bonne (2007)

Spectrin repeat containing, nuclear envelope 1

(nesprin-1)

Spectrin repeat containing, nuclear envelope 2 (nesprin-2)

Transmembrane protein 43

(=LUMA)

Torsin A interacting

protein 1

(=Lamin-Associated

Peptide 1B)

Zhang et al. (2007)

Liang et al. (2011)

Kayman-Kurekci et al. (2014)
Zhang et al. (2007)
Allelic to CMD3B (group 10

Allelic to RSS (2), XPMA (5), XPMD (5), reducing body myopathy (group 5)

Allelic to EDMD3 (group 1), LGMD1B (group1), CMD1A (group 10), CMT2B1 (group

14), [+ several other phenotypes not in this table: FPLD2/151660, HGPS/176670, restrictive dermopathy/275210, MADA/248370]

Allelic to EDMD2 (group 1), LGMD1B (group 1), CMD1A (group 10), CMT2B1 (group

14), [+ several other phenotypes not in this table FPLD2/151660, HGPS/176670, restrictive dermopathy/275210, not in this table] Allelic to dilated cardiomyopathy with nesprin-1 defect (group 10), SCAR8 (group 13), AMC with nesprin-1 defect (group 16)

Allelic to ARVD5 (group 10)
(=LAP1B)

614512 


\begin{tabular}{|c|c|c|c|c|c|c|c|c|}
\hline DISEASE NAME & $\begin{array}{l}\text { Item } \\
\text { line } \\
\text { in this } \\
\text { group }\end{array}$ & Inheritance & $\begin{array}{l}\text { Locus or } \\
\text { disease } \\
\text { symbol and } \\
\text { OMIM } \\
\text { number }\end{array}$ & Chromosome & $\begin{array}{l}\text { Gene symbol } \\
\text { and OMIM } \\
\text { number }\end{array}$ & $\begin{array}{l}\text { Protein } \\
\text { (mitochondrial } \\
\text { proteins indicated } \\
\text { by symbol }[M] \text { ) }\end{array}$ & $\begin{array}{l}\text { Key } \\
\text { references }\end{array}$ & $\begin{array}{l}\text { Other allelic disease(s) } \\
\text { (group in this table) }\end{array}$ \\
\hline $\begin{array}{l}\text { Facioscapulohumeral muscular } \\
\text { dystrophy, type } 1\end{array}$ & 1.10 & $\mathrm{AD}$ & $\begin{array}{l}\text { FSHMD1A } \\
158900\end{array}$ & $4 q 35$ & $\begin{array}{l}\text { DUX } 4^{*} \\
606009 \\
\left({ }^{*} \text { inappropriate }\right. \\
\text { reactivation) }\end{array}$ & $\begin{array}{l}\text { Double homeobox } \\
4\end{array}$ & $\begin{array}{l}\text { Wijmenga et al. (1990, } \\
\text { 1991, 1992, 1993) } \\
\text { Upadhyaya et al. (1990, } \\
\text { 1992) } \\
\text { Wright et al. (1993), van } \\
\text { Deutekom et al. (1993) } \\
\text { Gabellini et al. (2002), Van } \\
\text { der Maarel et al. (2005) } \\
\text { Gabellini et al. (2006) } \\
\text { Petrov et al. (2006) } \\
\text { Lemmers et al. (2010) }\end{array}$ & \\
\hline $\begin{array}{l}\text { Facioscapulohumeral muscular } \\
\text { dystrophy, type } 2\end{array}$ & 1.11 & $\mathrm{AD}$ & $\begin{array}{l}\text { FSHMD1B } \\
158901\end{array}$ & $18 \mathrm{p} 11.32$ & $\begin{array}{l}\text { SMCHDI* } \\
\text { (=KIAA0650) } \\
614982 \\
\left({ }^{*} \text { causing }\right. \\
\text { inappropriate } \\
\text { reactivation of } \\
\text { DUX } 4 * 606009)\end{array}$ & $\begin{array}{l}\text { Structural } \\
\text { maintenance of } \\
\text { chromosomes } \\
\text { flexible hinge } \\
\text { domain containing } \\
1\end{array}$ & $\begin{array}{l}\text { de Greef et al. (2010) } \\
\text { Sacconi et al. (2012) } \\
\text { Lemmers et al. (2012) } \\
\text { Sacconi et al. (2013) }\end{array}$ & $\begin{array}{l}\text { Allelic to Bosma Arhinia } \\
\text { Microphthalmia Syndrome; } \\
\text { BAMS (\#603457) }\end{array}$ \\
\hline $\begin{array}{l}\text { Muscular dystrophy with } \\
\text { generalized lipodystrophy }\end{array}$ & 1.12 & $\mathrm{AD}$ & & $17 \mathrm{q} 21-\mathrm{q} 23$ & $\begin{array}{l}\text { PTRF } \\
603198\end{array}$ & $\begin{array}{l}\text { Polymerase I and } \\
\text { transcript release } \\
\text { factor } \\
\text { (cavin-1) }\end{array}$ & Hayashi et al. (2009) & \\
\hline \multicolumn{9}{|c|}{ Limb girdle muscular dystrophies, dominant } \\
\hline LGMD1A & 1.13 & $\mathrm{AD}$ & $\begin{array}{l}\text { LGMD1A } \\
159000\end{array}$ & $5 q 31$ & $\begin{array}{l}\text { MYOT } \\
604103\end{array}$ & $\begin{array}{l}\text { Myotilin (titin } \\
\text { immunoglobulin } \\
\text { domain protein) }\end{array}$ & $\begin{array}{l}\text { Speer et al. (1992) } \\
\text { Hauser et al. (2000) }\end{array}$ & $\begin{array}{l}\text { Allelic to distal myotilinopathy } \\
\text { (group 4), MFM (group 5), } \\
\text { spheroid body myopathy } \\
\text { (group 5) }\end{array}$ \\
\hline LGMD1B & 1.14 & $\mathrm{AD}$ & $\begin{array}{l}\text { LGMD1B } \\
159001\end{array}$ & $1 \mathrm{q} 21.2$ & $\begin{array}{l}\boldsymbol{L M N A} \\
150330\end{array}$ & Lamin $\mathrm{A} / \mathrm{C}$ & $\begin{array}{l}\text { van der Koo et al (1997) } \\
\text { Muchir et al. (2000) } \\
\text { Worman and Bonne (2007) }\end{array}$ & $\begin{array}{l}\text { Allelic to EDMD2 (group1), } \\
\text { EDMD3 (group1), CMD1A } \\
\text { (group10), CMT2B1 } \\
\text { (group14), [+ several other } \\
\text { phenotypes FPLD2/151660, } \\
\text { HGPS/176670, restrictive } \\
\text { dermopathy/275210, not in this } \\
\text { table] }\end{array}$ \\
\hline LGMD1C & 1.15 & $\mathrm{AD}$ & $\begin{array}{l}\text { LGMD1C } \\
607801\end{array}$ & $3 \mathrm{p} 25$ & $\begin{array}{l}\text { CAV3 } \\
601253\end{array}$ & Caveolin-3 & $\begin{array}{l}\text { Minetti et al. (1998) } \\
\text { McNally et al. (1998) }\end{array}$ & $\begin{array}{l}\text { Allelic to distal myopathy } \\
\text { (group 4), hyper CKemia } \\
\text { (group 5), RMD2 (group 6), } \\
\text { CMH (group 10), LQT9 (group } \\
\text { 10). }\end{array}$ \\
\hline LGMD1D & 1.16 & $\mathrm{AD}$ & $\begin{array}{l}\text { LGMD1D } \\
603511\end{array}$ & $7 \mathrm{q} 36$ & $\begin{array}{l}\text { DNAJB6 } \\
611332\end{array}$ & $\begin{array}{l}\text { Hsp40 homolog, } \\
\text { subfamily B, } \\
\text { number } 6\end{array}$ & $\begin{array}{l}\text { Speer et al. (1999), } \\
\text { Sarparanta et al (2012) } \\
\text { Harms et al. (2012) }\end{array}$ & \\
\hline LGMD1E & 1.17 & $\mathrm{AD}$ & $\begin{array}{l}\text { LGMD1E } \\
602067\end{array}$ & $6 \mathrm{q} 23$ & $\begin{array}{l}\text { DES } \\
125660\end{array}$ & Desmin & $\begin{array}{l}\text { Messina et al. (1997) } \\
\text { Greenberg et al. (2012) } \\
\text { Hedberg et al. (2012) }\end{array}$ & $\begin{array}{l}\text { Allelic to myofibrillar } \\
\text { myopathy (group 5) and } \\
\text { CMD1I (group 10A), ARVD7 } \\
\text { (group 10B) }\end{array}$ \\
\hline LGMD1F & 1.18 & $\mathrm{AD}$ & $\begin{array}{l}\text { LGMD1F } \\
608423\end{array}$ & $7 \mathrm{q} 32.1-\mathrm{q} 32.2$ & $\begin{array}{l}\text { TNPO3 } \\
610032\end{array}$ & Transportin 3 & $\begin{array}{l}\text { Palenzuela et al. (2003) } \\
\text { Melià et al. (2013) } \\
\text { Torella et al. (2013) }\end{array}$ & \\
\hline LGMD1G & 1.19 & $\mathrm{AD}$ & $\begin{array}{l}\text { LGMD1G } \\
609115\end{array}$ & $4 \mathrm{q} 21$ & $\begin{array}{l}\text { HNRPDL } \\
607137\end{array}$ & $\begin{array}{l}\text { Heterogeneous } \\
\text { nuclear } \\
\text { ribonucleoprotein } \\
\text { D-like }\end{array}$ & $\begin{array}{l}\text { Starling et al. (2005) } \\
\text { Vieira et al. (2014) }\end{array}$ & \\
\hline LGMD1H & 1.20 & $\mathrm{AD}$ & $\begin{array}{l}\text { LGMD1H } \\
613530\end{array}$ & $3 \mathrm{p} 25.1-\mathrm{p} 23$ & $?$ & & Bisceglia et al. (2010) & \\
\hline \multicolumn{9}{|c|}{ Limb girdle muscular dystrophies, recessive } \\
\hline LGMD2A & 1.21 & AR & $\begin{array}{l}\text { LGMD2A } \\
253600\end{array}$ & $15 \mathrm{q} 15.1$ & $\begin{array}{l}C A P N 3 \\
114240\end{array}$ & calpain-3 & $\begin{array}{l}\text { Beckmann et al. (1991) } \\
\text { Young et al. (1992), Richard } \\
\text { et al. (1995, 1997) }\end{array}$ & \\
\hline LGMD2B & 1.22 & $\mathrm{AR}$ & $\begin{array}{l}\text { LGMD2B } \\
253601\end{array}$ & $2 \mathrm{p} 13.2$ & $\begin{array}{l}\text { DYSF } \\
603009\end{array}$ & dysferlin & $\begin{array}{l}\text { Bashir et al. (1994) } \\
\text { Bashir et al. (1998) } \\
\text { Liu et al. (1998) }\end{array}$ & Allelic to MM (group 4) \\
\hline LGMD2C & 1.23 & AR & $\begin{array}{l}\text { LGMD2C } \\
253700\end{array}$ & $13 \mathrm{q} 12$ & $\begin{array}{l}S G C G \\
608896\end{array}$ & Gamma-sarcoglycan & $\begin{array}{l}\text { Ben Othmane et al. (1992) } \\
\text { Azibi et al. (1993) } \\
\text { Noguchi et al. (1995) } \\
\text { McNally et al. (1996) } \\
\text { Piccolo et al. (1996) }\end{array}$ & \\
\hline
\end{tabular}




\begin{tabular}{|c|c|c|c|c|c|c|c|c|}
\hline DISEASE NAME & $\begin{array}{l}\text { Item } \\
\text { line } \\
\text { in this } \\
\text { group }\end{array}$ & Inheritance & $\begin{array}{l}\text { Locus or } \\
\text { disease } \\
\text { symbol and } \\
\text { OMIM } \\
\text { number }\end{array}$ & Chromosome & $\begin{array}{l}\text { Gene symbol } \\
\text { and OMIM } \\
\text { number }\end{array}$ & $\begin{array}{l}\text { Protein } \\
\text { (mitochondrial } \\
\text { proteins indicated } \\
\text { by symbol }[M] \text { ) }\end{array}$ & $\begin{array}{l}\text { Key } \\
\text { references }\end{array}$ & $\begin{array}{l}\text { Other allelic disease(s) } \\
\text { (group in this table) }\end{array}$ \\
\hline LGMD2D & 1.24 & AR & $\begin{array}{l}\text { LGMD2D } \\
608099\end{array}$ & $17 \mathrm{q} 21.33$ & $\begin{array}{l}\text { SGCA } \\
600119\end{array}$ & alpha-sarcoglycan & $\begin{array}{l}\text { Roberds et al. (1994) } \\
\text { Piccolo et al. (1995) } \\
\text { Passos-Bueno et al. (1995) } \\
\text { Ljunggren et al. (1995) } \\
\text { Carrié et al. (1997) }\end{array}$ & \\
\hline LGMD2E & 1.25 & AR & $\begin{array}{l}\text { LGMD2E } \\
604286\end{array}$ & $4 \mathrm{q} 12$ & $\begin{array}{l}S G C B \\
600900\end{array}$ & beta-sarcoglycan & $\begin{array}{l}\text { Lim et al. (1995) } \\
\text { Bönnemann et al. (1995) } \\
\text { Bönnemann et al. (1996) }\end{array}$ & \\
\hline LGMD2F & 1.26 & AR & $\begin{array}{l}\text { LGMD2F } \\
601287\end{array}$ & $5 \mathrm{q} 33.3$ & $\begin{array}{l}S G C D \\
601411\end{array}$ & delta-sarcoglycan & $\begin{array}{l}\text { Passos-Bueno et al. (1996) } \\
\text { Nigro et al. (1996) }\end{array}$ & Allelic to CMD1L (group 10) \\
\hline LGMD2G & 1.27 & $\mathrm{AR}$ & $\begin{array}{l}\text { LGMD2G } \\
601954\end{array}$ & $17 \mathrm{q} 12$ & $\begin{array}{l}\text { TCAP } \\
604488\end{array}$ & $\begin{array}{l}\text { titin-cap } \\
\text { (telethonin) }\end{array}$ & $\begin{array}{l}\text { Moreira et al. (1997) } \\
\text { Moreira et al. (2000) }\end{array}$ & $\begin{array}{l}\text { Allelic to congenital muscular } \\
\text { dystrophy with telethonin } \\
\text { defect (group 2), CMD1N } \\
\text { (group10) }\end{array}$ \\
\hline LGMD2H & 1.28 & AR & $\begin{array}{l}\text { LGMD2H } \\
254110\end{array}$ & $9 \mathrm{q} 31.2$ & $\begin{array}{l}\text { TRIM32 } \\
602290\end{array}$ & $\begin{array}{l}\text { tripartite } \\
\text { motif-containing } 32\end{array}$ & $\begin{array}{l}\text { Weiler et al. (1998) } \\
\text { Frosk et al. (2002) }\end{array}$ & $\begin{array}{l}\text { Allelic to sarcotubular } \\
\text { myopathy (group 3) }\end{array}$ \\
\hline LGMD2I & 1.29 & $\mathrm{AR}$ & $\begin{array}{l}\text { LGMD2I } \\
(\text { MDDGC5) } \\
607155\end{array}$ & $19 \mathrm{q} 13.3$ & $\begin{array}{l}\text { FKRP } \\
606596\end{array}$ & $\begin{array}{l}\text { fukutin-related } \\
\text { protein }\end{array}$ & $\begin{array}{l}\text { Driss et al. (2000) } \\
\text { Brockington et al. (2001a) }\end{array}$ & $\begin{array}{l}\text { Allelic to MDC1C (group 2), } \\
\text { WWS (group 2), MEB (group } \\
\text { 2) }\end{array}$ \\
\hline LGMD2J & 1.30 & $\mathrm{AR}$ & $\begin{array}{l}\text { LGMD2J } \\
608807\end{array}$ & $2 \mathrm{q} 31$ & $\begin{array}{l}\boldsymbol{T T N} \\
188840\end{array}$ & titin & Hackman et al. (2003) & $\begin{array}{l}\text { Allelic to congenital myopathy } \\
\text { with fatal cardiomyopathy } \\
\text { (group 3), TMD (group 4), } \\
\text { HMERF (group 5), CMH9 } \\
\text { (group10), CMD1G (group10) }\end{array}$ \\
\hline LGMD2K & 1.31 & $\mathrm{AR}$ & $\begin{array}{l}\text { LGMD2K } \\
\text { (MDDGC1) } \\
609308\end{array}$ & $9 \mathrm{q} 34.13$ & $\begin{array}{l}\text { POMT1 } \\
607423\end{array}$ & $\begin{array}{l}\text { protein } \\
\text { O-mannosyltransferase } \\
1\end{array}$ & $\begin{array}{l}\text { Balci et al. (2005) } \\
\text { D'Amico et al. (2006) }\end{array}$ & Allelic to WWS (group 2) \\
\hline LGMD2L & 1.32 & $\mathrm{AR}$ & $\begin{array}{l}\text { LGMD2L } \\
611307\end{array}$ & $11 \mathrm{p} 14.3$ & $\begin{array}{l}\text { ANO5 } \\
(\text { TMEM16E) } \\
608662\end{array}$ & anoctamin 5 & $\begin{array}{l}\text { Jarry et al. (2007), Bolduc } \\
\text { et al. }(2008,2010) \text {, Hicks } \\
\text { et al. }(2011)\end{array}$ & $\begin{array}{l}\text { Allelic to early onset calf distal } \\
\text { myopathy (group 4) }\end{array}$ \\
\hline LGMD2M & 1.33 & $\mathrm{AR}$ & $\begin{array}{l}\text { LGMD2M } \\
(\text { MDDGC4) } \\
611588\end{array}$ & $9 q 31-q 33$ & $\begin{array}{l}\boldsymbol{F K T N} \\
607440\end{array}$ & fukutin & $\begin{array}{l}\text { Murakami et al. (2006) } \\
\text { Godfrey et al. (2006) }\end{array}$ & $\begin{array}{l}\text { Allelic to FCMD (group 2), } \\
\text { WWS (group2) dilated } \\
\text { cardiomyopathy (group10) }\end{array}$ \\
\hline LGMD2N & 1.34 & AR & $\begin{array}{l}\text { LGMD2N } \\
(\text { MDDGC2) } \\
613158\end{array}$ & $14 \mathrm{q} 24.3$ & $\begin{array}{l}\text { POMT2 } \\
607439\end{array}$ & $\begin{array}{l}\text { protein O-mannosyl } \\
\text { transferase } 2\end{array}$ & Biancheri et al. (2007) & $\begin{array}{l}\text { Allelic to WWS (group 2) and } \\
\text { to MEB (group 2) }\end{array}$ \\
\hline LGMD2O & 1.35 & $\mathrm{AR}$ & $\begin{array}{l}\text { LGMD2O } \\
(\text { MDDGC3) } \\
613157\end{array}$ & $1 \mathrm{p} 34.1$ & $\begin{array}{l}\text { POMGNT1 } \\
606822\end{array}$ & $\begin{array}{l}\text { protein O-linked } \\
\text { mannose } \\
\text { beta1,2-N- } \\
\text { acetylglucosaminyl } \\
\text { transferase } 1\end{array}$ & $\begin{array}{l}\text { Godfrey et al. (2007); } \\
\text { Clement et al. (2008) } \\
\text { Raducu et al. (2012) }\end{array}$ & $\begin{array}{l}\text { Allelic to WWS (group 2) and } \\
\text { to MEB (group 2) }\end{array}$ \\
\hline LGMD2P & 1.36 & $\mathrm{AR}$ & $\begin{array}{l}\text { MDDGC9 } \\
613818\end{array}$ & $3 \mathrm{p} 21$ & $\begin{array}{l}\text { DAG1 } \\
128239\end{array}$ & $\begin{array}{l}\text { Alpha-dystroglycan } \\
\text { Dystroglycan } 1 \\
\text { (dystrophin- } \\
\text { associated } \\
\text { glycoprotein 1) }\end{array}$ & Hara et al. (2011) & Allelic to MDDGA9 (group 2) \\
\hline LGMD2Q & 1.37 & $\mathrm{AR}$ & $\begin{array}{l}\text { LGMD2Q } \\
613723\end{array}$ & $8 \mathrm{q} 24.3$ & $\begin{array}{l}\text { PLEC } \\
601282\end{array}$ & plectin & Gundesli et al. (2010) & $\begin{array}{l}\text { Allelic to LGMD with } \\
\text { ophthalmoplegia (group 1) } \\
\text { MDEBS (group 5), and } \\
\text { Myasthenic syndrome with } \\
\text { plectin defect (group 11) }\end{array}$ \\
\hline LGMD2R & 1.38 & $\mathrm{AR}$ & $\begin{array}{l}\text { LGMD2R } \\
615325\end{array}$ & $2 \mathrm{q} 35$ & $\begin{array}{l}\text { DES } \\
125660\end{array}$ & desmin & Cetin et al. (2013) & $\begin{array}{l}\text { Allelic to other desminopathies } \\
\text { (groups 1,5 and 10) }\end{array}$ \\
\hline LGMD2S & 1.39 & $\mathrm{AR}$ & $\begin{array}{l}\text { LGMD2S } \\
615356\end{array}$ & $4 \mathrm{q} 35.1$ & $\begin{array}{l}\text { TRAPPC11 } \\
614138\end{array}$ & $\begin{array}{l}\text { trafficking protein } \\
\text { particle complex } 11\end{array}$ & Bögershausen et al. (2013) & $\begin{array}{l}\text { Allelic to CMD related to } \\
\text { TRAPPC11 (group 2) }\end{array}$ \\
\hline LGMD2T & 1.40 & $\mathrm{AR}$ & $\begin{array}{l}\text { MDDGC14 } \\
615352\end{array}$ & $3 \mathrm{p} 21.31$ & $\begin{array}{l}\boldsymbol{G M P P B} \\
615320\end{array}$ & $\begin{array}{l}\text { GDP-mannose } \\
\text { pyrophosphorylase } \\
\text { B }\end{array}$ & $\begin{array}{l}\text { Carss et al. (2013), } \\
\text { Cabrera-Serrano et al. } \\
(2015)\end{array}$ & $\begin{array}{l}\text { Allelic to MDDGA14, } \\
\text { MDDGB14 (group 2) }\end{array}$ \\
\hline LGMD2U & 1.41 & AR & $\begin{array}{l}\text { MDDGC7 } \\
616052\end{array}$ & $7 \mathrm{p} 21.2$ & $\begin{array}{l}\text { ISPD } \\
614631\end{array}$ & $\begin{array}{l}\text { Isoprenoid synthase } \\
\text { domain containing }\end{array}$ & Tasca et al. (2013) & $\begin{array}{l}\text { Allelic to WWS/MDDGA7 } \\
\text { (group 2) }\end{array}$ \\
\hline LGMD2V & 1.42 & $\mathrm{AR}$ & & $17 \mathrm{q} 25$ & $\begin{array}{l}\boldsymbol{G A A} \\
606800\end{array}$ & $\begin{array}{l}\text { Glucosidase alpha, } \\
\text { acid }\end{array}$ & Preisler et al. (2013) & $\begin{array}{l}\text { Allelic to Pompe disease } \\
\text { (groups } 9 \text { and 10) }\end{array}$ \\
\hline LGMD2W & 1.43 & $\mathrm{AR}$ & 616827 & $2 \mathrm{q} 14.3$ & $\begin{array}{l}\text { LIMS2 } \\
(=P I N C H 2) \\
607908\end{array}$ & $\begin{array}{l}\text { LIM and senescent } \\
\text { cell antigen-like } \\
\text { domains } 2\end{array}$ & Chardon et al. (2015) & \\
\hline LGMD2X & 1.44 & $\mathrm{AR}$ & $\begin{array}{l}\text { LGMD2X } \\
616812\end{array}$ & $6 \mathrm{q} 21$ & $\begin{array}{l}\text { BVES } \\
(=P O P D C 1) \\
604577\end{array}$ & $\begin{array}{l}\text { blood vessel } \\
\text { epicardial substance }\end{array}$ & Schindler et al. (2016) & \\
\hline
\end{tabular}




\begin{tabular}{|c|c|c|c|c|c|c|c|c|}
\hline DISEASE NAME & $\begin{array}{l}\text { Item } \\
\text { line } \\
\text { in this } \\
\text { group }\end{array}$ & Inheritance & $\begin{array}{l}\text { Locus or } \\
\text { disease } \\
\text { symbol and } \\
\text { OMIM } \\
\text { number }\end{array}$ & Chromosome & $\begin{array}{l}\text { Gene symbol } \\
\text { and OMIM } \\
\text { number }\end{array}$ & $\begin{array}{l}\text { Protein } \\
\text { (mitochondrial } \\
\text { proteins indicated } \\
\text { by symbol }[M] \text { ) }\end{array}$ & $\begin{array}{l}\text { Key } \\
\text { references }\end{array}$ & $\begin{array}{l}\text { Other allelic disease(s) } \\
\text { (group in this table) }\end{array}$ \\
\hline LGMD2Y & 1.45 & AR & $\begin{array}{l}\text { LGMD2Y } \\
617072\end{array}$ & $1 \mathrm{q} 25.2$ & $\begin{array}{l}\text { TOR1AIP1 } \\
614512\end{array}$ & $\begin{array}{l}\text { torsin } 1 \mathrm{~A} \\
\text { interacting protein } \\
1 \\
\text { (=lamin-associated } \\
\text { protein } 1 \text { ) }\end{array}$ & $\begin{array}{l}\text { Kayman-Kurekci et al. } \\
\text { (2014); Sewry et al. (2014) }\end{array}$ & \\
\hline LGMD2Z & 1.46 & $\mathrm{AR}$ & $\begin{array}{l}\text { LGMD2Z } \\
617232\end{array}$ & $3 q 13.33$ & $\begin{array}{l}\text { POGLUT1 } \\
615618\end{array}$ & $\begin{array}{l}\text { Protein } \\
\text { O-Glucosyltransferase } \\
1\end{array}$ & Servian-Morilla et al. (2016) & \\
\hline $\begin{array}{l}\text { Muscle dystrophy with } \\
\text { glycosylation defect, type Io }\end{array}$ & 1.47 & $\mathrm{AR}$ & $\begin{array}{l}\text { CDG1O } \\
612937\end{array}$ & $1 \mathrm{q} 22$ & $\begin{array}{l}\text { DPM3 } \\
605951\end{array}$ & $\begin{array}{l}\text { Dolichyl-phosphate } \\
\text { mannosyltransferase } \\
\text { polypeptide } 3\end{array}$ & Lefeber et al. (2009) & \\
\hline $\begin{array}{l}\text { Scapuloperoneal muscular } \\
\text { dystrophy and dropped head } \\
\text { syndrome }\end{array}$ & 1.48 & $\mathrm{AR}$ & 600416 & $9 \mathrm{p} 13-\mathrm{p} 12$ & $\begin{array}{l}\boldsymbol{V C P} \\
601023\end{array}$ & $\begin{array}{l}\text { Valosin-containing } \\
\text { protein }\end{array}$ & Liewluck et al. (2014) & $\begin{array}{l}\text { Allelic to IBMPFD (groups } 4 \\
\text { and 5), to ALS14 (group 12) } \\
\text { and CMT2Y (group 14) }\end{array}$ \\
\hline LGMD with ophthalmoplegia & 1.49 & $\mathrm{AR}$ & & $8 \mathrm{q} 24.3$ & $\begin{array}{l}\text { PLEC } \\
601282\end{array}$ & Plectin & Fattahi et al. (2015) & $\begin{array}{l}\text { Allelic to LGMD2Q (group 1), } \\
\text { MDEBS (group 5), myasthenic } \\
\text { syndrome with plectin defect } \\
\text { (group 11) }\end{array}$ \\
\hline
\end{tabular}

\section{GROUP 2. CONGENITAL MUSCULAR DYSTROPHIES}

$\begin{array}{llll}\text { Congenital muscular dystrophy } & 2.1 & \mathrm{AR} & \mathrm{MDC} 1 \mathrm{~A}\end{array}$

with merosin deficiency

607855

$6 \mathrm{q} 2$

LAMA2

156225

Laminin alpha2

\begin{tabular}{|c|c|c|c|c|c|}
\hline Bethlem myopathy & 2.2 & $\mathrm{AD}$ & $\begin{array}{l}\text { BTHLM1 } \\
158810\end{array}$ & $21 \mathrm{q} 22.3$ & $\begin{array}{l}\text { COL6A1 } \\
120220\end{array}$ \\
\hline Bethlem myopathy & 2.3 & $\mathrm{AD}$ & $\begin{array}{l}\text { BTHLM1 } \\
158810\end{array}$ & $21 \mathrm{q} 22.3$ & $\begin{array}{l}\text { COL6A2 } \\
120240\end{array}$ \\
\hline Bethlem myopathy & 2.4 & $\mathrm{AD}$ & $\begin{array}{l}\text { BTHLM1 } \\
158810\end{array}$ & $2 \mathrm{q} 37$ & $\begin{array}{l}\text { COL6A3 } \\
120250\end{array}$ \\
\hline Bethlem myopathy (recessive) & 2.5 & AR & $\begin{array}{l}\text { BTHLM1 } \\
158810\end{array}$ & $21 \mathrm{q} 22.3$ & $\begin{array}{l}\text { COL6A2 } \\
120240\end{array}$ \\
\hline Ullrich syndrome & 2.6 & AR & $\begin{array}{l}\text { UCMD } \\
254090\end{array}$ & $21 \mathrm{q} 22.3$ & $\begin{array}{l}\text { COL6A1 } \\
120220\end{array}$ \\
\hline Ullrich syndrome & 2.7 & AR & $\begin{array}{l}\text { UCMD } \\
254090\end{array}$ & $21 \mathrm{q} 22.3$ & $\begin{array}{l}\text { COL6A2 } \\
120240\end{array}$ \\
\hline Ullrich syndrome & 2.8 & AR & $\begin{array}{l}\text { UCMD } \\
254090\end{array}$ & $2 \mathrm{q} 37$ & $\begin{array}{l}\text { COL6A3 } \\
120250\end{array}$ \\
\hline $\begin{array}{l}\text { Ullrich congenital muscular } \\
\text { dystrophy } 2\end{array}$ & 2.9 & AR & $\begin{array}{l}\text { UCMD2 } \\
616470\end{array}$ & $6 q 13-q 14$ & $\begin{array}{l}\text { COL12A1 } \\
120320\end{array}$ \\
\hline Bethlem myopathy 2 & 2.10 & $\mathrm{AD}$ & $\begin{array}{l}\text { BTHLM2 } \\
616471\end{array}$ & $6 q 13-q 14$ & $\begin{array}{l}\text { COL12A1 } \\
120320\end{array}$ \\
\hline $\begin{array}{l}\text { COL12Al-related congenital } \\
\text { muscular dystrophy }\end{array}$ & 2.11 & $\mathrm{AD}$ & & $6 q 13-q 14$ & $\begin{array}{l}\text { COL12A1 } \\
120320\end{array}$ \\
\hline Myosclerosis & 2.12 & $\mathrm{AR}$ & 255600 & $21 \mathrm{q} 22.3$ & $\begin{array}{l}\text { COL6A2 } \\
120240\end{array}$ \\
\hline $\begin{array}{l}\text { Rigid spine syndrome related } \\
\text { to } S E P N 1\end{array}$ & 2.13 & AR & $\begin{array}{l}\text { RSMD1 } \\
602771\end{array}$ & $1 \mathrm{p} 36$ & $\begin{array}{l}\text { SEPN1 } \\
606210\end{array}$ \\
\hline $\begin{array}{l}\text { Rigid spine syndrome related to } \\
\text { FHLI }\end{array}$ & 2.14 & $\mathrm{AR}$ & $\begin{array}{l}\text { RSMD1 } \\
602771\end{array}$ & $\mathrm{Xq} 26.3$ & $\begin{array}{l}\text { FHL1 } \\
300163\end{array}$ \\
\hline $\begin{array}{l}\text { Congenital muscular dystrophy } \\
\text { related to integrin }\end{array}$ & 2.15 & AR & 613204 & $12 \mathrm{q} 13$ & $\begin{array}{l}\text { ITGA7 } \\
600536\end{array}$ \\
\hline $\begin{array}{l}\text { Congenital muscular dystrophy } \\
\text { related to dynamin } 2\end{array}$ & 2.16 & $\mathrm{AD}$ & & $19 \mathrm{p} 13.2$ & $\begin{array}{l}\text { DNM2 } \\
602378\end{array}$ \\
\hline $\begin{array}{l}\text { Congenital muscular dystrophy } \\
\text { related to telethonin }\end{array}$ & 2.17 & $\mathrm{AR}$ & & $17 \mathrm{q} 12$ & $\begin{array}{l}\text { TCAP } \\
604488\end{array}$ \\
\hline $\begin{array}{l}\text { Congenital muscular dystrophy } \\
\text { related to } L M N A\end{array}$ & 2.18 & $\mathrm{AD}$ & $\begin{array}{l}\text { MDCL } \\
613205\end{array}$ & $1 \mathrm{q} 21.2$ & $\begin{array}{l}\text { LMNA } \\
150330\end{array}$ \\
\hline
\end{tabular}

subunit alpha 2 chain of merosin

(=laminin-2)

Tomé et al. (1994)

Hillaire et al. (1994)

Helbling-Leclerc et al.

(1995)

Allamand et al. (1997)

Jöbsis et al. (1996)

Jöbsis et al. (1996)

Speer et al. (1996)

Bertini et al. (1998)

Pan et al. (1998)

Gualandi et al. (2009)

Pan et al. (2003)

Giusti et al. (2005)

Vanegas et al. (2001)

Higuchi et al. (2001)

Demir et al. (2002)

collagen type VI,

subunit alpha 3

collagen type XII,

alpha 1 chain

collagen type XII,

alpha 1 chain

collagen type XII,

alpha 1 chain

collagen type VI,

subunit alpha 2

selenoprotein $\mathrm{N}$

Zou et al. (2014)

Zou et al. (2014)

Punetha et al. (2016)

Merlini et al. (2008)

Moghadaszadeh et al. (1998,

2001)

Ferreiro et al. (2002a, 2004)

four and a half LIM Shalaby et al. (2008

domain 1

integrin $\alpha 7$

dynamin 2

Hayashi et al. (1998)

Susman et al. (2008)

titin-cap (telethonin)

Ferreiro et al. (2011)

Lamin $\mathrm{A} / \mathrm{C}$

Quijano-Roy et al. (2008) allelic to UCMD (group 2)

allelic to UCMD (group 2), and myosclerosis (group 2) allelic to UCMD (group 2)

allelic to UCMD (group 2)

allelic to Bethlem myopathy (group 2)

allelic to Bethlem myopathy (group 2) and myosclerosis (group 2)

allelic to allelic to Bethlem myopathy (group 2) and myosclerosis (group 2)

allelic to UCMD (group 2) and to Bethlem myopathy (group 2) allelic to CFTD (group 3), multiminicore disease (group 3), and desmin-related myopathy with Mallory bodies (group 5) allelic to EDMD6 (1), RSS (2), XPMA(5), XPMD (5)

allelic to CNM (group 3) and CMTIB (group 14) Allelic to LGMD2G (group 1) and to CMD1N (group 10A) Allelic to EDMD3 (group 1), LGMD1B (group 1), L-CMD (group 2), CMD1A (group 10/A), CMT2B1 (group 14), [ + several other phenotypes not in this table: FPLD2/151660, HGPS/176670, restrictive dermopathy/275210, MADA/248370] 


\begin{tabular}{|c|c|c|c|c|c|c|c|c|}
\hline DISEASE NAME & $\begin{array}{l}\text { Item } \\
\text { line } \\
\text { in this } \\
\text { group }\end{array}$ & Inheritance & $\begin{array}{l}\text { Locus or } \\
\text { disease } \\
\text { symbol and } \\
\text { OMIM } \\
\text { number }\end{array}$ & Chromosome & $\begin{array}{l}\text { Gene symbol } \\
\text { and OMIM } \\
\text { number }\end{array}$ & $\begin{array}{l}\text { Protein } \\
\text { (mitochondrial } \\
\text { proteins indicated } \\
\text { by symbol }[M] \text { ) }\end{array}$ & $\begin{array}{l}\text { Key } \\
\text { references }\end{array}$ & $\begin{array}{l}\text { Other allelic disease(s) } \\
\text { (group in this table) }\end{array}$ \\
\hline \multicolumn{9}{|c|}{ Congenital muscle dystrophies due to defective glycosylation } \\
\hline $\begin{array}{l}\text { Fukuyama congenital muscular } \\
\text { dystrophy }\end{array}$ & 2.19 & $\mathrm{AR}$ & $\begin{array}{l}\text { MDDGA4 } \\
253800 \\
\text { MDDGB4 } \\
613152\end{array}$ & $9 q 31-q 33$ & $\begin{array}{l}\text { FKTN } \\
607440\end{array}$ & fukutin & $\begin{array}{l}\text { Toda et al. (1993) } \\
\text { Kobayashi et al. (1998) }\end{array}$ & allelic to WWS (group 2) \\
\hline $\begin{array}{l}\text { Walker-Warburg syndrome } \\
\text { (WWS) }\end{array}$ & 2.20 & AR & $\begin{array}{l}\text { MDDGA4 } \\
253800 \\
\text { MDDGB4 } \\
613152\end{array}$ & $9 q 31-q 33$ & $\begin{array}{l}\text { FKTN } \\
607440\end{array}$ & fukutin & $\begin{array}{l}\text { Beltran-Valero de Bernabe } \\
(2003) \\
\text { Mercuri et al. (2009) }\end{array}$ & $\begin{array}{l}\text { allelic to LGMD2L (group 1) } \\
\text { and Fukuyama (group 2) }\end{array}$ \\
\hline $\begin{array}{l}\text { Walker-Warburg syndrome } \\
\text { (WWS) }\end{array}$ & 2.21 & AR & $\begin{array}{l}\text { MDDGA1 } \\
236670 \\
\text { MDDGB1 } \\
607423\end{array}$ & $9 \mathrm{q} 34$ & $\begin{array}{l}\text { POMT1 } \\
607423\end{array}$ & $\begin{array}{l}\text { protein-O- } \\
\text { mannosyltransferase } \\
1\end{array}$ & $\begin{array}{l}\text { Beltran-Valero De Bernabe } \\
\text { et al. (2002) } \\
\text { van Reeuwijk et al. (2006) } \\
\text { Mercuri et al. (2009) }\end{array}$ & allelic to LGMD2K (group 1) \\
\hline $\begin{array}{l}\text { Walker-Warburg syndrome } \\
\text { (WWS) }\end{array}$ & 2.22 & AR & $\begin{array}{l}\text { MDDGA2 } \\
613150 \\
\text { MDDGB2 } \\
613156\end{array}$ & $14 \mathrm{q} 24.3$ & $\begin{array}{l}\text { POMT2 } \\
607439\end{array}$ & $\begin{array}{l}\text { protein O-mannosyl } \\
\text { transferase } 2\end{array}$ & $\begin{array}{l}\text { van Reeuwijk et al. (2005) } \\
\text { Mercuri et al. (2009) }\end{array}$ & $\begin{array}{l}\text { allelic to LGMD2N (group 1) } \\
\text { and MEB (group 2) }\end{array}$ \\
\hline $\begin{array}{l}\text { Walker-Warburg syndrome } \\
\text { (WWS) }\end{array}$ & 2.23 & AR & $\begin{array}{l}\text { MDDGA5 } \\
613153 \\
\text { MDDGB5 } \\
606612\end{array}$ & $19 \mathrm{q} 13$ & $\begin{array}{l}\text { FKRP } \\
606596\end{array}$ & $\begin{array}{l}\text { fukutin-related } \\
\text { protein }\end{array}$ & $\begin{array}{l}\text { Beltran-Valero De Bernabe } \\
\text { et al. (2004) }\end{array}$ & $\begin{array}{l}\text { allelic to LGMD2I (group 1), } \\
\text { MDC1C (group 2), MEB } \\
\text { (group 2) }\end{array}$ \\
\hline $\begin{array}{l}\text { Walker-Warburg syndrome } \\
\text { (WWS) }\end{array}$ & 2.24 & AR & $\begin{array}{l}\text { MDDGA3 } \\
253280 \\
\text { MDDGB3 } \\
613151\end{array}$ & $1 \mathrm{p} 34.1$ & $\begin{array}{l}\text { POMGNT1 } \\
606822\end{array}$ & $\begin{array}{l}\text { O-mannose } \\
\text { beta1,2- } \\
\text { N-acetylglucosaminyl } \\
\text { transferase }\end{array}$ & $\begin{array}{l}\text { Taniguchi et al. (2003) } \\
\text { Mercuri et al. (2009) }\end{array}$ & allelic to MEB (group 2) \\
\hline $\begin{array}{l}\text { Walker-Warburg syndrome } \\
\text { (WWS) }\end{array}$ & 2.25 & AR & $\begin{array}{l}\text { MDDGA7 } \\
614643\end{array}$ & $7 \mathrm{p} 21.2$ & $\begin{array}{l}\text { ISPD } \\
614631\end{array}$ & $\begin{array}{l}\text { isoprenoid synthase } \\
\text { domain containing }\end{array}$ & $\begin{array}{l}\text { Roscioli et al. (2012) } \\
\text { Willer et al. (2012) }\end{array}$ & \\
\hline $\begin{array}{l}\text { Walker-Warburg syndrome } \\
\text { (WWS) }\end{array}$ & 2.26 & AR & $\begin{array}{l}\text { MDDGA8 } \\
614830\end{array}$ & $3 \mathrm{p} 22.1$ & $\begin{array}{l}\text { GTDC2 } \\
614828\end{array}$ & $\begin{array}{l}\text { glycosyltransferase- } \\
\text { like domain } \\
\text { containing } 2\end{array}$ & Manzini et al. (2012) & \\
\hline $\begin{array}{l}\text { Walker-Warburg syndrome } \\
\text { (WWS) }\end{array}$ & 2.27 & AR & $\begin{array}{l}\text { MDDGA13 } \\
615287\end{array}$ & $11 \mathrm{q} 13.2$ & $\begin{array}{l}B 3 G N T 1 \\
605517\end{array}$ & $\begin{array}{l}\text { UDP-GlcNAc: } \\
\text { betaGal beta-1,3-N- } \\
\text { acetylglucosaminyl- } \\
\text { transferase } 1\end{array}$ & $\begin{array}{l}\text { Buysse et al. (2013) } \\
\text { Shaheen et al. (2013 }\end{array}$ & \\
\hline $\begin{array}{l}\text { Muscle-eye-brain disease } \\
\text { (MEB) }\end{array}$ & 2.28 & AR & $\begin{array}{l}\text { MDDGA3 } \\
253280\end{array}$ & $1 \mathrm{p} 34.1$ & $\begin{array}{l}\text { POMGNT1 } \\
606822\end{array}$ & $\begin{array}{l}\text { O-mannose } \\
\text { beta1,2-N- } \\
\text { acetylglucosaminyl } \\
\text { transferase }\end{array}$ & $\begin{array}{l}\text { Yoshida et al. (2001) } \\
\text { Taniguchi et al. (2003) }\end{array}$ & allelic to WWS (group 2) \\
\hline $\begin{array}{l}\text { Muscle-eye-brain disease } \\
\text { (MEB) }\end{array}$ & 2.29 & AR & $\begin{array}{l}\text { MDDGA5 } \\
613153 \\
\text { MDDGB5 } \\
606612\end{array}$ & $19 \mathrm{q} 13.32$ & $\begin{array}{l}\boldsymbol{F K R P} \\
606596\end{array}$ & $\begin{array}{l}\text { Fukutin-related } \\
\text { protein }\end{array}$ & $\begin{array}{l}\text { Beltran-Valero De Bernabe } \\
\text { et al. }(2004)\end{array}$ & $\begin{array}{l}\text { allelic to LGMD2I (group 1), } \\
\text { MDC1C/(group 2), WWS } \\
\text { (group 2) }\end{array}$ \\
\hline $\begin{array}{l}\text { Muscle-eye-brain disease } \\
\text { (MEB) }\end{array}$ & 2.30 & AR & $\begin{array}{l}\text { MDDGA2 } \\
613150 \\
\text { MDDGB2 } \\
613156\end{array}$ & $14 \mathrm{q} 24.3$ & $\begin{array}{l}\text { РОМТ2 } \\
607439\end{array}$ & $\begin{array}{l}\text { protein O-mannosyl } \\
\text { transferase } 2\end{array}$ & Mercuri et al. (2006) & allelic to WWS (group 2) \\
\hline $\begin{array}{l}\text { Muscle-eye-brain disease } \\
\text { (MEB) }\end{array}$ & 2.31 & AR & $\begin{array}{l}\text { MDDGC14 } \\
615350\end{array}$ & $3 \mathrm{p} 21.31$ & $\begin{array}{l}\boldsymbol{G M P P B} \\
615320\end{array}$ & $\begin{array}{l}\text { GDP-mannose } \\
\text { pyrophosphorylase } \\
\text { B }\end{array}$ & de Carss et al. (2013) & $\begin{array}{l}\text { Allelic to LGMD2T (group 1) } \\
\text { and to MDDGB14 (group 2) }\end{array}$ \\
\hline $\begin{array}{l}\text { Congenital muscular dystrophy } \\
\text { with hypoglycosylation of } \\
\text { dystroglycan }\end{array}$ & 2.32 & AR & $\begin{array}{l}\text { MDDGA5 } \\
613153 \\
\text { MDDGB5 } \\
606612\end{array}$ & $19 \mathrm{q} 13$ & $\begin{array}{l}\boldsymbol{F K R P} \\
606596\end{array}$ & $\begin{array}{l}\text { Fukutin-related } \\
\text { protein }\end{array}$ & $\begin{array}{l}\text { Brockington et al. (2001b) } \\
\text { Topaloglu et al. (2003) } \\
\text { Mercuri et al. (2009) }\end{array}$ & $\begin{array}{l}\text { allelic to LGMD2I (group 1), } \\
\text { WWS (group 2), MEB (group } \\
\text { 2) }\end{array}$ \\
\hline $\begin{array}{l}\text { Congenital muscular dystrophy } \\
\text { with hypoglycosylation of } \\
\text { dystroglycan }\end{array}$ & 2.33 & AR & $\begin{array}{l}\text { MDDGA6 } \\
608840 \\
\text { MDDGB6 } \\
613154\end{array}$ & $22 \mathrm{q} 12$ & $\begin{array}{l}\text { LARGE } \\
603590\end{array}$ & $\begin{array}{l}\text { like-glycosyl } \\
\text { transferase }\end{array}$ & $\begin{array}{l}\text { Longman et al. (2003) } \\
\text { Mercuri et al. (2009) }\end{array}$ & \\
\hline $\begin{array}{l}\text { Congenital muscular dystrophy } \\
\text { with hypoglycosylation of } \\
\text { dystroglycan }\end{array}$ & 2.34 & AR & $\begin{array}{l}\text { CDG1E } \\
608799\end{array}$ & $20 \mathrm{q} 13.13$ & $\begin{array}{l}\text { DPM1 } \\
603503\end{array}$ & $\begin{array}{l}\text { dolichyl-phosphate } \\
\text { mannosyltransferase } \\
1 \text {, catalytic subunit }\end{array}$ & Yang et al. (2013) & \\
\hline $\begin{array}{l}\text { Congenital muscular dystrophy } \\
\text { with hypoglycosylation of } \\
\text { dystroglycan and severe } \\
\text { epilepsy }\end{array}$ & 2.35 & AR & $\begin{array}{l}\text { CDG1U } \\
615042\end{array}$ & $9 \mathrm{q} 34.13$ & $\begin{array}{l}\text { DPM2 } \\
603564\end{array}$ & $\begin{array}{l}\text { dolichyl-phosphate } \\
\text { mannosyltransferase } \\
\text { polypeptide } 2, \\
\text { regulatory subunit }\end{array}$ & Barone et al. (2012) & \\
\hline $\begin{array}{l}\text { Congenital muscular dystrophy } \\
\text { with hypoglycosylation of } \\
\text { dystroglycan }\end{array}$ & 2.36 & $\mathrm{XR}$ & $\begin{array}{l}\text { CDG1S } \\
300884\end{array}$ & $\mathrm{Xq} 23$ & $\begin{array}{r}A L G 13 \\
300776\end{array}$ & $\begin{array}{l}\text { UDP-N- } \\
\text { acetylglucosami- } \\
\text { nyltransferase } \\
\text { subunit }\end{array}$ & Timal et al. (2012 & $\begin{array}{l}\text { Congenital myasthenia Group } \\
11 .\end{array}$ \\
\hline $\begin{array}{l}\text { Congenital muscular dystrophy } \\
\text { with hypoglycosylation of } \\
\text { dystroglycan type A9 }\end{array}$ & 2.37 & $\mathrm{AR}$ & $\begin{array}{l}\text { MDDGA9 } \\
616538\end{array}$ & $3 \mathrm{p} 21$ & $\begin{array}{l}\text { DAG1 } \\
128239\end{array}$ & $\begin{array}{l}\text { Dystrophin- } \\
\text { Associated } \\
\text { Glycoprotein } 1\end{array}$ & Geis et al. (2013) & Allelic to LGMD2P (group 1) \\
\hline
\end{tabular}




\begin{tabular}{|c|c|c|c|c|c|c|c|c|}
\hline DISEASE NAME & $\begin{array}{l}\text { Item } \\
\text { line } \\
\text { in this } \\
\text { group }\end{array}$ & Inheritance & $\begin{array}{l}\text { Locus or } \\
\text { disease } \\
\text { symbol and } \\
\text { OMIM } \\
\text { number }\end{array}$ & Chromosome & $\begin{array}{l}\text { Gene symbol } \\
\text { and OMIM } \\
\text { number }\end{array}$ & $\begin{array}{l}\text { Protein } \\
\text { (mitochondrial } \\
\text { proteins indicated } \\
\text { by symbol }[M] \text { ) }\end{array}$ & $\begin{array}{l}\text { Key } \\
\text { references }\end{array}$ & $\begin{array}{l}\text { Other allelic disease(s) } \\
\text { (group in this table) }\end{array}$ \\
\hline $\begin{array}{l}\text { Congenital muscular dystrophy } \\
\text { with hypoglycosylation of } \\
\text { dystroglycan type A } 10\end{array}$ & 2.38 & AR & $\begin{array}{l}\text { MDGGA10 } \\
615041\end{array}$ & $12 \mathrm{q} 14.2$ & $\begin{array}{l}\text { TMEM5 } \\
605862\end{array}$ & $\begin{array}{l}\text { transmembrane } \\
\text { protein } 5\end{array}$ & $\begin{array}{l}\text { Vuillaumier-Barrot et al. } \\
\text { (2013) }\end{array}$ & \\
\hline $\begin{array}{l}\text { Congenital muscular dystrophy } \\
\text { with hypoglycosylation of } \\
\text { dystroglycan WWWS/MEB } \\
\text { like }\end{array}$ & 2.39 & AR & $\begin{array}{l}\text { MDDGA11 } \\
615181\end{array}$ & $1 \mathrm{q} 42.3$ & $\begin{array}{l}\text { B3GALNT2 } \\
610194\end{array}$ & $\begin{array}{l}\text { beta-1,3-N- } \\
\text { acetylgalactosaminyl- } \\
\text { transferase } 2\end{array}$ & Stevens et al. (2013) & \\
\hline $\begin{array}{l}\text { Congenital muscular dystrophy } \\
\text { with hypoglycosylation of } \\
\text { dystroglycan type A12 }\end{array}$ & 2.40 & AR & $\begin{array}{l}\text { MDDGA12 } \\
615249\end{array}$ & $8 \mathrm{p} 11.21$ & $\begin{array}{l}\text { POMK } \\
(=S G K 196) \\
615247\end{array}$ & $\begin{array}{l}\text { protein-O-mannose } \\
\text { kinase }\end{array}$ & Jae et al. (2013) & \\
\hline $\begin{array}{l}\text { Congenital muscular dystrophy } \\
\text { with hypoglycosylation of } \\
\text { dystroglycan and mental } \\
\text { retardation }\end{array}$ & 2.41 & AR & $\begin{array}{l}\text { MDDGB14 } \\
615351\end{array}$ & $3 \mathrm{p} 21.31$ & $\begin{array}{l}\boldsymbol{G M P P B} \\
615320\end{array}$ & $\begin{array}{l}\text { GDP-mannose } \\
\text { pyrophosphorylase } \\
\text { B }\end{array}$ & Carss et al. (2013) & $\begin{array}{l}\text { Allelic to LGMD2T (group 1), } \\
\text { MDDGC14 (group 2) }\end{array}$ \\
\hline \multicolumn{9}{|c|}{ Other congenital muscular dystrophies } \\
\hline $\begin{array}{l}\text { Congenital muscle dystrophy } \\
\text { with joint hyperlaxity }\end{array}$ & 2.42 & AR & & $3 \mathrm{p} 23-21$ & $?$ & & Tetreault et al. (2006) & \\
\hline $\begin{array}{l}\text { Congenital muscle dystrophy } \\
\text { with mitochondrial structural } \\
\text { abnormalities (megaconial } \\
\text { type) }\end{array}$ & 2.43 & AR & $\begin{array}{l}\text { MDCMC } \\
602541\end{array}$ & $22 \mathrm{q} 13$ & $\begin{array}{l}\text { CHKB } \\
612395\end{array}$ & Choline kinase beta & Mitsuhashi et al. (2011) & \\
\hline Congenital muscular dystrophy & 2.44 & AR & $\begin{array}{l}\text { MDC1B } \\
604801\end{array}$ & $1 \mathrm{q} 42$ & $?$ & & Brockington et al. (2000) & \\
\hline $\begin{array}{l}\text { Congenital muscular dystrophy } \\
\text { with rigid spine related to } \\
\text { ACTAl }\end{array}$ & 2.45 & AR & $\begin{array}{l}\text { Possibly } \\
\text { identical to } \\
\text { MDC1B } \\
604801\end{array}$ & $1 \mathrm{q} 42.1$ & $\begin{array}{l}\text { ACTA1 } \\
102610\end{array}$ & $\begin{array}{l}\text { Alpha actin, } \\
\text { skeletal muscle }\end{array}$ & O'Grady et al. (2014) & $\begin{array}{l}\text { Allelic to NEM3, CFTD, cap } \\
\text { myopathy related to ACTA1 } \\
\text { (group 3) }\end{array}$ \\
\hline $\begin{array}{l}\text { Congenital muscular dystrophy } \\
\text { with fatty liver and } \\
\text { infantile-onset cataract caused } \\
\text { by TRAPPC11 mutations }\end{array}$ & 2.46 & AR & CMD & $4 \mathrm{q} 35.1$ & $\begin{array}{l}\text { TRAPPC11 } \\
614138\end{array}$ & $\begin{array}{l}\text { Trafficking protein } \\
\text { particle complex } 11\end{array}$ & Liang et al. (2015) & Allelic to LGMD2S (group 1) \\
\hline $\begin{array}{l}\text { GOLGA2-related congenital } \\
\text { muscle dystrophy with brain } \\
\text { involvement }\end{array}$ & 2.47 & AR & & $9 q 34.113$ & $\begin{array}{l}\boldsymbol{G O L G A 2} \\
602580\end{array}$ & golgin A2 & Shamseldin et al. (2016) & \\
\hline $\begin{array}{l}\text { Muscular dystrophy, congenital } \\
\text { Davignon-Chauveau type }\end{array}$ & 2.48 & AR & $\begin{array}{l}\text { MDCDC } \\
617066\end{array}$ & $15 \mathrm{q} 22.31$ & $\begin{array}{l}\text { TRIP4 } \\
604501\end{array}$ & $\begin{array}{l}\text { thyroid hormone } \\
\text { receptor interactor } \\
4\end{array}$ & Davignon et al. (2016) & allelic to SMABF1 (group 12) \\
\hline $\begin{array}{l}\text { Muscular dystrophy, } \\
\text { congenital, with cataracts and } \\
\text { intellectual disability }\end{array}$ & 2.49 & AR & $\begin{array}{l}\text { MDCCAID } \\
617404\end{array}$ & $17 \mathrm{p} 13.3$ & $\begin{array}{l}\text { INPP5K } \\
607875\end{array}$ & $\begin{array}{l}\text { Inositol } \\
\text { Polyphosphate- } \\
\text { 5-Phosphatase K }\end{array}$ & $\begin{array}{l}\text { Osborn et al. (2017) } \\
\text { Wiessner et al. (2017) }\end{array}$ & \\
\hline
\end{tabular}

\section{GROUP 3. CONGENITAL MYOPATHIES}

Nemaline myopathy

NEM1

609284

191030

\begin{tabular}{|c|c|c|c|c|c|}
\hline NEM2 & 3.2 & $\mathrm{AR}$ & $\begin{array}{l}\text { NEM2 } \\
256030\end{array}$ & $2 q 22$ & $\begin{array}{l}\boldsymbol{N E B} \\
161650\end{array}$ \\
\hline NEM3 & 3.3 & $\mathrm{AD}$ & $\begin{array}{l}\text { NEM3 } \\
161800\end{array}$ & $1 \mathrm{q} 42.1$ & $\begin{array}{l}\text { ACTA1 } \\
102610\end{array}$ \\
\hline NEM4 & 3.4 & $\mathrm{AD}$ & $\begin{array}{l}\text { NEM4 } \\
609285\end{array}$ & $9 \mathrm{p} 13$ & $\begin{array}{l}\text { TPM2 } \\
190990\end{array}$ \\
\hline NEM5 & 3.5 & AR & $\begin{array}{l}\text { NEM5 } \\
605355\end{array}$ & $19 \mathrm{q} 13$ & $\begin{array}{l}\text { TNNT1 } \\
191041\end{array}$ \\
\hline NEM6 & 3.6 & $\mathrm{AD}$ & $\begin{array}{l}\text { NEM6 } \\
609273\end{array}$ & $15 \mathrm{q} 22.31$ & $\begin{array}{l}\boldsymbol{K B T B D} \\
613727\end{array}$ \\
\hline NEM7 & 3.7 & AR & $\begin{array}{l}\text { NEM7 } \\
610687\end{array}$ & $14 \mathrm{q} 12$ & $\begin{array}{l}\text { CFL2 } \\
601443\end{array}$ \\
\hline NEM8 & 3.8 & AR & $\begin{array}{l}\text { NEM8 } \\
615348\end{array}$ & $2 \mathrm{p} 22.1$ & $\begin{array}{l}\text { KLHL40 } \\
615340\end{array}$ \\
\hline NEM9 & 3.9 & AR & $\begin{array}{l}\text { NEM9 } \\
615731\end{array}$ & $2 \mathrm{q} 31.1$ & $\begin{array}{l}\text { KLHL41 } \\
607701\end{array}$ \\
\hline NEM10 & 3.10 & $\mathrm{AR}$ & $\begin{array}{l}\text { NEM } 10 \\
616165\end{array}$ & $3 \mathrm{p} 14.1$ & $\begin{array}{l}\text { LMOD3 } \\
616112\end{array}$ \\
\hline NEM11 & 3.11 & $\mathrm{AE}$ & $\begin{array}{l}\text { NEM11 } \\
617336\end{array}$ & $10 \mathrm{q} 21.3$ & $\begin{array}{l}\text { MYPN } \\
608517\end{array}$ \\
\hline
\end{tabular}

Tropomyosin 3

Actin, alpha 1 ,

skeletal muscle

Tropomyosin 2

(beta)

Troponin $\mathrm{T}$ type 1

(skeletal, slow)

Kelch repeat and

BTB (POZ) domain

containing 13

Cofilin 2 (muscle)

Kelch-like family

member 40

Kelch-like family

member 41

Leiomodin 3 (fetal)

Myopalladin

Laing et al. (1992)

Laing et al. (1995b)

Tan et al. (1999)

Wattanasirichaigoon et al

(2002)

Wallgren-Pettersson et al.

(1995, 2002)

Pelin et al. (1999)

Lehtokari et al. (2006)

Nowak et al. (1999)

allelic to CFTD (group 3)

Donner et al. (2002)

Monnier et al. (2009)

Johnston et al. (2000

Gommans et al. (2003)

Samburghin et al. (2010)

Agrawal et al. (2007)

Ravenscroft et al. (2013)

Gupta et al. (2013)

Yuen et al. (2014) 


\begin{tabular}{|c|c|c|c|c|c|c|c|c|}
\hline DISEASE NAME & $\begin{array}{l}\text { Item } \\
\text { line } \\
\text { in this } \\
\text { group }\end{array}$ & Inheritance & $\begin{array}{l}\text { Locus or } \\
\text { disease } \\
\text { symbol and } \\
\text { OMIM } \\
\text { number }\end{array}$ & Chromosome & $\begin{array}{l}\text { Gene symbol } \\
\text { and OMIM } \\
\text { number }\end{array}$ & $\begin{array}{l}\text { Protein } \\
\text { (mitochondrial } \\
\text { proteins indicated } \\
\text { by symbol }[M] \text { ) }\end{array}$ & $\begin{array}{l}\text { Key } \\
\text { references }\end{array}$ & $\begin{array}{l}\text { Other allelic disease(s) } \\
\text { (group in this table) }\end{array}$ \\
\hline $\begin{array}{l}\text { Myopathy, congenital, with } \\
\text { fiber-type disproportion }\end{array}$ & 3.12 & $\mathrm{AD}$ & $\begin{array}{l}\text { CFTD } \\
255310\end{array}$ & $1 \mathrm{q} 42.1$ & $\begin{array}{l}\text { ACTA1 } \\
102610\end{array}$ & $\begin{array}{l}\text { actin, alpha } 1 \text {, } \\
\text { skeletal muscle }\end{array}$ & $\begin{array}{l}\text { Clarke et al. (2003); Laing } \\
\text { et al. (2004) }\end{array}$ & allelic to NEM3 (group 3) \\
\hline $\begin{array}{l}\text { Myopathy, congenital, with } \\
\text { fiber-type disproportion }\end{array}$ & 3.13 & $\mathrm{AR}$ & $\begin{array}{l}\text { CFTD } \\
255310\end{array}$ & $1 \mathrm{p} 36$ & $\begin{array}{l}\text { SEPN1 } \\
606210\end{array}$ & selenoprotein $\mathrm{N} 1$ & Clarke et al. (2006) & $\begin{array}{l}\text { allelic to RSMD1 (group 2), } \\
\text { multiminicore disease (group } \\
\text { 3), desmin-related myopathy } \\
\text { with Mallory bodies (group 5) }\end{array}$ \\
\hline $\begin{array}{l}\text { Myopathy, congenital, with } \\
\text { fiber-type disproportion }\end{array}$ & 3.14 & $\mathrm{AD}$ & $\begin{array}{l}\text { CFTD } \\
255310\end{array}$ & $1 \mathrm{q} 21.2$ & $\begin{array}{l}\text { TPM3 } \\
191030\end{array}$ & tropomyosin 3 & Clarke et al. (2008) & allelic to NEM1 (group 3) \\
\hline $\begin{array}{l}\text { Myopathy, congenital, with } \\
\text { fiber-type disproportion }\end{array}$ & 3.15 & $\mathrm{AR}$ & $\begin{array}{l}\text { CFTD } \\
255310\end{array}$ & $19 \mathrm{q} 13.1$ & $\begin{array}{l}\text { RYR1 } \\
180901\end{array}$ & ryanodine receptor & Clarke et al. (2010) & $\begin{array}{l}\text { allelic to CCD (group 3), } \\
\text { minicore myopathy with } \\
\text { external ophthalmoplegia } \\
\text { (group 3), MHS1 (group 8) }\end{array}$ \\
\hline $\begin{array}{l}\text { Myopathy congenital, with } \\
\text { fiber-type disproportion }\end{array}$ & 3.16 & $\mathrm{AD}$ & $\begin{array}{l}\text { CFTD } \\
255310\end{array}$ & $14 q 12$ & $\begin{array}{l}\text { МYH7 } \\
160760\end{array}$ & $\begin{array}{l}\text { myosin, heavy } \\
\text { chain } 7 \text {, cardiac } \\
\text { muscle, b }\end{array}$ & Ortolano et al. (2011) & $\begin{array}{l}\text { allelic to MPD1 (group 4), } \\
\text { CMH1 (group 10), CMD1S } \\
\text { (group 10) }\end{array}$ \\
\hline Myotubular myopathy & 3.17 & $\mathrm{XR}$ & $\begin{array}{l}\text { CNMX } \\
310400\end{array}$ & $\mathrm{Xq} 28$ & $\begin{array}{l}\text { MTM1 } \\
300415\end{array}$ & myotubularin 1 & $\begin{array}{l}\text { Thomas et al. (1987); } \\
\text { Laporte (1996, 1997, 2000) }\end{array}$ & \\
\hline $\begin{array}{l}\text { Centronuclear myopathy related } \\
\text { to } D N M 2\end{array}$ & 3.18 & $\mathrm{AD}$ & $\begin{array}{l}\text { CNM1 } \\
160150\end{array}$ & 19.p13.2 & $\begin{array}{l}\mathrm{DNM2} \\
602378\end{array}$ & dynamin 2 & Bitoun et al. (2005) & \\
\hline $\begin{array}{l}\text { Centronuclear myopathy related } \\
\text { to } B I N 1 \text {, recessive }\end{array}$ & 3.19 & $\mathrm{AR}$ & $\begin{array}{l}\text { CMN2 } \\
255200\end{array}$ & $2 q 14$ & $\begin{array}{l}\text { BIN1 } \\
601248\end{array}$ & amphiphysin & $\begin{array}{l}\text { Nicot et al. (2007) } \\
\text { Böhm et al. (2014) }\end{array}$ & \\
\hline $\begin{array}{l}\text { Centronuclear myopathy related } \\
\text { to } B I N 1 \text {, dominant }\end{array}$ & 3.20 & $\mathrm{AD}$ & & $2 q 14$ & $\begin{array}{l}\text { BIN1 } \\
601248\end{array}$ & amphiphysin & Böhm et al. (2014) & \\
\hline $\begin{array}{l}\text { Centronuclear myopathy related } \\
\text { to } R Y R I\end{array}$ & 3.21 & AR & 255200 & $19 \mathrm{q} 13.1$ & $\begin{array}{l}\text { RYRI } \\
180901\end{array}$ & ryanodine receptor & Wilmshurst et al. (2010) & $\begin{array}{l}\text { allelic to CCD (group 3), } \\
\text { minicore myopathy with } \\
\text { external ophthalmoplegia } \\
\text { (group 3), MHS1 (group 8) }\end{array}$ \\
\hline $\begin{array}{l}\text { Centronuclear myopathy related } \\
\text { to } T T N\end{array}$ & 3.22 & AR & & $2 \mathrm{q} 24.3$ & $\begin{array}{l}\text { TTN } \\
188840\end{array}$ & titin & Ceyhan-Birsoy et al. (2013) & $\begin{array}{l}\text { Allelic to \# 1.29, 3.34, 4.2, } \\
5.13,10.8,10.33\end{array}$ \\
\hline $\begin{array}{l}\text { Centronuclear myopathy with } \\
\text { dilated cardiomyopathy }\end{array}$ & 3.23 & AR & $\begin{array}{l}\text { CMN5 } \\
615959\end{array}$ & $2 \mathrm{q} 35$ & $\begin{array}{l}\text { SPEG } \\
615950\end{array}$ & $\begin{array}{l}\text { SPEG complex } \\
\text { locus }\end{array}$ & Agrawal et al. (2014) & \\
\hline Central core disease, dominant & 3.24 & $\mathrm{AD}$ & $\begin{array}{l}\text { CCD } \\
117000\end{array}$ & $19 \mathrm{q} 13.1$ & $\begin{array}{l}\text { RYR1 } \\
180901\end{array}$ & ryanodine receptor & $\begin{array}{l}\text { Kausch et al. (1991) } \\
\text { Zhang et al. (1993) } \\
\text { Quane et al. (1993), } \\
\text { Robinson et al. (2002) }\end{array}$ & $\begin{array}{l}\text { allelic to CCD (group 3), } \\
\text { minicore myopathy with } \\
\text { external ophthalmoplegia } \\
\text { (group 3), MHS1 (group 8) }\end{array}$ \\
\hline $\begin{array}{l}\text { Central core disease, recessive } \\
\text { (transient multiminicore } \\
\text { myopathy) }\end{array}$ & 3.25 & $\mathrm{AR}$ & $\begin{array}{l}\text { CCD } \\
117000\end{array}$ & $19 \mathrm{q} 13.1$ & $\begin{array}{l}\boldsymbol{R Y R 1} \\
180901\end{array}$ & ryanodine receptor & $\begin{array}{l}\text { Ferreiro et al. (2002a); } \\
\text { Jungbluth et al. (2002) }\end{array}$ & $\begin{array}{l}\text { allelic to CCD (group 3), } \\
\text { minicore myopathy with } \\
\text { external ophthalmoplegia } \\
\text { (group 3), MHS1 (group 8) }\end{array}$ \\
\hline $\begin{array}{l}\text { Multiminicore disease with } \\
\text { external ophthalmoplegia }\end{array}$ & 3.26 & AR & 255320 & $19 \mathrm{q} 13.1$ & $\begin{array}{l}\text { RYR1 } \\
180901\end{array}$ & ryanodine receptor & $\begin{array}{l}\text { Monnier et al. (2003), } \\
\text { Jungbluth et al. (2005) }\end{array}$ & $\begin{array}{l}\text { allelic to CCD (group 3), CCD } \\
\text { (group 3), MHS1 (group 8) }\end{array}$ \\
\hline $\begin{array}{l}\text { Multiminicore disease, classical } \\
\text { form }\end{array}$ & 3.27 & AR & 255320 & $1 \mathrm{p} 36$ & $\begin{array}{l}\text { SEPN1 } \\
606210\end{array}$ & selenoprotein N1 & $\begin{array}{l}\text { Ferreiro et al. (2002b), } \\
\text { Ferreiro et al. (2004) }\end{array}$ & $\begin{array}{l}\text { allelic to RSMD1 (group 2), } \\
\text { desmin related myopathy with } \\
\text { Mallory bodies (group 5) }\end{array}$ \\
\hline $\begin{array}{l}\text { Early-onset myopathy, } \\
\text { areflexia, respiratory distress } \\
\text { and dysphagia }\end{array}$ & 3.28 & $\mathrm{AR}$ & $\begin{array}{l}\text { EMARDD } \\
614399\end{array}$ & $5 \mathrm{q} 23.2$ & $\begin{array}{l}\text { MEGF10 } \\
612453\end{array}$ & $\begin{array}{l}\text { multiple EGF-like } \\
\text { domains } 10\end{array}$ & Logan et al. (2011) & See item \# 3.28 \\
\hline $\begin{array}{l}\text { Recessive congenital myopathy } \\
\text { with minicores }\end{array}$ & 3.29 & $\mathrm{AR}$ & $\begin{array}{l}\text { EMARDD } \\
614399\end{array}$ & $5 \mathrm{q} 23.2$ & $\begin{array}{l}\text { MEGF10 } \\
612453\end{array}$ & $\begin{array}{l}\text { multiple EGF-like } \\
\text { domains } 10\end{array}$ & Boyden et al. (2012) & See item \# 3.27 \\
\hline $\begin{array}{l}\text { Hyaline body myopathy } \\
\text { (recessive) }\end{array}$ & 3.30 & AR & 255160 & $3 \mathrm{p} 22.2-\mathrm{p} 21.32$ & ? & $?$ & Onengut et al. (2004) & \\
\hline $\begin{array}{l}\text { Hyaline body myopathy, } \\
\text { dominant (myosin storage } \\
\text { myopathy) }\end{array}$ & 3.31 & $\mathrm{AD}$ & $\begin{array}{l}\text { MSMA } \\
608358\end{array}$ & $14 q 12$ & $\begin{array}{l}\text { МYH7 } \\
160760\end{array}$ & $\begin{array}{l}\text { myosin, heavy } \\
\text { chain } 7 \text {, cardiac } \\
\text { muscle, b }\end{array}$ & $\begin{array}{l}\text { Tajsharghi et al. (2003) } \\
\text { Bohlega et al. (2004) } \\
\text { Laing et al. (2005) }\end{array}$ & $\begin{array}{l}\text { allelic to CFTD (group 3), } \\
\text { MPD1 (group 4), CMH1 } \\
\text { (group 10), CMD1S (group 10) }\end{array}$ \\
\hline $\begin{array}{l}\text { Myosin storage myopathy and } \\
\text { cardiomyopathy, recessive }\end{array}$ & 3.32 & AR & & $14 \mathrm{q} 12$ & $\begin{array}{l}\text { МYH7 } \\
160780\end{array}$ & $\begin{array}{l}\text { myosin, heavy } \\
\text { chain } 7 \text {, cardiac } \\
\text { muscle, b }\end{array}$ & Tajsharghi et al. (2007a) & $\begin{array}{l}\text { allelic to CFTD (group 3), } \\
\text { MPD1 (group 4), CMH1 } \\
\text { (group 10), CMD1S (group 10) }\end{array}$ \\
\hline $\begin{array}{l}\text { Myosin IIa myopathy, dominant } \\
\text { (Inclusion body myopathy } 3 \text { ) }\end{array}$ & 3.33 & $\mathrm{AD}$ & $\begin{array}{l}\text { IBM3 } \\
605637\end{array}$ & $17 \mathrm{p} 13.1$ & $\begin{array}{l}\text { MYH2 } \\
160740\end{array}$ & $\begin{array}{l}\text { myosin, heavy } \\
\text { chain } 2 \text {, skeletal } \\
\text { muscle, adult }\end{array}$ & $\begin{array}{l}\text { Martinsson et al. (1999, } \\
\text { 2000) }\end{array}$ & \\
\hline $\begin{array}{l}\text { Myopathy proximal with } \\
\text { ophthalmoplegia dominant } \\
\text { (Inclusion body myopathy } 3 \text { ) }\end{array}$ & 3.34 & $\mathrm{AD}$ & $\begin{array}{l}\text { MYPOP } \\
605637\end{array}$ & $17 \mathrm{p} 13.1$ & $\begin{array}{c}\text { МYH2 } \\
160740\end{array}$ & $\begin{array}{l}\text { myosin, heavy } \\
\text { chain } 2 \text {, skeletal } \\
\text { muscle, adult }\end{array}$ & $\begin{array}{l}\text { Martinsson et al. (1999, } \\
2000)\end{array}$ & \\
\hline $\begin{array}{l}\text { Myopathy proximal with } \\
\text { ophthalmoplegia recessive } \\
\text { (Inclusion body myopathy } 3 \text { ) }\end{array}$ & 3.35 & AR & $\begin{array}{l}\text { MYPOP } \\
605637\end{array}$ & $17 \mathrm{p} 13.1$ & $\begin{array}{l}\text { МYH2 } \\
160740\end{array}$ & $\begin{array}{l}\text { myosin, heavy } \\
\text { chain } 2 \text {, skeletal } \\
\text { muscle, adult }\end{array}$ & Tajsharghi et al. (2010) & \\
\hline $\begin{array}{l}\text { Isolated inclusion body } \\
\text { myopathy }\end{array}$ & 3.36 & $\mathrm{AD}$ & $\begin{array}{l}\text { IBMPFD3 } \\
615424\end{array}$ & $12 \mathrm{q} 13.13$ & $\begin{array}{l}\text { HNRPA1 } \\
164017\end{array}$ & $\begin{array}{l}\text { heterogeneous } \\
\text { nuclear } \\
\text { ribonucleoprotein } \\
\text { A1 }\end{array}$ & Izumi et al. (2015) & allelic to ALS20 (group 12) \\
\hline
\end{tabular}




\begin{tabular}{|c|c|c|c|c|c|c|c|c|}
\hline DISEASE NAME & $\begin{array}{l}\text { Item } \\
\text { line } \\
\text { in this } \\
\text { group }\end{array}$ & Inheritance & $\begin{array}{l}\text { Locus or } \\
\text { disease } \\
\text { symbol and } \\
\text { OMIM } \\
\text { number }\end{array}$ & Chromosome & $\begin{array}{l}\text { Gene symbol } \\
\text { and OMIM } \\
\text { number }\end{array}$ & $\begin{array}{l}\text { Protein } \\
\text { (mitochondrial } \\
\text { proteins indicated } \\
\text { by symbol }[M] \text { ) }\end{array}$ & $\begin{array}{l}\text { Key } \\
\text { references }\end{array}$ & $\begin{array}{l}\text { Other allelic disease(s) } \\
\text { (group in this table) }\end{array}$ \\
\hline Cap myopathy & 3.37 & $\mathrm{AD}$ & $\begin{array}{l}\text { CAPM2 } \\
609285\end{array}$ & $9 \mathrm{p} 13$ & $\begin{array}{l}\text { TPM2 } \\
190990\end{array}$ & tropomyosin $2, \mathrm{~b}$ & $\begin{array}{l}\text { Tajsharghi et al. (2007b) } \\
\text { Lehtokari et al. (2007) }\end{array}$ & $\begin{array}{l}\text { allelic to NEM4 (group 3) DA1 } \\
\text { (group 16) and DA2B (group } \\
\text { 16) }\end{array}$ \\
\hline Cap myopathy & 3.38 & $\mathrm{AD}$ & $\begin{array}{l}\text { CAPM1 } \\
609284\end{array}$ & $1 \mathrm{q} 21.2$ & $\begin{array}{l}\text { TPM3 } \\
191030\end{array}$ & tropomyosin 3 & $\begin{array}{l}\text { De Paula et al. (2009) } \\
\text { Ohlsson et al. (2009) }\end{array}$ & allelic to NEM1 (group 3) \\
\hline Cap myopathy & 3.39 & $\mathrm{AD}$ & & $1 \mathrm{q} 42.1$ & $\begin{array}{l}\text { ACTA1 } \\
102610\end{array}$ & $\begin{array}{l}\text { actin, alpha 1, } \\
\text { skeletal muscle }\end{array}$ & Hung et al. (2010) & allelic to NEM3 (group 3) \\
\hline $\begin{array}{l}\text { Congenital neuromuscular } \\
\text { disease with uniform type } 1 \\
\text { fiber }\end{array}$ & 3.40 & $\mathrm{AR}, \mathrm{AD}$ & $\begin{array}{l}\text { CCD } \\
117000\end{array}$ & $19 \mathrm{q} 13.1$ & $\begin{array}{l}\text { RYR1 } \\
180901\end{array}$ & $\begin{array}{l}\text { ryanodine receptor } \\
\text { I }\end{array}$ & Sato et al. (2007) & $\begin{array}{l}\text { allelic to CDD (group 3), } \\
\text { multi-minicore disease (group } \\
\text { 3), MHS1 (group 8) }\end{array}$ \\
\hline $\begin{array}{l}\text { Congenital myopathy with fatal } \\
\text { cardiomyopathy }\end{array}$ & 3.41 & & & $2 \mathrm{q} 31$ & $\begin{array}{l}\text { TTN } \\
188840\end{array}$ & titin & Carmignac et al. (2007) & $\begin{array}{l}\text { allelic to LGMD2J (group 1), } \\
\text { TMD (group 4,) HMERF } \\
\text { (group 5), CMH9 (group 10), } \\
\text { CMD1G (group 10) }\end{array}$ \\
\hline $\begin{array}{l}\text { Congenital skeletal myopathy } \\
\text { and fatal cardiomyopathy }\end{array}$ & 3.42 & $\mathrm{AR}$ & & $11 \mathrm{p} 11.2$ & $\begin{array}{l}\text { МYВРC3 } \\
600958\end{array}$ & $\begin{array}{l}\text { cardiac myosin } \\
\text { binding protein-C }\end{array}$ & Tajsharghi et al. (2010) & allelic to CMH4 (group 10) \\
\hline Congenital lethal myopathy & 3.43 & AR & $\begin{array}{l}\text { MYPCN } \\
612540\end{array}$ & $12 \mathrm{q} 11-\mathrm{q} 12$ & $\begin{array}{l}\text { CNTN1 } \\
600016\end{array}$ & contactin-1 & Compton et al. (2008) & \\
\hline Sarcotubular myopathy & 3.44 & $\mathrm{AR}$ & & $9 \mathrm{q} 31$ & $\begin{array}{l}\text { TRIM32 } \\
602290\end{array}$ & $\begin{array}{l}\text { tripartite motif } \\
\text { containing } 32 \\
\text { (ubiquitin ligase) }\end{array}$ & Schoser et al. (2005) & allelic to LGMD2H (group 1) \\
\hline $\begin{array}{l}\text { Congenital myopathy related to } \\
\text { PTPLA }\end{array}$ & 3.45 & $\mathrm{AR}$ & & $10 \mathrm{p} 12.33$ & $\begin{array}{l}\text { HACD1 } \\
(=\text { PTPLA) } \\
610467\end{array}$ & $\begin{array}{l}\text { protein tyrosine } \\
\text { phosphatase-like } \\
\text { (3-Hydroxyacyl-CoA } \\
\text { dehydratase) }\end{array}$ & Muhammad et al. (2013) & ARVD6 (item \# 10-80) \\
\hline $\begin{array}{l}\text { Congenital myopathy with } \\
\text { ophthalmoplegia related to } \\
\text { CACNAIS }\end{array}$ & 3.46 & $\mathrm{AR}$ & & $1 \mathrm{q} 32.1$ & $\begin{array}{l}\text { CACNA1S } \\
114208\end{array}$ & $\begin{array}{l}\text { calcium channel, } \\
\text { voltage-dependent, } \\
\text { L type, alpha 1S } \\
\text { subunit }\end{array}$ & Hunter et al. (2015) & $\begin{array}{l}\text { Allelic to hypoKPP1 (group 7) } \\
\text { MHS5 (group 8) }\end{array}$ \\
\hline $\begin{array}{l}\text { Myopathy, Congenital, With } \\
\text { Neuropathy And Deafness }\end{array}$ & 3.47 & $\mathrm{AR}$ & $\begin{array}{l}\text { CMND } \\
617519\end{array}$ & $19 \mathrm{q} 13$ & $\begin{array}{l}\text { SPTBN4 } \\
606214\end{array}$ & $\begin{array}{l}\text { Spectrin, Beta, } \\
\text { Nonerythrocytic, } 4\end{array}$ & Knierim et al. (2017) & \\
\hline $\begin{array}{l}\text { Myopathy, Congenital, with } \\
\text { fiber type disproportion }\end{array}$ & 3.48 & $\mathrm{AR}$ & & $2 \mathrm{q} 31.1$ & $\begin{array}{l}Z A K \\
609479\end{array}$ & $\begin{array}{l}\text { Leucine Zipper- } \\
\text { And Sterile Alpha } \\
\text { Motif-Containing } \\
\text { Kinase }\end{array}$ & Vasli et al. (2017) & \\
\hline $\begin{array}{l}\text { Nemaline Myopathy with } \\
\text { Cardiomyopathy }\end{array}$ & 3.49 & $\mathrm{AR}$ & & $22 \mathrm{q} 12.1$ & $\begin{array}{l}\text { МYO18B } \\
607295\end{array}$ & Myosin XVIIIB & Malfatti et al. (2015) & \\
\hline $\begin{array}{l}\text { Myopathy, congenital, With } \\
\text { excess of muscle spindles }\end{array}$ & 3.50 & $\mathrm{AD}$ & $\begin{array}{l}\text { CMEMS } \\
218040\end{array}$ & $11 \mathrm{p} 15.5$ & $\begin{array}{l}\text { HRAS } \\
190020\end{array}$ & $\begin{array}{l}\text { V-Ha-RAS Harvey } \\
\text { Rat Sarcoma Viral } \\
\text { Oncogene Homolog }\end{array}$ & Quélin et al. (2017) & \\
\hline $\begin{array}{l}\text { Myopathy, Congenital } \\
\text { nonprogressive, with Moebius } \\
\text { sequence and Robin sequence }\end{array}$ & 3.51 & $\mathrm{AR}$ & $\begin{array}{l}\text { CFZS } \\
254940\end{array}$ & $9 \mathrm{q} 34.2$ & $\begin{array}{r}\text { МYMK } \\
615345\end{array}$ & Myomaker & Di Gioia et al. (2017) & \\
\hline \multicolumn{9}{|c|}{ GROUP 4. DISTAL MYOPATHIES } \\
\hline $\begin{array}{l}\text { Distal recessive myopathy } \\
\text { (Miyoshi) }\end{array}$ & 4.1 & AR & $\begin{array}{l}\text { MMD1 } \\
254130\end{array}$ & $2 \mathrm{p} 12-14$ & $\begin{array}{l}\text { DYSF } \\
603009\end{array}$ & dysferlin & $\begin{array}{l}\text { Bejaoui et al. (1995) } \\
\text { Bashir et al. (1998) } \\
\text { Liu et al. (1998) }\end{array}$ & allelic to LGMD2B (group 1) \\
\hline $\begin{array}{l}\text { Tibial muscular dystrophy } \\
\text { (Udd) }\end{array}$ & 4.2 & $\mathrm{AD}$ & $\begin{array}{l}\text { TMD } \\
600334\end{array}$ & $2 q 31$ & $\begin{array}{l}\boldsymbol{T T N} \\
188840\end{array}$ & titin & $\begin{array}{l}\text { Haravuori et al. (1998) } \\
\text { Haravuori et al. (2001) } \\
\text { Hackman et al. (2002) }\end{array}$ & $\begin{array}{l}\text { allelic to LGMD2J (group } \\
\text { 1),congenital myopathy with } \\
\text { fatal cardiomyopathy (group 3), } \\
\text { HMERF (group 5), CMH9 } \\
\text { (group 10), CMD1G (group } \\
\text { 10) }\end{array}$ \\
\hline $\begin{array}{l}\text { Distal myopathy with rimmed } \\
\text { vacuoles (Nonaka) and } \\
\text { Hereditary inclusion body } \\
\text { myopathy }\end{array}$ & 4.3 & $\mathrm{AR}$ & $\begin{array}{l}\text { NM } \\
605820 \\
\text { IBM2 } \\
600737\end{array}$ & $9 \mathrm{p} 12-\mathrm{p} 12$ & $\begin{array}{l}\boldsymbol{G N E} \\
603824\end{array}$ & $\begin{array}{l}\text { glucosamine } \\
\text { (UDP-N-acetyl)-2- } \\
\text { epimerase/N- } \\
\text { acetylmannosamine } \\
\text { kinase }\end{array}$ & $\begin{array}{l}\text { Mitrani- } \\
\text { Rosenbaum et al. (1996), } \\
\text { Ikeuchi et al. (1997) } \\
\text { Eisenberg et al. (2001) }\end{array}$ & \\
\hline Distal myopathy (Laing) & 4.4 & $\mathrm{AD}$ & $\begin{array}{l}\text { MPD1 } \\
160500\end{array}$ & $14 \mathrm{q} 11.2$ & $\begin{array}{l}\text { МYH7 } \\
160760\end{array}$ & $\begin{array}{l}\text { myosin, heavy } \\
\text { chain } 7 \text {, cardiac } \\
\text { muscle, beta }\end{array}$ & $\begin{array}{l}\text { Laing et al. (1995a), } \\
\text { Mastaglia et al. (2000), } \\
\text { Meredith et al. (2004) }\end{array}$ & $\begin{array}{l}\text { allelic to CFTD (group 3), } \\
\text { myosin storage myopathy } \\
\text { (group 3), CMH1 (group 10), } \\
\text { CMD1S (group 10) }\end{array}$ \\
\hline $\begin{array}{l}\text { Vocal cord and pharyngeal } \\
\text { distal myopathy }\end{array}$ & 4.5 & $\mathrm{AD}$ & $\begin{array}{l}\text { MPD2 } \\
606070\end{array}$ & $5 q 31$ & $\begin{array}{l}\text { MATR3 } \\
164015\end{array}$ & Matrin 3 & $\begin{array}{l}\text { Feit et al. (1998) } \\
\text { Senderek et al. (2009) }\end{array}$ & Allelic to ALS21 (group 12) \\
\hline Adult-onset distal myopathy & 4.6 & $\mathrm{AD}$ & $\begin{array}{l}\text { MPD3 } \\
610099\end{array}$ & $8 \mathrm{p} 22-\mathrm{q} 11$ & $?$ & & Haravuori et al. (2004) & \\
\hline Welander distal myopathy & 4.7 & $\mathrm{AD}$ & $\begin{array}{l}\text { WDM } \\
604454\end{array}$ & $2 \mathrm{p} 13$ & $\begin{array}{l}\text { TIA1 } \\
603518\end{array}$ & $\begin{array}{l}\text { cytotoxic } \\
\text { granule-associated } \\
\text { RNA binding } \\
\text { protein }\end{array}$ & $\begin{array}{l}\text { Ahlberg et al. (1999) } \\
\text { Hackman et al. (2013) } \\
\text { Klar et al (2013) }\end{array}$ & \\
\hline
\end{tabular}




\begin{tabular}{|c|c|c|c|c|c|c|c|c|}
\hline DISEASE NAME & $\begin{array}{l}\text { Item } \\
\text { line } \\
\text { in this } \\
\text { group }\end{array}$ & Inheritance & $\begin{array}{l}\text { Locus or } \\
\text { disease } \\
\text { symbol and } \\
\text { OMIM } \\
\text { number }\end{array}$ & Chromosome & $\begin{array}{l}\text { Gene symbol } \\
\text { and OMIM } \\
\text { number }\end{array}$ & $\begin{array}{l}\text { Protein } \\
\text { (mitochondrial } \\
\text { proteins indicated } \\
\text { by symbol }[M] \text { ) }\end{array}$ & $\begin{array}{l}\text { Key } \\
\text { references }\end{array}$ & $\begin{array}{l}\text { Other allelic disease(s) } \\
\text { (group in this table) }\end{array}$ \\
\hline $\begin{array}{l}\text { Distal myopathy with pes cavus } \\
\text { and areflexia (Vacuolar } \\
\text { neuromyopathy) }\end{array}$ & 4.8 & $\mathrm{AD}$ & 601846 & 19.p13 & $?$ & & Servidei et al. (1999) & \\
\hline $\begin{array}{l}\text { Distal myopathy with myotilin } \\
\text { defect }\end{array}$ & 4.9 & $\mathrm{AD}$ & & $5 \mathrm{q} 31$ & $\begin{array}{l}\text { МYOT } \\
604103\end{array}$ & myotilin & $\begin{array}{l}\text { Penisson- } \\
\text { Besnier et al. }(1998,2006)\end{array}$ & $\begin{array}{l}\text { allelic to LGMD1A (group 1), } \\
\text { MFM (group 5), spheroid body } \\
\text { myopathy (group 5) }\end{array}$ \\
\hline $\begin{array}{l}\text { Distal myopathy with nebulin } \\
\text { defect }\end{array}$ & 4.10 & AR & & $2 \mathrm{q} 22$ & $\begin{array}{l}N E B \\
161650\end{array}$ & nebulin & $\begin{array}{l}\text { Wallgren- } \\
\text { Pettersson et al. (2007) }\end{array}$ & allelic to NEM2 (group 3) \\
\hline $\begin{array}{l}\text { Distal myopathy with caveolin } \\
\text { defect }\end{array}$ & 4.11 & $\mathrm{AD}$ & & $3 \mathrm{p} 25$ & $\begin{array}{l}\text { CAV3 } \\
601253\end{array}$ & caveolin-3 & $\begin{array}{l}\text { Tateyama et al. (2002); } \\
\text { Fulizio et al. (2005) }\end{array}$ & $\begin{array}{l}\text { allelic to LGMD1C (group 1), } \\
\text { hyper CKemia (group 5), } \\
\text { RMD2 (group 6), CMH (group } \\
\text { 10) }\end{array}$ \\
\hline $\begin{array}{l}\text { Late-onset distal myopathy } \\
\text { (Markesbery-Griggs) }\end{array}$ & 4.12 & $\mathrm{AD}$ & & $10 \mathrm{q} 23.2$ & $\begin{array}{l}\mathbf{L D B 3} \\
(=Z A S P) \\
605906\end{array}$ & $\begin{array}{l}\text { LIM domain } \\
\text { binding }-3 \text { ( } Z \text { band } \\
\text { alternatively spliced } \\
\text { PDZ motif) }\end{array}$ & Griggs et al. (2007) & allelic to MFM (group 5) \\
\hline Early-onset calf distal myopathy & 4.13 & $\mathrm{AR}$ & $\begin{array}{l}\text { MMD3 } \\
613319\end{array}$ & $11 \mathrm{p} 14-12$ & $\begin{array}{l}\text { AN05 } \\
608662\end{array}$ & anoctamin 5 & Bolduc et al. (2010) & allelic to LGMD2L (group 1) \\
\hline $\begin{array}{l}\text { Dynamin 2-related distal } \\
\text { myopathy }\end{array}$ & 4.14 & $\mathrm{AD}$ & $\begin{array}{l}\text { CNM1 } \\
160150\end{array}$ & $19 \mathrm{p} 13.2$ & $\begin{array}{l}\text { DNM2 } \\
602378\end{array}$ & dynamin 2 & Fischer et al (2006) & $\begin{array}{l}\text { allelic to CNM (group 3) and } \\
\text { CMTDIB (group 14) }\end{array}$ \\
\hline $\begin{array}{l}\text { Early-onset distal myopathy } \\
\text { with KLHL9 defect }\end{array}$ & 4.15 & $\mathrm{AD}$ & & $9 \mathrm{p} 22$ & $\begin{array}{l}\text { KLHL9 } \\
611201\end{array}$ & $\begin{array}{l}\text { Kelch-like homolog } \\
9\end{array}$ & Cirak et al. (2010) & \\
\hline $\begin{array}{l}\text { Filamin C-related distal } \\
\text { myopathy }\end{array}$ & 4.16 & $\mathrm{AD}$ & $\begin{array}{l}\text { MPD4 } \\
614065\end{array}$ & $7 \mathrm{q} 32$ & $\begin{array}{l}\text { FLNC } \\
102565\end{array}$ & $\begin{array}{l}\text { filamin } \mathrm{C} \text {, gamma } \\
\text { (actin binding } \\
\text { protein 280) }\end{array}$ & Duff et al. (2011) & allelic to MFM5 (group 5) \\
\hline $\begin{array}{l}\text { Distal myopathy with VCP } \\
\text { defect }\end{array}$ & 4.17 & $\mathrm{AD}$ & $\begin{array}{l}\text { IBMPFD } \\
167320\end{array}$ & 9p13-p12 & $\begin{array}{l}\boldsymbol{V C P} \\
601023\end{array}$ & $\begin{array}{l}\text { valosin-containing } \\
\text { protein }\end{array}$ & Palmio et al. (2011) & $\begin{array}{l}\text { Allelic to \#1.48, IBMBFD } \\
\text { (group 5), ALS14 (group 12) } \\
\text { and CMT2Y (group 14) }\end{array}$ \\
\hline $\begin{array}{l}\text { Adolescent-onset distal } \\
\text { myopathy }\end{array}$ & 4.18 & AR & $\begin{array}{l}\text { MPD5 } \\
617030\end{array}$ & $14 q 32-33$ & $\begin{array}{l}\text { ADSSL1 } \\
612498\end{array}$ & $\begin{array}{l}\text { Adénylosuccinate } \\
\text { synthase-like }\end{array}$ & Park et al. (2018) & \\
\hline
\end{tabular}

\section{GROUP 5. OTHER MYOPATHIES}

\begin{tabular}{|c|c|c|c|c|c|c|}
\hline $\begin{array}{l}\text { A. Myofibrillar myopathies } \\
\text { Myofibrillar myopathy, } \\
\text { desmin-related myopathy }\end{array}$ & 5.1 & $\mathrm{AD}$ & $\begin{array}{l}\text { MFM1 } \\
601419\end{array}$ & $2 \mathrm{q} 35$ & $\begin{array}{l}\text { DES } \\
125660\end{array}$ & desmin \\
\hline $\begin{array}{l}\text { Myofibrillar myopathy, alpha-B } \\
\text { crystallin related }\end{array}$ & 5.2 & $\mathrm{AD}$ & $\begin{array}{l}\text { MFM2 } \\
608810\end{array}$ & $11 \mathrm{q} 22$ & $\begin{array}{l}\text { CRYAB } \\
123590\end{array}$ & crystallin, alpha B \\
\hline $\begin{array}{l}\text { Myofibrillar myopathy, myotilin } \\
\text { related }\end{array}$ & 5.3 & $\mathrm{AD}$ & $\begin{array}{l}\text { MFM3 } \\
609200\end{array}$ & $5 \mathrm{q} 31$ & $\begin{array}{l}\text { MYOT } \\
604103\end{array}$ & $\begin{array}{l}\text { myotilin (titin } \\
\text { immunoglobulin } \\
\text { domain protein) }\end{array}$ \\
\hline Spheroid body myopathy & 5.4 & $\mathrm{AD}$ & $\begin{array}{l}\text { MFM3 } \\
182920\end{array}$ & $5 \mathrm{q} 31$ & $\begin{array}{l}\text { MYOT } \\
604103\end{array}$ & $\begin{array}{l}\text { myotilin (titin } \\
\text { immunoglobulin } \\
\text { domain protein) }\end{array}$ \\
\hline Myofibrillar myopathy & 5.5 & $\mathrm{AD}$ & $\begin{array}{l}\text { MFM4 } \\
609452\end{array}$ & $10 \mathrm{q} 22$ & $\begin{array}{l}\text { LDB3 } \\
=Z A S P \\
605906\end{array}$ & $\begin{array}{l}\text { LIM domain } \\
\text { binding-3 ( } \mathrm{Z} \text { band } \\
\text { alternatively spliced } \\
\text { PDZ motif) }\end{array}$ \\
\hline $\begin{array}{l}\text { Myofibrillar myopathy, } \\
\text { filamin-C related }\end{array}$ & 5.6 & $\mathrm{AD}$ & $\begin{array}{l}\text { MFM5 } \\
609524\end{array}$ & $7 \mathrm{q} 32$ & $\begin{array}{l}\boldsymbol{F L N C} \\
102565\end{array}$ & $\begin{array}{l}\text { filamin } \mathrm{C} \text {, gamma } \\
\text { (actin binding } \\
\text { protein 280) }\end{array}$ \\
\hline $\begin{array}{l}\text { Myofibrillar myopathy with } \\
\text { BAG3 defect }\end{array}$ & 5.7 & $\mathrm{AD}$ & $\begin{array}{l}\text { MFM6 } \\
612954\end{array}$ & $10 \mathrm{q} 25-\mathrm{q} 26$ & $\begin{array}{l}\text { BAG3 } \\
603883\end{array}$ & $\begin{array}{l}\text { BCL2-associated } \\
\text { athanogene } 3\end{array}$ \\
\hline Myopathy microfibrillar type 7 & 5.8 & AR & $\begin{array}{l}\text { MFM7 } \\
617114\end{array}$ & $3 q 22.2$ & $\begin{array}{l}\boldsymbol{K} \boldsymbol{Y} \\
605739\end{array}$ & $\begin{array}{l}\text { Kyphoscoliosis } \\
\text { peptidase }\end{array}$ \\
\hline $\begin{array}{l}\text { Early-onset myofibrillar } \\
\text { myopathy with PYRODX1 } \\
\text { defect }\end{array}$ & 5.9 & AR & $\begin{array}{l}\text { MFM8 } \\
617258\end{array}$ & $12 \mathrm{p} 12.1$ & $\begin{array}{l}\text { PYRODX1 } \\
617220\end{array}$ & $\begin{array}{l}\text { Pyridine } \\
\text { nucleotide-disulphide } \\
\text { oxidoreductase } \\
\text { domain } 1\end{array}$ \\
\hline $\begin{array}{l}\text { Desmin-related myopathy with } \\
\text { Mallory bodies }\end{array}$ & 5.10 & $\mathrm{AD}$ & 602771 & $1 \mathrm{p} 36$ & $\begin{array}{l}\text { SEPN1 } \\
606210\end{array}$ & selenoprotein $\mathrm{N} 1$ \\
\hline $\begin{array}{l}\text { Cardiac and skeletal aggregate } \\
\text { myopathy }\end{array}$ & 5.11 & Digenic & & $\begin{array}{l}1 \mathrm{p} 36.11 \\
2 \mathrm{p} .23 .3\end{array}$ & $\begin{array}{l}\text { TRIM63 } \\
\text { (=MURF1) } \\
606131 \\
+ \text { TRIM54 } \\
\text { (=MURF3) } \\
606474\end{array}$ & $\begin{array}{l}\text { tripartite motif } \\
\text { containing } 63, \text { E3 } \\
\text { ubiquitin protein } \\
\text { ligase + tripartite } \\
\text { motif containing } 54\end{array}$ \\
\hline
\end{tabular}

Goldfarb et al. (1998) Allelic to LGMD1E (group 1), Munoz-Marmol et al. (1998) CMD1I (group 10/A), ARVD7 (group 10/B)

Vicart et al. (1998); Selcen et al. (2003)

Selcen and Engel (2004) allelic to LGMD1A (group 1), spheroid body myopathy (group 5)

Foroud et al. (2005) allelic to LGMD1A (group 1), MFM (group 5)

Selcen and Engel (2005) allelic to Markesbery-Grigg (group 4) and to CMD1C (group 10)

Vorgerd et al. (2005)

Allelic to filamin C related distal myopathy (group 4)

Selcen et al. (2009)

Hedberg-Oldfors et al.

(2016); Straussberg et al.

(2016)

O'Grady et al. (2016)

Ferreiro et al. (2004)

Olivé et al. (2015)

allelic to RSMD1 (group 2), CFTD (group 3) multiminicore disease (group 3) 


\begin{tabular}{|c|c|c|c|c|c|c|c|c|}
\hline DISEASE NAME & $\begin{array}{l}\text { Item } \\
\text { line } \\
\text { in this } \\
\text { group }\end{array}$ & Inheritance & $\begin{array}{l}\text { Locus or } \\
\text { disease } \\
\text { symbol and } \\
\text { OMIM } \\
\text { number }\end{array}$ & Chromosome & $\begin{array}{l}\text { Gene symbol } \\
\text { and OMIM } \\
\text { number }\end{array}$ & $\begin{array}{l}\text { Protein } \\
\text { (mitochondrial } \\
\text { proteins indicated } \\
\text { by symbol }[M] \text { ) }\end{array}$ & $\begin{array}{l}\text { Key } \\
\text { references }\end{array}$ & $\begin{array}{l}\text { Other allelic disease(s) } \\
\text { (group in this table) }\end{array}$ \\
\hline $\begin{array}{l}\text { Myofibrillar myopathy with } \\
\text { arrhythmogenic right } \\
\text { ventricular cardiomyopathy }\end{array}$ & 5.12 & $\mathrm{AD}$ & $\begin{array}{l}\text { MFM/ARVC } \\
609160\end{array}$ & $10 \mathrm{q} 22$ & $?$ & & $\begin{array}{l}\text { Melberg et al. (1999) } \\
\text { Kuhl et al. (2008) }\end{array}$ & \\
\hline \multicolumn{9}{|l|}{ B. Miscellaneous } \\
\hline Danon disease & 5.13 & $\mathrm{XD}$ & $\begin{array}{l}\text { GSD IIb } \\
300257\end{array}$ & $\mathrm{Xq} 24$ & $\begin{array}{l}\boldsymbol{L A M P 2} \\
309060\end{array}$ & $\begin{array}{l}\text { lysosomal-associated } \\
\text { membrane protein } 2\end{array}$ & $\begin{array}{l}\text { Nishino et al. (2000) } \\
\text { Musumeci et al. (2005) }\end{array}$ & \\
\hline $\begin{array}{l}\text { Myopathy with excessive } \\
\text { autophagia }\end{array}$ & 5.14 & $\mathrm{XR}$ & $\begin{array}{l}\text { MEAX } \\
(\mathrm{XMEA}) \\
310440\end{array}$ & $\mathrm{Xq} 28$ & $\begin{array}{l}\text { VMA21 } \\
300913\end{array}$ & $\begin{array}{l}\text { VMA21 Vacuolar } \\
\text { H+-ATPase } \\
\text { Homolog (S. } \\
\text { cerevisiae) }\end{array}$ & $\begin{array}{l}\text { Saviranta et al. (1988) } \\
\text { Villard et al. (2000) } \\
\text { Minassian et al. (2002); } \\
\text { Munteanu et al. (2008), } \\
\text { Ramachandran et al. (2013), } \\
\text { Crockett et al. (2014) }\end{array}$ & \\
\hline Autophagic vacuolar myopathy & 5.15 & AR & & $16 \mathrm{p} 11.2$ & $\begin{array}{l}C L N 3 \\
607042\end{array}$ & $\begin{array}{l}\text { ceroid-lipofuscinosis, } \\
\text { neuronal } 3 \\
\text { (=battenin) }\end{array}$ & Cortese et al. (2014) & \\
\hline $\begin{array}{l}\text { Oculopharyngeal muscular } \\
\text { dystrophy }\end{array}$ & 5.16 & $\mathrm{AD}$ & $\begin{array}{l}\text { OPMD } \\
164300\end{array}$ & $14 \mathrm{q} 11.2-\mathrm{q} 13$ & $\begin{array}{l}\text { PABPN1 } \\
602279\end{array}$ & $\begin{array}{l}\text { poly }(\mathrm{A}) \text { binding } \\
\text { protein, nuclear } 1\end{array}$ & $\begin{array}{l}\text { Brais et al. }(1995,1998) \\
\text { Robinson et al. }(2005)\end{array}$ & \\
\hline $\begin{array}{l}\text { Hereditary myopathy with early } \\
\text { respiratory failure (Edström } \\
\text { myopathy) }\end{array}$ & 5.17 & $\mathrm{AD}$ & $\begin{array}{l}\text { HMERF } \\
603689\end{array}$ & $2 q 24-3$ & $\begin{array}{l}\text { TTN } \\
188840\end{array}$ & titin & $\begin{array}{l}\text { Nicolao et al. (1999) } \\
\text { Lange et al. (2005) }\end{array}$ & $\begin{array}{l}\text { allelic to LGMD2J (group 1), } \\
\text { congenital myopathy with fatal } \\
\text { cardiomyopathy (group 3), } \\
\text { TMD (group 4), CMH9 (group } \\
\text { 10), CMD1G (group 10) }\end{array}$ \\
\hline $\begin{array}{l}\text { Epidermolysis bullosa simplex } \\
\text { associated with late-onset } \\
\text { muscular dystrophy }\end{array}$ & 5.18 & AR & $\begin{array}{l}\text { MDEBS } \\
226670\end{array}$ & 8q24-qter & $\begin{array}{l}\text { PLEC1 } \\
601282\end{array}$ & plectin & $\begin{array}{l}\text { Gache et al. (1996) } \\
\text { Smith et al. (1996) } \\
\text { Wuyts et al. (1996) }\end{array}$ & $\begin{array}{l}\text { allelic to LGMD2Q (group 1), } \\
\text { myasthenic syndrome with } \\
\text { plectin defect (group 11) }\end{array}$ \\
\hline Muscle hypertrophy & 5.19 & AR & $\begin{array}{l}\text { MSLHP } \\
614160\end{array}$ & $2 \mathrm{q} 32$ & $\begin{array}{l}\text { MSTN } \\
(=\mathrm{GDF} 8) \\
601788\end{array}$ & $\begin{array}{l}\text { Myostatin (growth } \\
\text { differentiation } \\
\text { factor } 8 \text { ) }\end{array}$ & Schuelke et al. (2004) & \\
\hline $\begin{array}{l}\text { Fibrodysplasia ossificans } \\
\text { progressiva }\end{array}$ & 5.20 & $\mathrm{AD}$ & $\begin{array}{l}\text { FOP } \\
135100\end{array}$ & $2 q 23-q 24$ & $\begin{array}{l}\text { ACVR1 } \\
102576\end{array}$ & $\begin{array}{l}\text { activin A receptor, } \\
\text { type } 1\end{array}$ & Shore et al. (2006) & \\
\hline HyperCKemia, idiopathic & 5.21 & $\mathrm{AD}$ & 123320 & $3 \mathrm{p} 25$ & $\begin{array}{l}\text { CAV3 } \\
601253\end{array}$ & caveolin-3 & Carbone et al. (2000) & $\begin{array}{l}\text { allelic to LGMD1C (group 1) } \\
\text { and RMD2 (group 6), CMH } \\
\text { (group 10) }\end{array}$ \\
\hline $\begin{array}{l}\text { X-linked myopathy with } \\
\text { postural muscle atrophy }\end{array}$ & 5.22 & $\mathrm{XR}$ & $\begin{array}{l}\text { XMPMA } \\
300696\end{array}$ & Xq26.3 & $\begin{array}{l}\text { FHL1 } \\
300163\end{array}$ & $\begin{array}{l}\text { four and a half LIM } \\
\text { domain } 1\end{array}$ & Windpassinger et al. (2008) & $\begin{array}{l}\text { allelic to Emery-Dreifuss MD } \\
\text { X-linked type } 2 \text { (group 1) } \\
\text { reducing body myopathy } \\
\text { (group 3), XPMD (group 5) }\end{array}$ \\
\hline Scapuloperoneal myopathy & 5.23 & $\mathrm{XD}$ & $\begin{array}{l}\text { XPMD } \\
300695\end{array}$ & $\mathrm{Xq} 26.3$ & $\begin{array}{l}\text { FHL1 } \\
300163\end{array}$ & $\begin{array}{l}\text { four and a half LIM } \\
\text { domain } 1\end{array}$ & Quinzil et al. (2008) & $\begin{array}{l}\text { allelic to Emery-Dreifuss MD } \\
\text { X-linked type } 2 \text { (group 1) } \\
\text { reducing body myopathy } \\
\text { (group 3), XMPMA (group 5) }\end{array}$ \\
\hline Reducing body myopathy & 5.24 & $\mathrm{XD}$ & $\begin{array}{l}300717 \\
300718\end{array}$ & Xq26.3 & $\begin{array}{l}\text { FHL1 } \\
300163\end{array}$ & $\begin{array}{l}\text { four and a half LIM } \\
\text { domain } 1\end{array}$ & $\begin{array}{l}\text { Schessl et al. (2008), } \\
\text { Shalaby et al. (2009) }\end{array}$ & $\begin{array}{l}\text { allelic to EDMD6 (group 1), } \\
\text { RSS (group 2), XPMA (group } \\
\text { 5), XPMD (group 5) }\end{array}$ \\
\hline $\begin{array}{l}\text { Episodic muscle weakness, } \\
\text { X-linked }\end{array}$ & 5.25 & $\mathrm{XR}$ & $\begin{array}{l}\text { EMWX } \\
300211\end{array}$ & Xp22.3 & $?$ & & Ryan et al. (1999) & \\
\hline $\begin{array}{l}\text { Inclusion body myopathy } \\
\text { associated with Paget disease } \\
\text { of bone and frontotemporal } \\
\text { dementia }\end{array}$ & 5.26 & $\mathrm{AD}$ & $\begin{array}{l}\text { IBMPFD } \\
167320\end{array}$ & 9 p13-p12 & $\begin{array}{l}\boldsymbol{V C P} \\
601023\end{array}$ & $\begin{array}{l}\text { valosin-containing } \\
\text { protein }\end{array}$ & $\begin{array}{l}\text { Watts et al. (2004), } \\
\text { Haubenberger et al. (2005) }\end{array}$ & $\begin{array}{l}\text { allelic to \#1.42, IBMPFD } \\
(\# 4.17), \text { ALS14 (\#12.46) and } \\
\text { CMT2Y (\#14.63) }\end{array}$ \\
\hline $\begin{array}{l}\text { Myopathy with exercise } \\
\text { intolerance, Swedish type }\end{array}$ & 5.27 & AR & $\begin{array}{l}\text { HML } \\
255125\end{array}$ & $12 \mathrm{q} 24.1$ & $\begin{array}{l}\text { ICSU } \\
611911\end{array}$ & $\begin{array}{l}\text { iron-sulfur cluster } \\
\text { scaffold homolog } \\
\text { (E. coli) }\end{array}$ & Mochel et al. (2008) & \\
\hline $\begin{array}{l}\text { Late-onset axial myopathy } \\
\text { related to RYR1 }\end{array}$ & 5.28 & $\mathrm{AD}$ & & $19 \mathrm{q} 13.1$ & $\begin{array}{l}\text { RYR1 } \\
180901\end{array}$ & $\begin{array}{l}\text { Ryanodine receptor } \\
1 \text { (skeletal) }\end{array}$ & Løseth et al. (2013) & $\begin{array}{l}\text { Allelic to items } 3.12,3.17, \\
3.18,3.19,3.20,3.32\end{array}$ \\
\hline \multicolumn{9}{|c|}{ GROUP 6. MYOTONIC SYNDROMES } \\
\hline Myotonic dystrophy (Steinert) & 6.1 & $\mathrm{AD}$ & $\begin{array}{l}\text { DM1 } \\
160900\end{array}$ & $19 \mathrm{q} 13$ & $\begin{array}{l}\text { DMPK } \\
605377\end{array}$ & $\begin{array}{l}\text { dystrophia } \\
\text { myotonica-protein } \\
\text { kinase }\end{array}$ & $\begin{array}{l}\text { Renwick et al. (1971) } \\
\text { Friedrich et al. (1987) } \\
\text { Harley et al. (1992) } \\
\text { Buxton et al. (1992) } \\
\text { Aslanidis et al. (1992) } \\
\text { Mahadevan et al. (1992) } \\
\text { Fu et al. (1992) } \\
\text { Brook et al. (1992) }\end{array}$ & \\
\hline $\begin{array}{l}\text { Myotonic dystrophy type } 2 \\
\text { (proximal myotonic myopathy) }\end{array}$ & 6.2 & $\mathrm{AD}$ & $\begin{array}{l}\text { DM2 } \\
\text { (PROMM) } \\
602668\end{array}$ & $3 q 21$ & $\begin{array}{l}\text { ZNF9 } \\
116955\end{array}$ & $\begin{array}{l}\text { zinc finger protein } \\
9\end{array}$ & $\begin{array}{l}\text { Ranum et al. (1998) } \\
\text { Liquori et al. (2001) }\end{array}$ & \\
\hline
\end{tabular}




\begin{tabular}{|c|c|c|c|c|c|c|c|c|}
\hline DISEASE NAME & $\begin{array}{l}\text { Item } \\
\text { line } \\
\text { in this } \\
\text { group }\end{array}$ & Inheritance & $\begin{array}{l}\text { Locus or } \\
\text { disease } \\
\text { symbol and } \\
\text { OMIM } \\
\text { number }\end{array}$ & Chromosome & $\begin{array}{l}\text { Gene symbol } \\
\text { and OMIM } \\
\text { number }\end{array}$ & $\begin{array}{l}\text { Protein } \\
\text { (mitochondrial } \\
\text { proteins indicated } \\
\text { by symbol }[M] \text { ) }\end{array}$ & $\begin{array}{l}\text { Key } \\
\text { references }\end{array}$ & $\begin{array}{l}\text { Other allelic disease(s) } \\
\text { (group in this table) }\end{array}$ \\
\hline Myotonia, dominant (Thomsen) & 6.3 & $\mathrm{AD}$ & $\begin{array}{l}\text { see under } \\
\text { Ion } \\
\text { channel } \\
\text { muscle } \\
\text { diseases }\end{array}$ & & & & & \\
\hline Myotonia, recessive (Becker) & 6.4 & $\mathrm{AR}$ & $\begin{array}{l}\text { see under } \\
\text { Ion } \\
\text { channel } \\
\text { muscle } \\
\text { diseases }\end{array}$ & & & & & \\
\hline $\begin{array}{l}\text { Rippling muscle disease, } \\
\text { dominant }\end{array}$ & 6.5 & $\mathrm{AD}$ & $\begin{array}{l}\text { RMD1 } \\
600332\end{array}$ & $1 \mathrm{q} 41$ & $?$ & & Stephan et al. (1994) & \\
\hline $\begin{array}{l}\text { Rippling muscle disease, } \\
\text { dominant }\end{array}$ & 6.6 & $\mathrm{AD}$ & $\begin{array}{l}\text { RMD2 } \\
606072\end{array}$ & $3 \mathrm{p} 25$ & $\begin{array}{l}\text { CAV3 } \\
601253\end{array}$ & caveolin-3 & Betz et al. (2001) & $\begin{array}{l}\text { allelic to LGMD1C (group 1), } \\
\text { hyper- Ckemia (group 5), } \\
\text { RMD2 (group 6), CMH (group } \\
\text { 10) }\end{array}$ \\
\hline $\begin{array}{l}\text { Rippling muscle disease, } \\
\text { recessive }\end{array}$ & 6.7 & $\mathrm{AR}$ & $\begin{array}{l}\text { RMD2 } \\
606072\end{array}$ & $3 \mathrm{p} 25$ & $\begin{array}{l}\boldsymbol{C A V 3} \\
601253\end{array}$ & caveolin-3 & Kubisch et al. $(2003,2005)$ & $\begin{array}{l}\text { allelic to LGMD1C (group 1), } \\
\text { hyper- Ckemia (group 5), } \\
\text { RMD2 (group 6), CMH (group } \\
\text { 10) }\end{array}$ \\
\hline Schwartz-Jampel syndrome & 6.8 & $\mathrm{AR}$ & $\begin{array}{l}\text { SJS1 } \\
255800\end{array}$ & 1p34-p36.1 & $\begin{array}{l}\boldsymbol{H S P G} \\
2142461 \\
\text { (perlecan) }\end{array}$ & $\begin{array}{l}\text { heparan sulfate } \\
\text { proteoglycan } 2 \\
\text { (perlecan) }\end{array}$ & Nicole et al. $(1995,2000)$ & \\
\hline Brody disease & 6.9 & AR AD & 601003 & $16 \mathrm{p} 12$ & $\begin{array}{l}\text { ATP2A1 } \\
=S E R C A 1 \\
108730\end{array}$ & $\begin{array}{l}\text { ATPase, } \mathrm{Ca}++ \\
\text { transporting, } \\
\text { cardiac muscle, fast } \\
\text { twitch } 1\end{array}$ & Odermatt et al. (1996) & \\
\hline \multicolumn{9}{|c|}{ Group 7. ION CHANNEL MUSCLE DISEASES } \\
\hline \multicolumn{9}{|l|}{ A. Chloride channel } \\
\hline $\begin{array}{l}\text { Myotonia congenita, dominant } \\
\text { (Thomsen) }\end{array}$ & 7.1 & $\mathrm{AD}$ & $\begin{array}{l}\text { THD } \\
160800\end{array}$ & $7 \mathrm{q} 35$ & $\begin{array}{l}\text { CLCN1 } \\
118425\end{array}$ & $\begin{array}{l}\text { muscle chloride } \\
\text { channel }\end{array}$ & $\begin{array}{l}\text { Koch et al. (1992b) George } \\
\text { Jr et al. (1993) }\end{array}$ & $\begin{array}{l}\text { allelic to Becker myotonia } \\
\text { (group 7) }\end{array}$ \\
\hline Myotonia, recessive (Becker) & 7.2 & $\mathrm{AR}$ & 255700 & $7 \mathrm{q} 35$ & $\begin{array}{l}\text { CLCN1 } \\
118425\end{array}$ & $\begin{array}{l}\text { muscle chloride } \\
\text { channel }\end{array}$ & Koch et al. (1992b) & $\begin{array}{l}\text { allelic to Thomsen myotonia } \\
\text { (group 7) }\end{array}$ \\
\hline \multicolumn{9}{|l|}{ B. Sodium channel } \\
\hline $\begin{array}{l}\text { Hyperkalemic periodic } \\
\text { paralysis }\end{array}$ & 7.3 & $\mathrm{AD}$ & $\begin{array}{l}\text { hyperKPP } \\
170500\end{array}$ & $17 \mathrm{q} 23$ & $\begin{array}{l}S C N 4 A \\
603967\end{array}$ & $\begin{array}{l}\text { sodium channel, } \\
\text { voltage-gated, type } \\
\text { IV, alpha }\end{array}$ & $\begin{array}{l}\text { Fontaine et al. (1990), } \\
\text { Ptáček et al. (1991a), Rojas } \\
\text { et al. (1991), Miller et al. } \\
\text { (2004) }\end{array}$ & $\begin{array}{l}\text { allelic to HOKPP2 (group 7), } \\
\text { PMC (group 7), K-aggravated } \\
\text { myotonia (group 7) }\end{array}$ \\
\hline $\begin{array}{l}\text { Hypokalemic periodic } \\
\text { Paralysis, type } 2\end{array}$ & 7.4 & $\mathrm{AD}$ & $\begin{array}{l}\text { hypoKPP } \\
170400\end{array}$ & $17 \mathrm{q} 23$ & $\begin{array}{l}S C N 4 A \\
603967\end{array}$ & $\begin{array}{l}\text { sodium channel, } \\
\text { voltage-gated, type } \\
\text { IV, alpha }\end{array}$ & $\begin{array}{l}\text { Bulman et al. (1999) } \\
\text { Jurkat-Rott et al. (2000) }\end{array}$ & $\begin{array}{l}\text { allelic to HYPP (group 7), } \\
\text { PMC (group 7), K-aggravated } \\
\text { myotonia (group 7) }\end{array}$ \\
\hline Paramyotonia congenita & 7.5 & $\mathrm{AD}$ & $\begin{array}{l}\text { PMC } \\
168300\end{array}$ & $17 \mathrm{q} 23$ & $\begin{array}{l}S C N 4 A \\
603967\end{array}$ & $\begin{array}{l}\text { sodium channel, } \\
\text { voltage-gated, type } \\
\text { IV, alpha }\end{array}$ & $\begin{array}{l}\text { Ptáček et al. (1991b, 1992a, } \\
\text { 1993); Ebers et al. (1991) } \\
\text { Koch et al. (1992a) } \\
\text { Mc Clatchey et al. (1992) }\end{array}$ & $\begin{array}{l}\text { allelic to HYPP (group 7), } \\
\text { HOKPP2 (group 7), } \\
\text { K-aggravated myotonia (group } \\
\text { 7) }\end{array}$ \\
\hline Potassium-aggravated myotonia & 7.6 & $\mathrm{AD}$ & 608390 & $17 \mathrm{q} 23$ & $\begin{array}{l}S C N 4 A \\
603967\end{array}$ & $\begin{array}{l}\text { sodium channel, } \\
\text { voltage-gated, type } \\
\text { IV, alpha }\end{array}$ & $\begin{array}{l}\text { Ptáček et al. (1992a, 1992b, } \\
\text { 1994a) } \\
\text { Heine et al. (1993) } \\
\text { Lerche et al. (1993) }\end{array}$ & $\begin{array}{l}\text { allelic to HYPP (group 7), } \\
\text { HOKPP2 (group 7), PMC } \\
\text { (group 7) }\end{array}$ \\
\hline \multicolumn{9}{|l|}{ C. Calcium channel } \\
\hline $\begin{array}{l}\text { Hypokalemic periodic } \\
\text { paralysis, type } 1\end{array}$ & 7.7 & $\mathrm{AD}$ & $\begin{array}{l}\text { hypoKPP1 } \\
170400\end{array}$ & $1 \mathrm{q} 31-\mathrm{q} 32$ & $\begin{array}{l}\text { CACNA1S } \\
114208\end{array}$ & $\begin{array}{l}\text { calcium channel, } \\
\text { voltage-dependent, } \\
\text { L type, alpha } 1 \mathrm{~S} \\
\text { subunit }\end{array}$ & $\begin{array}{l}\text { Fontaine et al. (1994) } \\
\text { Ptáček et al. (1994b) } \\
\text { Jurkat-Rott et al. (1994) } \\
\text { Elbaz et al. (1995) }\end{array}$ & \\
\hline $\begin{array}{l}\text { Acetazolamide responsive } \\
\text { hereditary paroxysmal } \\
\text { cerebellar ataxia (also listed in } \\
\text { group } 13 \text { "Ataxias") }\end{array}$ & 7.8 & $\mathrm{AD}$ & $\begin{array}{l}\text { APCA } \\
108500\end{array}$ & $19 \mathrm{p} 13$ & $\begin{array}{l}\text { CACNA1A } \\
601011\end{array}$ & $\begin{array}{l}\text { calcium channel, } \\
\text { voltage-dependent, } \\
\mathrm{P} / \mathrm{Q} \text { type, alpha } 1 \mathrm{~A} \\
\text { subunit }\end{array}$ & $\begin{array}{l}\text { von Brederlow et al. (1995) } \\
\text { Vahedi et al. (1995) }\end{array}$ & $\begin{array}{l}\text { allelic to EA2 (group 7), SCA6 } \\
\text { (group 13) }\end{array}$ \\
\hline Episodic ataxia type-2 & 7.9 & $\mathrm{AD}$ & $\begin{array}{l}\text { EA2 } \\
108500\end{array}$ & $19 \mathrm{p} 13$ & $\begin{array}{l}\text { CACNA1A } \\
601011\end{array}$ & $\begin{array}{l}\text { calcium channel, } \\
\text { voltage-dependent, } \\
\text { P/Q type, alpha } 1 \mathrm{~A} \\
\text { subunit }\end{array}$ & $\begin{array}{l}\text { Ophoff et al. (1996) } \\
\text { Jodice et al. (1997 }\end{array}$ & $\begin{array}{l}\text { allelic to APCA (group 7), } \\
\text { SCA6 (group 13) }\end{array}$ \\
\hline \multicolumn{9}{|l|}{ D. Potassium channel } \\
\hline $\begin{array}{l}\text { Hypokalemic periodic } \\
\text { paralysis, type } 3\end{array}$ & 7.10 & $\mathrm{AD}$ & $\begin{array}{l}\text { hypoKPP3 } \\
170400\end{array}$ & $11 \mathrm{q} 13$ & $\begin{array}{l}\text { KCNE3 } \\
604433\end{array}$ & $\begin{array}{l}\text { potassium } \\
\text { voltage-gated } \\
\text { channel, Isk-related } \\
\text { family, member } 3\end{array}$ & Abbott et al. (2001) & \\
\hline
\end{tabular}




\begin{tabular}{|c|c|c|c|c|c|c|c|c|}
\hline DISEASE NAME & $\begin{array}{l}\text { Item } \\
\text { line } \\
\text { in this } \\
\text { group }\end{array}$ & Inheritance & $\begin{array}{l}\text { Locus or } \\
\text { disease } \\
\text { symbol and } \\
\text { OMIM } \\
\text { number }\end{array}$ & Chromosome & $\begin{array}{l}\text { Gene symbol } \\
\text { and OMIM } \\
\text { number }\end{array}$ & $\begin{array}{l}\text { Protein } \\
\text { (mitochondrial } \\
\text { proteins indicated } \\
\text { by symbol }[M] \text { ) }\end{array}$ & $\begin{array}{l}\text { Key } \\
\text { references }\end{array}$ & $\begin{array}{l}\text { Other allelic disease(s) } \\
\text { (group in this table) }\end{array}$ \\
\hline Episodic ataxia/myokymia & 7.11 & $\mathrm{AD}$ & $\begin{array}{l}\text { EA1 } \\
160120\end{array}$ & $12 \mathrm{p} 13$ & $\begin{array}{l}\text { KCNA1 } \\
176260 \\
\text { (voltage gated } \\
K+\text { channel) }\end{array}$ & $\begin{array}{l}\text { potassium } \\
\text { voltage-gated } \\
\text { channel, } \\
\text { shaker-related } \\
\text { subfamily, member } \\
1\end{array}$ & $\begin{array}{l}\text { Browne et al. (1994); } \\
\text { Adelman et al. (1995) }\end{array}$ & \\
\hline $\begin{array}{l}\text { Thyrotoxic hypokalemic } \\
\text { periodic paralysis }\end{array}$ & 7.12 & & $\begin{array}{l}\text { ТТРP2 } \\
613239\end{array}$ & $17 \mathrm{p} 11.2$ & $\begin{array}{l}\text { KCNJ18 } \\
613239\end{array}$ & $\begin{array}{l}\text { Kir2.6 (inwardly } \\
\text { rectifying } \\
\text { potassium channel } \\
\text { 2.6) }\end{array}$ & Ryan et al. (2010) & \\
\hline $\begin{array}{l}\text { Periodic paralysis, potassium } \\
\text { sensitive cardiodysrythmic } \\
\text { (Andersen syndrome) }\end{array}$ & 7.13 & see $L Q 7$ unc & er hereditary c & rdiomyopathies & group 10/online only & & & \\
\hline Long QT syndromes & 7.14 & see under $h$ & reditary cardio & nyopathies (grou & p 10/online only)) & & & \\
\hline \multicolumn{9}{|c|}{ GROUP 8. MALIGNANT HYPERTHERMIAS } \\
\hline Malignant hyperthermia & 8.1 & $\mathrm{AD}$ & $\begin{array}{l}\text { MHS1 } \\
145600\end{array}$ & $19 \mathrm{q} 13.1$ & $\begin{array}{l}\boldsymbol{R Y R 1} \\
180901\end{array}$ & $\begin{array}{l}\text { ryanodine receptor } \\
1 \text { (skeletal) }\end{array}$ & $\begin{array}{l}\text { MacLennan et al. (1990) } \\
\text { McCarthy et al. (1990) } \\
\text { Fujii et al. (1991) } \\
\text { Gillard et al. (1991, 1992) } \\
\text { Quane et al. (1993, 1994) } \\
\text { Keating et al. (1994) }\end{array}$ & $\begin{array}{l}\text { allelic to CCD (group 3), } \\
\text { minicore myopathy with } \\
\text { external ophthalmoplegia } \\
\text { (group 3), CNMDU1 (group 3) }\end{array}$ \\
\hline Malignant hyperthermia & 8.2 & $\mathrm{AD}$ & $\begin{array}{l}\text { MHS2 } \\
154275\end{array}$ & $17 \mathrm{q} 11.2-\mathrm{q} 24$ & ? & & $\begin{array}{l}\text { Levitt et al. (1992) } \\
\text { Moslehi et al. (1998) }\end{array}$ & \\
\hline Malignant hyperthermia & 8.3 & $\mathrm{AD}$ & $\begin{array}{l}\text { MHS3 } \\
154276\end{array}$ & $7 q 21-q 22$ & ? & & Iles et al. (1994) & \\
\hline Malignant hyperthermia & 8.4 & $\mathrm{AD}$ & $\begin{array}{l}\text { MHS4 } \\
600467\end{array}$ & $3 \mathrm{q} 13.1$ & $?$ & & Sudbrak et al. (1995) & \\
\hline Malignant hyperthermia & 8.5 & $\mathrm{AD}$ & $\begin{array}{l}\text { MHS5 } \\
601887\end{array}$ & $1 \mathrm{q} 31-\mathrm{q} 32$ & $\begin{array}{l}\text { CACNA1S } \\
(\text { ex CACNL1A3) } \\
114208\end{array}$ & $\begin{array}{l}\text { calcium channel, } \\
\text { voltage-dependent, } \\
\text { L type, alpha 1S } \\
\text { subunit }\end{array}$ & Monnier et al. (1997) & allelic to HOKPP1 (group 7) \\
\hline Malignant hyperthermia & 8.6 & $\mathrm{AD}$ & $\begin{array}{l}\text { MHS6 } \\
601888\end{array}$ & $5 \mathrm{p}$ & $?$ & & Robinson et al. (1997) & \\
\hline
\end{tabular}

\section{GROUP 9. METABOLIC MYOPATHIES}

A. Glycogen storage diseases

Glycogen storage disease type

II (Pompe disease) also listed

$9.1 \quad$ AR

in group 10 Hereditary

cardiomyopathies

Glycogen storage disease type IIIa

Glycogen storage disease type

9.3

AR
GSD2

232300

GSD

232400

$1 \mathrm{p} 21$

610860

GSD

232500

$3 \mathrm{p} 12$

GBE1

607839

\begin{tabular}{|c|c|c|c|c|c|}
\hline $\begin{array}{l}\text { Glycogen storage type V } \\
\text { (McArdle) }\end{array}$ & 9.4 & AR & $\begin{array}{l}\text { GSD5 } \\
232600\end{array}$ & $11 \mathrm{q} 13$ & $\begin{array}{l}\text { PYGM } \\
608455\end{array}$ \\
\hline $\begin{array}{l}\text { Glycogen storage type VII } \\
\text { (Tarui) }\end{array}$ & 9.5 & AR & $\begin{array}{l}\text { GSD7 } \\
232800\end{array}$ & $12 \mathrm{q} 13$ & $\begin{array}{l}P F K M \\
610681\end{array}$ \\
\hline $\begin{array}{l}\text { Glycogen storage disease type } \\
\text { IXd (ex type VIII) or muscle } \\
\text { phosphorylase kinase defiency }\end{array}$ & 9.6 & $\mathrm{XR}$ & $\begin{array}{l}\text { GSD9D } \\
300559\end{array}$ & $\mathrm{Xq13}$ & $\begin{array}{l}\text { PHKA1 } \\
311870\end{array}$ \\
\hline Glycogenosis type XIV & 9.7 & $\mathrm{AR}$ & $\begin{array}{l}\text { GSD14 } \\
612934\end{array}$ & $1 \mathrm{p} 31$ & $\begin{array}{l}\text { PGM1 } \\
171900\end{array}$ \\
\hline Glycogenosis type XV & 9.8 & AR & $\begin{array}{l}\text { GSD15 } \\
613507\end{array}$ & $3 q 24$ & $\begin{array}{l}\boldsymbol{G Y G 1} \\
603942\end{array}$ \\
\hline
\end{tabular}

glucosidase, alpha; Hers (1963); Martiniuk et al. allelic to GSDII (group 10) acid

(1990); Wokke et al. (1995)

amylo-1,

Sheng et al. (1996)

6-glucosidase

4-alpha-glucanotransferase

(glycogen

debranching

enzyme)

1,4- $\alpha-\mathrm{D}=$ glucan $\quad$ Brown et al. (1966)

6-ß-D-[1.4-D-glucano] Bao et al. (1996)

transferase,

Bruno et al. (2004)

branching enzyme

1 (glycogen

branching enzyme)

A

glycogen Mommaerts et al. (1959)

phosphorylase, $\quad$ Schmidt et al. (1959)

muscle Lebo et al. (1984)

Tsujino et al. (1993a)

muscle-type $\quad$ Tarui et al. (1965)

phos-phofructokinase Nakajima et al. (1991),

Howard et al. (1996)

$\begin{array}{ll}\text { Phosphorylase b } & \text { Wehner et al. (1994) } \\ \text { kinase, alpha } & \text { Burwinkel et al. (2004) }\end{array}$

Stojkovic et al. (2009)

Glycogenin 1

Moslemi et al. (2010)

Allelic to PGBM2 (group 9) 


\begin{tabular}{|c|c|c|c|c|c|c|c|c|}
\hline DISEASE NAME & $\begin{array}{l}\text { Item } \\
\text { line } \\
\text { in this } \\
\text { group }\end{array}$ & Inheritance & $\begin{array}{l}\text { Locus or } \\
\text { disease } \\
\text { symbol and } \\
\text { OMIM } \\
\text { number }\end{array}$ & Chromosome & $\begin{array}{l}\text { Gene symbol } \\
\text { and OMIM } \\
\text { number }\end{array}$ & $\begin{array}{l}\text { Protein } \\
\text { (mitochondrial } \\
\text { proteins indicated } \\
\text { by symbol }[M] \text { ) }\end{array}$ & $\begin{array}{l}\text { Key } \\
\text { references }\end{array}$ & $\begin{array}{l}\text { Other allelic disease(s) } \\
\text { (group in this table) }\end{array}$ \\
\hline $\begin{array}{l}\text { Glycogen storage disease type } \\
0\end{array}$ & 9.9 & $\mathrm{AR}$ & $\begin{array}{l}\text { GSD0b } \\
611556\end{array}$ & $9 \mathrm{q} 13$ & $\begin{array}{l}\text { GYS1 } \\
138570\end{array}$ & $\begin{array}{l}\text { Glycogen synthase } \\
1\end{array}$ & Kolberg et al. (2007) & \\
\hline $\begin{array}{l}\text { Glycogen storage disease of } \\
\text { heart, lethal congenital }\end{array}$ & 9.10 & $\mathrm{AD}$ & 261740 & $7 \mathrm{q} 36$ & $\begin{array}{l}\text { PRKAG2 } \\
602743\end{array}$ & $\begin{array}{l}\text { protein kinase, } \\
\text { AMP-activated } \\
\text { (AMPK) }\end{array}$ & Burwinkel et al. (2005) & \\
\hline $\begin{array}{l}\text { Polyglucosan Body Myopathy } \\
1 \text { with or without } \\
\text { immunodeficiency }\end{array}$ & 9.11 & $\mathrm{AR}$ & $\begin{array}{l}\text { PGBM1 } \\
615895\end{array}$ & $20 \mathrm{p} 13$ & $\begin{array}{l}\text { RBCK1 } \\
610924\end{array}$ & $\begin{array}{l}\text { RanBP-type and } \\
\text { C3HC4-type zinc } \\
\text { finger containing } 1 \\
\text { (heme-oxidized } \\
\text { IRP2 ubiquitin } \\
\text { ligase 1) }\end{array}$ & Nilsson et al. (2013) & \\
\hline $\begin{array}{l}\text { Polyglucosan Body Myopathy } \\
2\end{array}$ & 9.12 & $\mathrm{AR}$ & PGBM2 & $3 \mathrm{q} 24$ & $\begin{array}{l}\boldsymbol{G Y G 1} \\
603942\end{array}$ & Glycogenin 1 & Malfatti et al. (2014) & Allelic to GSD15 (group 9) \\
\hline B. Glycolytic pathway & & & & & & & & \\
\hline $\begin{array}{l}\text { Phosphoglycerate kinase } \\
\text { deficiency }\end{array}$ & 9.13 & $\mathrm{XR}$ & 300653 & $\mathrm{Xq} 13$ & $\begin{array}{l}\text { PGK1 } \\
311800\end{array}$ & $\begin{array}{l}\text { phosphoglycerate } \\
\text { kinase }\end{array}$ & $\begin{array}{l}\text { DiMauro et al. (1981a, } \\
\text { 1983) } \\
\text { Rosa R (1982) }\end{array}$ & \\
\hline $\begin{array}{l}\text { Phosphoglycerate mutase } \\
\text { deficiency }\end{array}$ & 9.14 & $\mathrm{AR}$ & $\begin{array}{l}\text { GSD10 } \\
261670\end{array}$ & $7 \mathrm{p} 12-\mathrm{p} 13$ & $\begin{array}{l}\text { PGAM2 } \\
612931\end{array}$ & $\begin{array}{l}\text { phosphoglycerate } \\
\text { mutase } 2 \text { (muscle) }\end{array}$ & $\begin{array}{l}\text { DiMauro et al. (1981b) } \\
\text { Edwards et al. (1989) } \\
\text { Castella-Escola et al. (1990) } \\
\text { Tsujino et al. (1993b) }\end{array}$ & \\
\hline $\begin{array}{l}\text { Lactate dehydrogenase-A } \\
\text { deficiency }\end{array}$ & 9.15 & $\mathrm{AR}$ & $\begin{array}{l}\text { GSD11 } \\
612933\end{array}$ & $11 \mathrm{p} 15.4$ & $\begin{array}{l}\text { LDHA } \\
150000\end{array}$ & $\begin{array}{l}\text { lactate } \\
\text { dehydrogenase A }\end{array}$ & $\begin{array}{l}\text { Kanno et al. }(1980) \\
\text { Scrable et al. (1990) }\end{array}$ & \\
\hline Enolase deficiency & 9.16 & $\mathrm{AD}$ & $\begin{array}{l}\text { GSD13 } \\
612932\end{array}$ & 17 pter-p12 & $\begin{array}{l}\text { ENO3 } \\
131370\end{array}$ & $\begin{array}{l}\text { enolase } 3 \text {, beta, } \\
\text { muscle specific }\end{array}$ & Comi et al. (2001) & \\
\hline \multicolumn{9}{|l|}{ C. Disorders of lipid metabolism } \\
\hline $\begin{array}{l}\text { Carnitine palmitoyl-transferase } \\
\text { deficiency }\end{array}$ & 9.17 & $\mathrm{AR}$ & 255110 & $1 \mathrm{p} 32$ & $\begin{array}{l}\text { CPT2 } \\
600650\end{array}$ & $\begin{array}{l}\text { carnitine palmitoyl } \\
\text { transferase II }\end{array}$ & $\begin{array}{l}\text { DiMauro et al. (1973) } \\
\text { Finocchiaro et al. (1991) } \\
\text { Taroni et al. (1993) } \\
\text { Gellera et al. (1994) }\end{array}$ & \\
\hline $\begin{array}{l}\text { Primary systemic carnitine } \\
\text { deficiency }\end{array}$ & 9.18 & $\mathrm{AR}$ & $\begin{array}{l}\text { CDSP } \\
212140\end{array}$ & $5 \mathrm{q} 31$ & $\begin{array}{l}\text { SLC22A5 } \\
603377\end{array}$ & $\begin{array}{l}\text { solute carrier } \\
\text { family } 22, \text { member } \\
5\end{array}$ & Nezu et al. (1999) & \\
\hline $\begin{array}{l}\text { Carnitine/acyl-carnitine } \\
\text { translocase deficiency }\end{array}$ & 9.19 & AR & $\begin{array}{l}\text { CACTD } \\
212138\end{array}$ & $3 \mathrm{p} 21.31$ & $\begin{array}{l}\text { SLC25A20 } \\
613698\end{array}$ & $\begin{array}{l}\text { solute carrier } \\
\text { family } 25 \\
\text { (carnitine/acylcarnitine } \\
\text { translocase), } \\
\text { member }\end{array}$ & $\begin{array}{l}\text { Huizing et al. (1997) } \\
\text { Ogawa et al. (2000) }\end{array}$ & \\
\hline $\begin{array}{l}\text { Multiple acyl-CoA } \\
\text { dehydrogenase deficiency } \\
\text { (MADD; Glutaric aciduria type } \\
\text { IIA) }\end{array}$ & 9.20 & $\mathrm{AR}$ & $\begin{array}{l}\text { GAIIA } \\
231680\end{array}$ & $15 \mathrm{q} 23-\mathrm{q} 25$ & $\begin{array}{l}\text { ETFA } \\
608053\end{array}$ & $\begin{array}{l}\text { electron-transfer- } \\
\text { flavoprotein, alpha } \\
\text { polypeptide }\end{array}$ & $\begin{array}{l}\text { Indo et al. (1991) } \\
\text { Freneaux et al. (1992) }\end{array}$ & \\
\hline $\begin{array}{l}\text { Multiple acyl-CoA } \\
\text { dehydrogenase deficiency } \\
\text { (MADD; Glutaric aciduria type } \\
\text { IIB) }\end{array}$ & 9.21 & $\mathrm{AR}$ & $\begin{array}{l}\text { GAIIB } \\
231680\end{array}$ & $19 \mathrm{q} 13.3-\mathrm{q} 13.4$ & $\begin{array}{l}\text { ETFB } \\
130410\end{array}$ & $\begin{array}{l}\text { electron-transfer- } \\
\text { flavoprotein, beta } \\
\text { polypeptide }\end{array}$ & Colombo et al. (1994) & \\
\hline $\begin{array}{l}\text { Multiple acyl-CoA } \\
\text { dehydrogenase deficiency } \\
\text { (MADD; Glutaric aciduria type } \\
\text { IIC) }\end{array}$ & 9.22 & $\mathrm{AR}$ & $\begin{array}{l}\text { GAIIC } \\
231680\end{array}$ & $4 \mathrm{q} 32-\mathrm{q} 35$ & $\begin{array}{l}\text { ETFDH } \\
231675\end{array}$ & $\begin{array}{l}\text { electron-transferring- } \\
\text { flavoprotein } \\
\text { dehydrogenase }\end{array}$ & Beard et al. (1993) & allelic to MADD (group 9) \\
\hline $\begin{array}{l}\text { Acyl-CoA dehydrogenase (very } \\
\text { long chain) deficiency } \\
\text { (VLCAD deficiency) }\end{array}$ & 9.23 & AR & $\begin{array}{l}\text { ACADVLD } \\
201475\end{array}$ & $17 \mathrm{p} 13$ & $\begin{array}{l}\text { ACADVL } \\
609575\end{array}$ & $\begin{array}{l}\text { acyl-Coenzyme A } \\
\text { dehydrogenase, } \\
\text { very long chain }\end{array}$ & $\begin{array}{l}\text { Aoyama }(1993,1995) \\
\text { Strauss et al. }(1995) \\
\text { Mathur et al. 1999) }\end{array}$ & \\
\hline $\begin{array}{l}\text { ACAD9-deficient mild } \\
\text { myopathy }\end{array}$ & 9.24 & AR & 611126 & $3 \mathrm{q} 21.3$ & $\begin{array}{l}A C A D 9 \\
611103\end{array}$ & $\begin{array}{l}\text { acyl-CoA } \\
\text { dehydrogenase } \\
\text { family member } 9 \\
\text { [M] }\end{array}$ & Fragaki et al (2016) & \\
\hline $\begin{array}{l}\text { Triglyceride storage disease } \\
\text { with ichthyosis [impaired } \\
\text { long-chain fatty acid oxidation] } \\
\text { (Chanarin-Dorfman syndrome) }\end{array}$ & 9.25 & AR & $\begin{array}{l}\text { CDS } \\
275630\end{array}$ & $3 \mathrm{p} 25.3-\mathrm{p} 24.3$ & $\begin{array}{l}\text { ABHD5 } \\
\text { (CGI-58) } \\
604780\end{array}$ & $\begin{array}{l}\text { abhydrolase domain } \\
\text { containing } 5\end{array}$ & Lefevre et al. (2001) & \\
\hline $\begin{array}{l}\text { Neutral lipid storage disease } \\
\text { with myopathy without } \\
\text { ichthyosis }\end{array}$ & 9.26 & $\mathrm{AR}$ & $\begin{array}{l}\text { NLSDM } \\
610717\end{array}$ & $11 \mathrm{p} 15.5$ & $\begin{array}{l}\text { PNPLA2 } \\
609059\end{array}$ & $\begin{array}{l}\text { adipose triglyceride } \\
\text { lipase }=\text { desnutrin }\end{array}$ & Fischer et al. (2007) & \\
\hline $\begin{array}{l}\text { Riboflavin-responsive multiple } \\
\text { acyl-CoA dehydrogenase } \\
\text { deficiency (Lipid storage } \\
\text { myopathy) }\end{array}$ & 9.27 & $\mathrm{AR}$ & $\begin{array}{l}\text { MADD } \\
231680\end{array}$ & $4 \mathrm{q} 32-\mathrm{q} 35$ & $\begin{array}{l}\text { ETFDH } \\
231675\end{array}$ & $\begin{array}{l}\text { Electrontransferring- } \\
\text { flavoprotein } \\
\text { dehydrogenase }\end{array}$ & Olsen et al. (2007) & allelic to GAIIC (group 9) \\
\hline
\end{tabular}




\begin{tabular}{|c|c|c|c|c|c|c|c|c|}
\hline DISEASE NAME & $\begin{array}{l}\text { Item } \\
\text { line } \\
\text { in this } \\
\text { group }\end{array}$ & Inheritance & $\begin{array}{l}\text { Locus or } \\
\text { disease } \\
\text { symbol and } \\
\text { OMIM } \\
\text { number }\end{array}$ & Chromosome & $\begin{array}{l}\text { Gene symbol } \\
\text { and OMIM } \\
\text { number }\end{array}$ & $\begin{array}{l}\text { Protein } \\
\text { (mitochondrial } \\
\text { proteins indicated } \\
\text { by symbol }[M] \text { ) }\end{array}$ & $\begin{array}{l}\text { Key } \\
\text { references }\end{array}$ & $\begin{array}{l}\text { Other allelic disease(s) } \\
\text { (group in this table) }\end{array}$ \\
\hline $\begin{array}{l}\text { Recurrent myoglobinuria, } \\
\text { autosomal recessive }\end{array}$ & 9.28 & $\mathrm{AR}$ & 268200 & $2 \mathrm{p} 25.1$ & $\begin{array}{l}\text { LPIN1 } \\
605518\end{array}$ & $\begin{array}{l}\text { lipin } 1 \\
\text { (phosphatidic acid } \\
\text { phosphatase 1) }\end{array}$ & Zeharia et al. (2008) & \\
\hline $\begin{array}{l}\text { Infantile neuroaxonal dystrophy } \\
\text { and neutral lipid storage } \\
\text { disease with myopathy }\end{array}$ & 9.29 & $\mathrm{AR}$ & $\begin{array}{l}\text { MMLA } \\
251950\end{array}$ & $7 \mathrm{q} 31.1$ & $\begin{array}{l}\text { PNPLA8 } \\
612123\end{array}$ & $\begin{array}{l}\text { Patatin-like } \\
\text { phospholipase } \\
\text { domain containing } \\
8[\mathbf{M}]\end{array}$ & Saunders et al. (2015) & \\
\hline $\begin{array}{l}\text { Lipid storage myopathy due to } \\
\text { Flavin Adenine Dinucleotide } \\
\text { Synthetase Deficiency }\end{array}$ & 9.30 & AR & $\begin{array}{l}\text { LSMFLAD } \\
255100\end{array}$ & $1 \mathrm{q} 21.3$ & $\begin{array}{l}\text { FLAD1 } \\
610595\end{array}$ & $\begin{array}{l}\text { Flavin Adenine } \\
\text { Dinucleotide } \\
\text { Synthetase, S. } \\
\text { cerevisiae, homolog } \\
\text { of (M) }\end{array}$ & Taylor et al. (2014) & \\
\hline
\end{tabular}

\section{GROUP 10/A HEREDITARY CARDIOMYOPATHIES non arrhythmogenic}

(a) Hypertrophic cardiomyopathies

Familial hypertic

cardiomyopathy, 1

10.1 $\mathrm{AD}$

Familial hypertrophic

cardiomyopathy, 2

Familial hypertrophic

cardiomyopathy, 3

Familial hypertrophic

cardiomyopathy, 4

Familial hypertrophic

cardiomyopathy, 6

Familial hypertrophic

cardiomyopathy, 7

Familial hypertrophic

cardiomyopathy, 8

Familial hypertrophic

cardiomyopathy, 9

Familial hypertrophic

cardiomyopathy, 10

Familial hypertrophic

cardiomyopathy, 11

Familial hypertrophic

cardiomyopathy, 12

Familial hypertrophic

cardiomyopathy, 13

Familial hypertrophic

cardiomyopathy, 14

Hypertrophic cardiomyopathy

related to vinculin

Hypertrophic cardiomyopathy

Hypertrophic cardiomyopathy

10.6 $\mathrm{AD}$

CMH7

10.7 AD

CMH8

608751

$10.8 \quad \mathrm{AD}$

CMH9

613765

$\begin{array}{lllll}10.9 & \text { AD } & \begin{array}{l}\text { CMH10 } \\ 608758\end{array} & 12 \mathrm{q} 23-\mathrm{q} 24 & \begin{array}{l}\text { MYL2 } \\ \text { 160781 }\end{array} \\ & & & & \\ 10.10 & \text { AD } & \text { CMH11 } & 15 \mathrm{q} 14 & \text { ACTC1 } \\ & & 612098 & & 102540 \\ 10.11 & \text { AD } & \text { CMH12 } & 11 \mathrm{p} 15.1 & \boldsymbol{C S R P 3} \\ & & 612124 & & 600824\end{array}$

10.12 AD

CMH13

$613243 \quad 191040$

$10.13 \quad \mathrm{AD}$

CMH15

613255

CMH1

192600

CMH1

192600

CMH16

Hypertrophic cardiomyopathy

related to myozenin 2
$10.17 \quad \mathrm{AD}$

613838
$19 \mathrm{q} 13.4$

TTNI3

$3 \mathrm{p} 21$

MYL3

160790

$2 \mathrm{q} 24.3$

TTN

188840

3p21-p14 TNNC1

$14 \mathrm{q} 12$

MYH6

MYH6

МYH 71

60760

NNT2

TPM1

191010

600958

R AG

602743

160710

$10 \mathrm{q} 22 \quad \boldsymbol{V C L}$

193065

20q13.3 MYLK2

606566

3p25 CAV3

CAV3
601253

$4 \mathrm{q} 26$

MYOZ2

605602
Myosin heavy Jarcho et al. (1989)

chain 6 (alpha) or 7 Solomon et al. (1990)

(beta), cardiac Tanigawa et al. (1990)

muscle Geisterfer-Lowrance et al

(1990)

cardiac troponin T Watkins et al. (1993)

Thierfelder et al. (1994)

Thierfelder et al. (1994)

tropomyosin-1

cardiac myosin

binding protein- $\mathrm{C}$

Carrier et al. (1993)

Bonne et al. (1995)

Watkins et al. (1995)

protein kinase,

Blair et al. (2001)

AMP-activated,

gamma 2

non-catalytic

subunit

cardiac troponin I Kimura et al. (1997)

myosin, light chain Poetter et al. (1996)

3, alkali;

ventricular, skeletal,

slow

titin

atoh et al. (1999)

Myosin, light chain

2 , regulatory,

cardiac, slow

actin, alpha, cardiac

muscle 1

Cysteine and

glycine-rich protein

3 (cardiac LIM

protein)

Slow troponin C

myosin, heavy

chain 6 , cardiac

muscle, alpha

vinculin

(metavinculin)

myosin light chain

kinase 2

caveolin-3

myozenin 2 , or

calsarcin 1, a Z

disk protein

Poetter et al. (1996)

Mogensen et al. (1999)

Geier et al. (2008)

Landstrom et al. (2008)

Carniel et al. (2005)

Vasile et al. (2006)

Davis et al. (2001)

Hayashi et al. (2004)

Fulizio et al. (2005) allelic to CFTD (group 3), myosin storage myopathy (group 3), MPD1 (group 4), CMD1S (group 10)

allelic to congenital skeletal myopathy and fatal cardiomyopathy (group 3) allelic to Glycogene storage disease of heart, lethal congenital (group 9)

allelic to RCM1 and CMD2A (group 10)

allelic to LGMD2J (group 1), congenital myopathy with fatal cardiomyopathy (group 3), TMD (group 4), HMERF (group 5), CMD1G; (group 10)

allelic to CMD1R (group 10)

allelic to CMD1M (group 10)

allelic to CMD1Z (group 10)

allelic to CMD1EE (group 10)

allelic to CMD1U (group 10)

allelic to LGMD1C (group 1), hyperCKemia (group 5) RMD2 (group 6) 


\begin{tabular}{|c|c|c|c|c|c|c|c|c|}
\hline DISEASE NAME & $\begin{array}{l}\text { Item } \\
\text { line } \\
\text { in this } \\
\text { group }\end{array}$ & Inheritance & $\begin{array}{l}\text { Locus or } \\
\text { disease } \\
\text { symbol and } \\
\text { OMIM } \\
\text { number }\end{array}$ & Chromosome & $\begin{array}{l}\text { Gene symbol } \\
\text { and OMIM } \\
\text { number }\end{array}$ & $\begin{array}{l}\text { Protein } \\
\text { (mitochondrial } \\
\text { proteins indicated } \\
\text { by symbol }[M] \text { ) }\end{array}$ & $\begin{array}{l}\text { Key } \\
\text { references }\end{array}$ & $\begin{array}{l}\text { Other allelic disease(s) } \\
\text { (group in this table) }\end{array}$ \\
\hline $\begin{array}{l}\text { Hypertrophic cardiomyopathy } \\
\text { related to junctophilin }\end{array}$ & 10.18 & $\mathrm{AD}$ & $\begin{array}{l}\text { CMH17 } \\
613873\end{array}$ & $20 \mathrm{q} 13.12$ & $\begin{array}{l}\text { JPH2 } \\
605267\end{array}$ & junctophilin-2 & $\begin{array}{l}\text { Landstrom et al. (2007) } \\
\text { Matsuhita et al. (2007) }\end{array}$ & \\
\hline $\begin{array}{l}\text { Hypertrophic cardiomyopathy } \\
\text { related to phospholamban }\end{array}$ & 10.19 & $\mathrm{AD}$ & $\begin{array}{l}\text { CMH18 } \\
613874\end{array}$ & $6 \mathrm{q} 22$ & $\begin{array}{l}\boldsymbol{P L N} \\
172405\end{array}$ & phospholamban & $\begin{array}{l}\text { Minamisawa et al. (2003) } \\
\text { Landstrom et al. (2011) }\end{array}$ & $\begin{array}{l}\text { Allelic to dilated } \\
\text { cardiomyopathy (group 10) }\end{array}$ \\
\hline $\begin{array}{l}\text { Hypertrophic cardiomyopathy } \\
\text { related calreticulin } 3\end{array}$ & 10.20 & $\mathrm{AD}$ & $\begin{array}{l}\text { CMH19 } \\
61387\end{array}$ & $19 \mathrm{p} 13.11$ & $\begin{array}{l}\text { CALR3 } \\
611414\end{array}$ & Calreticulin 3 & Chiu et al. (2007) & \\
\hline $\begin{array}{l}\text { Hypertrophic cardiomyopathy } \\
\text { related to nexilin }\end{array}$ & 10.21 & $\mathrm{AD}$ & $\begin{array}{l}\text { CMH20 } \\
613876\end{array}$ & $1 \mathrm{p} 31.1$ & $\begin{array}{l}N E X N \\
613121\end{array}$ & $\begin{array}{l}\text { Nexilin (F-actin } \\
\text { binding protein) }\end{array}$ & Wang et al. (2010) & Allelic to CMD1CC (group 10) \\
\hline $\begin{array}{l}\text { Hypertrophic cardiomyopathy } \\
\text { related to cardiac ankyrin } \\
\text { repeat domain protein }\end{array}$ & 10.22 & $\mathrm{AD}$ & & $10 \mathrm{q} 23.33$ & $\begin{array}{l}\text { ANKRD1 } \\
609599\end{array}$ & $\begin{array}{l}\text { ankyrin repeat } \\
\text { domain-protein } 1 \\
\text { (cardiac) }\end{array}$ & Arimura et al. (2009) & $\begin{array}{l}\text { Allelic to dilated } \\
\text { cardiomyopathy (group 19) }\end{array}$ \\
\hline $\begin{array}{l}\text { Hypertrophic cardiomyopathy } \\
\text { related to cardiac myopalladin }\end{array}$ & 10.23 & $\mathrm{AD}$ & $\begin{array}{l}\text { CMH22 } \\
615248\end{array}$ & $10 \mathrm{q} 21.1$ & $\begin{array}{l}M Y P N \\
608517\end{array}$ & Myopalladin & Purevjav et al. (2012) & $\begin{array}{l}\text { allelic to CMD1KK (group } \\
\text { 10A) and NEM11 (group 3) }\end{array}$ \\
\hline $\begin{array}{l}\text { Hypertrophic cardiomyopathy } \\
\text { related to actinin- } 2\end{array}$ & 10.24 & $\mathrm{AD}$ & $\begin{array}{l}\text { CMH23 } \\
612158\end{array}$ & $1 \mathrm{q} 43$ & $\begin{array}{l}A C T N 2 \\
102573\end{array}$ & actinin alpha2 & Chiu C et al. (2010) & $\begin{array}{l}\text { Allelic to CMD1AA (group } \\
\text { 10) }\end{array}$ \\
\hline $\begin{array}{l}\text { Hypertrophic cardiomyopathy } \\
\text { related to ZASP }\end{array}$ & 10.25 & $\mathrm{AD}$ & $\begin{array}{l}\text { CMH24 } \\
601493\end{array}$ & $10 \mathrm{q} 23.2$ & $\begin{array}{l}\text { LDB3 } \\
605906\end{array}$ & $\begin{array}{l}\text { LIM domain } \\
\text { binding }-3 \text { ( } Z \text { band } \\
\text { alternatively spliced } \\
\text { PDZ motif) }\end{array}$ & Theis et al. (2006) & Allelic to CMD1C (group 10A) \\
\hline $\begin{array}{l}\text { Hypertrophic cardiomyopathy } \\
\text { related to TCAP }\end{array}$ & 10.26 & $\mathrm{AD}$ & $\begin{array}{l}\text { CMH25 } \\
607487\end{array}$ & $17 \mathrm{q} 12$ & $\begin{array}{l}\text { TCAP } \\
604488\end{array}$ & $\begin{array}{l}\text { Telethonin } \\
\text { (titin-cap) }\end{array}$ & Hayashi et al. (2004) & $\begin{array}{l}\text { Allelic to CMD1N (group } \\
\text { 10A) and LGMD2G (group 1) }\end{array}$ \\
\hline $\begin{array}{l}\text { Mitochondrial hypertrophic } \\
\text { cardiomyopathy related to } \\
\text { NDUFAF1 }\end{array}$ & 10.27 & $\mathrm{AR}$ & & $15 \mathrm{q} 15.1$ & $\begin{array}{l}\text { NDUFAF1 } \\
606934\end{array}$ & $\begin{array}{l}\text { NADH-ubiquinone } \\
\text { oxidoreductase } 1 \\
\text { alpha subcomplex } \\
\text { (M) }\end{array}$ & Fassone et al. (2011) & \\
\hline $\begin{array}{l}\text { Mitochondrial hypertrophic } \\
\text { cardiomyopathy related to } \\
T S F M\end{array}$ & 10.28 & $\mathrm{AR}$ & $\begin{array}{l}\text { COXPD3 } \\
610505\end{array}$ & $12 \mathrm{q} 14.1$ & $\begin{array}{l}\text { TSFM } \\
604723\end{array}$ & $\begin{array}{l}\text { Ts translation } \\
\text { elongation factor, } \\
\text { mitochondrial (M) }\end{array}$ & Smeitink et al. (2006) & \\
\hline $\begin{array}{l}\text { Mitochondrial hypertrophic } \\
\text { cardiomyopathy related } \\
\text { to } A A R S 2\end{array}$ & 10.29 & $\mathrm{AR}$ & $\begin{array}{l}\text { COXPD8 } \\
614096\end{array}$ & $6 \mathrm{p} 21.1$ & $\begin{array}{l}\text { AARS2 } \\
612035\end{array}$ & $\begin{array}{l}\text { Alanyl-tRNA } \\
\text { synthetase 2, } \\
\text { mitochondrial (M) }\end{array}$ & Götz et al. (2011) & \\
\hline $\begin{array}{l}\text { Mitochondrial hypertrophic } \\
\text { cardiomyopathy related to } \\
\text { MRPL3 }\end{array}$ & 10.30 & $\mathrm{AR}$ & $\begin{array}{l}\text { COXPD9 } \\
614582\end{array}$ & $3 q 21-q 23$ & $\begin{array}{l}\text { MRPL3 } \\
607118\end{array}$ & $\begin{array}{l}\text { Mitochondrial } \\
\text { ribosomal protein } \\
\text { L3 (M) }\end{array}$ & Galmiche et al. (2011) & \\
\hline $\begin{array}{l}\text { Mitochondrial hypertrophic } \\
\text { cardiomyopathy, related to } \\
\text { COX15 }\end{array}$ & 10.31 & $\mathrm{AR}$ & $\begin{array}{l}\text { CEMCOX2 } \\
615119\end{array}$ & $10 \mathrm{q} 24$ & $\begin{array}{l}\text { COX15 } \\
603646\end{array}$ & $\begin{array}{l}\text { COX15 homolog, } \\
\text { cytochrome c } \\
\text { oxidase assembly } \\
\text { protein }(\mathbf{M})\end{array}$ & Antonicka et al. (2003) & \\
\hline $\begin{array}{l}\text { Mitochondrial hypertrophic } \\
\text { cardiomyopathy related to } \\
\text { MTOI }\end{array}$ & 10.32 & $\mathrm{AR}$ & $\begin{array}{l}\text { COXPD10 } \\
614702\end{array}$ & $6 \mathrm{q} 13$ & $\begin{array}{l}\text { MTO1 } \\
614667\end{array}$ & $\begin{array}{l}\text { mitochondrial } \\
\text { tRNA translation } \\
\text { optimization } 1 \text { (M) }\end{array}$ & $\begin{array}{l}\text { Ghezzi et al. (2012) } \\
\text { Baruffini et al. (2013) }\end{array}$ & \\
\hline $\begin{array}{l}\text { Mitochondrial hypertrophic } \\
\text { cardiomyopathy related to } \\
\text { MRPL44 }\end{array}$ & 10.33 & $\mathrm{AR}$ & $\begin{array}{l}\text { COXPD16 } \\
615395\end{array}$ & $2 \mathrm{q} 36.1$ & $\begin{array}{l}\text { MRPL44 } \\
611849\end{array}$ & $\begin{array}{l}\text { Mitochondrial } \\
\text { ribosomal protein } \\
\text { L44 (M) }\end{array}$ & Carroll et al. (2013) & \\
\hline \multicolumn{9}{|l|}{ (b) Dilated cardiomyopathies } \\
\hline Dilated cardiomyopathy, 1A & 10.34 & $\mathrm{AD}$ & $\begin{array}{l}\text { CMD1A } \\
115200\end{array}$ & $1 \mathrm{q} 21$ & $\begin{array}{l}\text { LMNA } \\
150330\end{array}$ & $\operatorname{lamin} \mathrm{A} / \mathrm{C}$ & Fatkin et al. (1999) & $\begin{array}{l}\text { allelic to EDMD2 (group 1), } \\
\text { EDMD3 (group 1), LGMD1B } \\
\text { (group 1), CMT2B1 (group } \\
\text { 14), [+ FPLD2/151660, } \\
\text { HGPS/176670, restrictive } \\
\text { dermopathy/275210, not in this } \\
\text { table] }\end{array}$ \\
\hline Dilated cardiomyopathy, 1B & 10.35 & $\mathrm{AD}$ & $\begin{array}{l}\text { CMD1B } \\
600884\end{array}$ & $9 \mathrm{q} 13$ & $?$ & & Krajinovic et al. (1995) & \\
\hline Dilated cardiomyopathy, 1C & 10.36 & $\mathrm{AD}$ & $\begin{array}{l}\text { CMD1C } \\
601493\end{array}$ & $10 \mathrm{q} 22-\mathrm{q} 23$ & $\begin{array}{l}\text { LDB3 } \\
(\boldsymbol{Z A S P}) \\
605906\end{array}$ & $\begin{array}{l}\text { LIM domain } \\
\text { binding-3 ( } \mathrm{Z} \text { band } \\
\text { alternatively spliced } \\
\text { PDZ motif) }\end{array}$ & $\begin{array}{l}\text { Bowles et al. (1996) } \\
\text { Vatta et al. (2003) } \\
\text { Arimura et al. (2004) }\end{array}$ & $\begin{array}{l}\text { allelic to Markesbery-Griggs } \\
\text { (group 4), MFM (group 5) }\end{array}$ \\
\hline Dilated cardiomyopathy, 1D & 10.37 & $\mathrm{AD}$ & $\begin{array}{l}\text { CMD1D } \\
601494\end{array}$ & $1 \mathrm{q} 32$ & $\begin{array}{l}\text { TNNT2 } \\
191045\end{array}$ & $\begin{array}{l}\text { Troponin type } 2 \\
\text { (cardiac) }\end{array}$ & $\begin{array}{l}\text { Durand et al. (1995) } \\
\text { Kamisago et al. (2000) }\end{array}$ & \\
\hline $\begin{array}{l}\text { Dilated cardiomyopathy, } 1 \mathrm{E} \\
\text { with conduction disorder and } \\
\text { arrhythmia }\end{array}$ & 10.38 & $\mathrm{AD}$ & $\begin{array}{l}\text { CMD1E } \\
601154\end{array}$ & $3 \mathrm{p} 21$ & $\begin{array}{l}\text { SCN5A } \\
600163\end{array}$ & $\begin{array}{l}\text { Sodium channel, } \\
\text { voltage-gated, type } \\
\text { V, alpha }\end{array}$ & McNair et al. (2004) & $\begin{array}{l}\text { allelic to LQT3 (group 10), } \\
\text { Brugada syndrome (group 10), } \\
\text { SSS1 (group 10) }\end{array}$ \\
\hline Dilated cardiomyopathy, $1 \mathrm{G}$ & 10.39 & $\mathrm{AD}$ & $\begin{array}{l}\text { CMD1G } \\
604145\end{array}$ & $2 \mathrm{q} 31$ & $\begin{array}{l}\boldsymbol{T T N} \\
188840\end{array}$ & Titin & $\begin{array}{l}\text { Siu et al. (1999) } \\
\text { Gerull et al. (2002) } \\
\text { Itoh-Satoh et al. (2002) }\end{array}$ & $\begin{array}{l}\text { allelic to LGMD2J (group 1), } \\
\text { congenital myopathy with fatal } \\
\text { cardiomyopathy (group 3), } \\
\text { TMD (group 4), HMERF } \\
\text { (group 5), CMH9 (group 10), }\end{array}$ \\
\hline Dilated cardiomyopathy, $1 \mathrm{H}$ & 10.40 & $\mathrm{AD}$ & $\mathrm{CMD} 1 \mathrm{H}$ & $2 q 14-q 22$ & $?$ & & Jung et al. (1999) & \\
\hline
\end{tabular}




\begin{tabular}{|c|c|c|c|c|c|c|c|c|}
\hline DISEASE NAME & $\begin{array}{l}\text { Item } \\
\text { line } \\
\text { in this } \\
\text { group }\end{array}$ & Inheritance & $\begin{array}{l}\text { Locus or } \\
\text { disease } \\
\text { symbol and } \\
\text { OMIM } \\
\text { number }\end{array}$ & Chromosome & $\begin{array}{l}\text { Gene symbol } \\
\text { and OMIM } \\
\text { number }\end{array}$ & $\begin{array}{l}\text { Protein } \\
\text { (mitochondrial } \\
\text { proteins indicated } \\
\text { by symbol }[M] \text { ) }\end{array}$ & $\begin{array}{l}\text { Key } \\
\text { references }\end{array}$ & $\begin{array}{l}\text { Other allelic disease(s) } \\
\text { (group in this table) }\end{array}$ \\
\hline Dilated cardiomyopathy, 1I & 10.41 & $\mathrm{AD}$ & $\begin{array}{l}\text { CMD1I } \\
604765\end{array}$ & $2 \mathrm{q} 35$ & $\begin{array}{l}\text { DES } \\
125660\end{array}$ & desmin & Li et al. (1999) & $\begin{array}{l}\text { Allelic to LGMD1E (group 1), } \\
\text { myofibrillar myopathy (group } \\
\text { 5), ARVD7 (group 10/B) }\end{array}$ \\
\hline Dilated cardiomyopathy, $1 \mathrm{~J}$ & 10.42 & $\mathrm{AD}$ & $\begin{array}{l}\text { CMD1J } \\
605362\end{array}$ & $6 \mathrm{q} 23-24$ & $\begin{array}{l}\boldsymbol{E} \boldsymbol{Y A 4} \\
603550\end{array}$ & $\begin{array}{l}\text { Eyes absent } \\
\text { homolog }\end{array}$ & Schönberger et al. (2005a) & \\
\hline Dilated cardiomyopathy, $1 \mathrm{~K}$ & 10.43 & $\mathrm{AD}$ & $\begin{array}{l}\text { CMD1K } \\
605582\end{array}$ & $6 q 12-q 16$ & $?$ & & Sylvius et al. (2001) & \\
\hline Dilated cardiomyopathy, 1L & 10.44 & $\mathrm{AD}$ & $\begin{array}{l}\text { CMD1L } \\
606685\end{array}$ & $5 \mathrm{q} 33$ & $\begin{array}{l}S G C D \\
601411\end{array}$ & sarcoglycan, delta & Tsubata et al. (2000) & allelic to LGMD2F (group 1) \\
\hline Dilated cardiomyopathy, $1 \mathrm{M}$ & 10.45 & $\mathrm{AD}$ & $\begin{array}{l}\text { CMD1M } \\
607482\end{array}$ & $11 \mathrm{p} 15.1$ & $\begin{array}{l}\text { CSRP3 } \\
600824\end{array}$ & $\begin{array}{l}\text { Cysteine and } \\
\text { glycine-rich protein } \\
3 \text { (cardiac LIM } \\
\text { protein) }\end{array}$ & Knoll et al. (2002) & allelic to $\mathrm{CMH} 12$ (group 10) \\
\hline Dilated cardiomyopathy, $1 \mathrm{~N}$ & 10.46 & $\mathrm{AD}$ & $\begin{array}{l}\text { CMD1N } \\
607487\end{array}$ & $17 \mathrm{q} 12$ & $\begin{array}{l}\text { TCAP } \\
604488\end{array}$ & $\begin{array}{l}\text { Telethonin } \\
\text { (titin-cap) }\end{array}$ & Knoll et al. (2002) & allelic to LGMD2G (group 1) \\
\hline Dilated cardiomyopathy, 10 & 10.47 & $\mathrm{AD}$ & $\begin{array}{l}\text { CMD1O } \\
605569\end{array}$ & $12 \mathrm{p} 12.1$ & $\begin{array}{l}\text { ABCC9 } \\
601439\end{array}$ & $\begin{array}{l}\text { ATP-binding } \\
\text { cassette, sub-family } \\
\text { C (member 9) }\end{array}$ & Bienengraeber et al (2004) & \\
\hline Dilated cardiomyopathy, $1 \mathrm{P}$ & 10.48 & $\mathrm{AD}$ & $\begin{array}{l}\text { CMD1P } \\
609909\end{array}$ & $6 \mathrm{q} 22$ & $\begin{array}{l}P L N \\
172405\end{array}$ & phospholamban & $\begin{array}{l}\text { Schmitt et al. (2003) } \\
\text { Haghighi et al. }(2003,2006)\end{array}$ & $\begin{array}{l}\text { allelic to hypertrophic } \\
\text { cardiomyopathy } \mathrm{CMH} 18 \\
\text { (group 10) }\end{array}$ \\
\hline Dilated cardiomyopathy, 1Q & 10.49 & $\mathrm{AD}$ & $\begin{array}{l}\text { CMD1Q } \\
609915\end{array}$ & $7 \mathrm{q} 22.3-\mathrm{q} 31.1$ & $?$ & & Schonberger et al. (2005b) & \\
\hline Dilated cardiomyopathy, 1R & 10.50 & $\mathrm{AD}$ & $\begin{array}{l}\text { CMD1R } \\
613424\end{array}$ & $15 \mathrm{q} 14$ & $\begin{array}{l}\text { ACTC1 } \\
102540\end{array}$ & $\begin{array}{l}\text { actin, alpha, cardiac } \\
\text { muscle } 1\end{array}$ & $\begin{array}{l}\text { Olson et al. (1998) } \\
\text { Mogensen et al. (1999) }\end{array}$ & allelic to $\mathrm{CMH}$ (group 10) \\
\hline Dilated cardiomyopathy, $1 \mathrm{~S}$ & 10.51 & $\mathrm{AD}$ & $\begin{array}{l}\text { CMD1S } \\
613426\end{array}$ & $14 \mathrm{q} 12$ & $\begin{array}{l}\text { МYH7 } \\
160760\end{array}$ & $\begin{array}{l}\text { myosin, heavy } \\
\text { chain } 7 \text {, cardiac } \\
\text { muscle, beta }\end{array}$ & Kamisago et al. (2000) & $\begin{array}{l}\text { allelic to allelic to CFTD } \\
\text { (group 3), myosin storage } \\
\text { myopathy (group 3), MPD1 } \\
\text { (group 4), CMH1 (group 10) }\end{array}$ \\
\hline Dilated cardiomyopathy, 1T & 10.52 & $\mathrm{AD}$ & CMD1T & $12 \mathrm{q} 22$ & $\begin{array}{l}\text { ТМРО } \\
188380\end{array}$ & $\begin{array}{l}\text { Thymopoietin } \\
\text { (lamina-associated } \\
\text { polypeptide 2) }\end{array}$ & Taylor et al. (2005) & \\
\hline Dilated cardiomyopathy, $1 \mathrm{U}$ & 10.53 & $\mathrm{AD}$ & $\begin{array}{l}\text { CMD1U } \\
613694\end{array}$ & $1 \mathrm{q} 42.13$ & $\begin{array}{l}\text { PSEN2 } \\
600759\end{array}$ & Presenilin 2 & Li et al. (2006) & \\
\hline Dilated cardiomyopathy, $1 \mathrm{~W}$ & 10.54 & $\mathrm{AD}$ & $\begin{array}{l}\text { CMD1W } \\
611407\end{array}$ & $10 \mathrm{q} 22$ & $\begin{array}{l}\text { VCL } \\
193065\end{array}$ & $\begin{array}{l}\text { vinculin } \\
\text { (metavinculin) }\end{array}$ & $\begin{array}{l}\text { Olson et al. (2002) } \\
\text { Vasile et al. (2006) }\end{array}$ & allelic to CMH 15 (group 10) \\
\hline $\begin{array}{l}\text { Dilated cardiomyopathy related } \\
\text { to fukutin }\end{array}$ & 10.55 & $\mathrm{AR}$ & $\begin{array}{l}\text { CMD1X } \\
611615\end{array}$ & $9 q 31-q 33$ & $\begin{array}{l}\text { FCMD } \\
607440\end{array}$ & Fukutin & Murakami et al. (2006) & allelic to LGMD2L (group 1) \\
\hline Dilated cardiomyopathy, $1 Y$ & 10.56 & $\mathrm{AD}$ & $\begin{array}{l}\text { CMD1Y } \\
611878\end{array}$ & $15 \mathrm{q} 22.2$ & $\begin{array}{l}\text { TPM1 } \\
191010\end{array}$ & Alpha-tropomyosin & Olson et al. (2010) & Allelic to CMH3 (group 10) \\
\hline Dilated cardiomyopathy, $1 \mathrm{Z}$ & 10.57 & $\mathrm{AD}$ & $\begin{array}{l}\text { CMD1Z } \\
611879\end{array}$ & 3 p21-p14 & $\begin{array}{l}\text { TNNC1 } \\
191040\end{array}$ & slow troponin $\mathrm{C}$ & Mogensen et al. (2004) & allelic to $\mathrm{CMH} 13$ (group 10) \\
\hline Dilated cardiomyopathy, 1AA & 10.58 & $\mathrm{AD}$ & $\begin{array}{l}\text { CMD1AA } \\
612158\end{array}$ & $1 q 42-q 43$ & $\begin{array}{l}\text { ACTN2 } \\
102573\end{array}$ & actinin alpha2 & Mohapatra et al. (2003) & Allelic to CMH (group 10) \\
\hline $\begin{array}{l}\text { Dilated cardiomyopathy, related } \\
\text { to DSG2 }\end{array}$ & 10.59 & $\mathrm{AD} / \mathrm{AR}$ & $\begin{array}{l}\text { CMD1BB } \\
612877\end{array}$ & $18 \mathrm{q} 12.1$ & $\begin{array}{l}\text { DSG2 } \\
125671\end{array}$ & Desmoglein 2 & Posch et al. (2008) & \\
\hline $\begin{array}{l}\text { Dilated cardiomyopathy related } \\
\text { to nexilin }\end{array}$ & 10.60 & $\mathrm{AD}$ & $\begin{array}{l}\text { CMD1CC } \\
613122\end{array}$ & 1p32-p31 & $\begin{array}{l}\text { NEXN } \\
613121\end{array}$ & $\begin{array}{l}\text { nexilin }(<\mathrm{F} \text {-actin } \\
\text { binding protein) }\end{array}$ & Hassel et al. (2009) & \\
\hline $\begin{array}{l}\text { Dilated cardiomyopathy related } \\
\text { to ribonucleic acid binding } \\
\text { protein }\end{array}$ & 10.61 & $\mathrm{AD}$ & $\begin{array}{l}\text { CMD1DD } \\
613172\end{array}$ & $10 \mathrm{q} 25.3$ & $\begin{array}{l}\boldsymbol{R B M 2 0} \\
613171\end{array}$ & $\begin{array}{l}\text { RNA binding motif } \\
\text { protein } 20\end{array}$ & Brauch et al. (2009) & \\
\hline $\begin{array}{l}\text { Dilated cardiomyopathy related } \\
\text { to alpha-myosin heavy chain }\end{array}$ & 10.62 & $\mathrm{AD}$ & $\begin{array}{l}\text { CMD1EE } \\
613252\end{array}$ & $14 \mathrm{q} 12$ & $\begin{array}{l}\text { МYH6 } \\
160710\end{array}$ & $\begin{array}{l}\text { myosin, heavy } \\
\text { chain } 6 \text {, cardiac } \\
\text { muscle, alpha }\end{array}$ & Carniel et al. (2005) & Allelic to CMH1 (group 10) \\
\hline Recessive neonatal isolated DC & 10.63 & AR & $\begin{array}{l}\text { CMD1GG } \\
613642\end{array}$ & $5 \mathrm{p} 15.33$ & $\begin{array}{l}\text { SDHA } \\
600857\end{array}$ & $\begin{array}{l}\text { Succinate } \\
\text { dehydrogenase } \\
\text { complex, subunit a, } \\
\text { flavoprotein }[\mathbf{M}]\end{array}$ & Levitas et al. (2010) & \\
\hline $\begin{array}{l}\text { Dilated cardiomyopathy related } \\
\text { to BAG3 }\end{array}$ & 10.64 & $\mathrm{AD}$ & $\begin{array}{l}\text { CMD1HH } \\
613881\end{array}$ & $10 \mathrm{q} 26.11$ & $\begin{array}{l}B A G 3 \\
603883\end{array}$ & $\begin{array}{l}\text { BCL2-Associated } \\
\text { Athanogene } 3\end{array}$ & Norton et al. (2011) & $\begin{array}{l}\text { Allelic to MMF6 (group 5) and } \\
\text { to CMT2 (group 14) }\end{array}$ \\
\hline $\begin{array}{l}\text { Dilated cardiomyopathy, related } \\
\text { to alpha-crystallin }\end{array}$ & 10.65 & $\mathrm{AD}$ & $\begin{array}{l}\text { CMD1II } \\
615184\end{array}$ & $11 \mathrm{q} 23.1$ & $\begin{array}{l}\text { CRYAB } \\
123590\end{array}$ & Alpha B crystallin & Inagaki et al. (2006) & $\begin{array}{l}\text { Allelic to myofibrillar } \\
\text { myopathy (group 5) }\end{array}$ \\
\hline $\begin{array}{l}\text { Dilated cardiomyopathy related } \\
\text { to laminin-alpha4 }\end{array}$ & 10.66 & $\mathrm{AD}$ & $\begin{array}{l}\text { CMD1JJ } \\
615235\end{array}$ & $6 \mathrm{q} 21$ & $\begin{array}{l}\mathbf{L A M A 4} \\
600133\end{array}$ & laminin-alpha4 & Knöll et al. (2007) & \\
\hline $\begin{array}{l}\text { Dilated cardiomyopathy related } \\
\text { to myopalladin }\end{array}$ & 10.67 & $\mathrm{AD}$ & $\begin{array}{l}\text { CMD1KK } \\
615248\end{array}$ & $10 \mathrm{q} 21.1$ & $\begin{array}{l}\text { MYPN } \\
608517\end{array}$ & myopalladin & Duboscq-Bidot (2008) & \\
\hline $\begin{array}{l}\text { Dilated cardiomyopathy related } \\
\text { to PRDM16 }\end{array}$ & 10.68 & $\mathrm{AD}$ & $\begin{array}{l}\text { CMD1LL } \\
\text { LVNC8 } \\
615373\end{array}$ & $1 \mathrm{p} 36.32$ & $\begin{array}{l}\text { PRDM1 } \\
605557\end{array}$ & $\begin{array}{l}\text { PR } \\
\text { Domain-Containing } \\
\text { Protein } 16\end{array}$ & Arndt et al. (2013) & \\
\hline $\begin{array}{l}\text { Dilated cardiomyopathy related } \\
\text { to } M Y B P C 3\end{array}$ & 10.69 & $\mathrm{AD}$ & $\begin{array}{l}\text { CMD1MM } \\
615396\end{array}$ & $11 \mathrm{p} 11.2$ & $\begin{array}{l}\text { МYВРC3 } \\
600958\end{array}$ & $\begin{array}{l}\text { Myosin-binding } \\
\text { protein C }\end{array}$ & Hershberger et al. (2010) & $\begin{array}{l}\text { Allelic to congenital myopathy } \\
\text { and fatal cardiomyopathy } \\
\text { (group 3), CMH4 (group 10) }\end{array}$ \\
\hline
\end{tabular}




\begin{tabular}{|c|c|c|c|c|c|c|c|c|}
\hline DISEASE NAME & $\begin{array}{l}\text { Item } \\
\text { line } \\
\text { in this } \\
\text { group }\end{array}$ & Inheritance & $\begin{array}{l}\text { Locus or } \\
\text { disease } \\
\text { symbol and } \\
\text { OMIM } \\
\text { number }\end{array}$ & Chromosome & $\begin{array}{l}\text { Gene symbol } \\
\text { and OMIM } \\
\text { number }\end{array}$ & $\begin{array}{l}\text { Protein } \\
\text { (mitochondrial } \\
\text { proteins indicated } \\
\text { by symbol }[M] \text { ) }\end{array}$ & $\begin{array}{l}\text { Key } \\
\text { references }\end{array}$ & $\begin{array}{l}\text { Other allelic disease(s) } \\
\text { (group in this table) }\end{array}$ \\
\hline $\begin{array}{l}\text { Dilated cardiomyopathy related } \\
\text { to RAF1 }\end{array}$ & 10.70 & $\mathrm{AD}$ & $\begin{array}{l}\text { CMD1NN } \\
615916\end{array}$ & $3 \mathrm{p} 25.2$ & $\begin{array}{l}\boldsymbol{R A F 1} \\
164760\end{array}$ & $\begin{array}{l}\text { V-Raf-1 Murine } \\
\text { Leukemia Viral } \\
\text { Oncogene Homolog } \\
1\end{array}$ & Dhandapany et al. (2014) & \\
\hline $\begin{array}{l}\text { Dilated cardiomyopathy related } \\
\text { to integrin-linked kinase }\end{array}$ & 10.71 & $\mathrm{AD}$ & & $11 \mathrm{p} 15.4$ & $\begin{array}{l}\text { ILK } \\
602366\end{array}$ & $\begin{array}{l}\text { integrin-linked } \\
\text { kinase }\end{array}$ & Knöll et al. (2007) & \\
\hline $\begin{array}{l}\text { Dilated cardiomyopathy related } \\
\text { to cardiac ankyrin repeat } \\
\text { protein }\end{array}$ & 10.72 & $\mathrm{AD}$ & & $10 \mathrm{q} 23.33$ & $\begin{array}{l}\text { ANKRD1 } \\
609599\end{array}$ & $\begin{array}{l}\text { ankyrin repeat } \\
\text { domain } 1 \text { (cardiac } \\
\text { muscle) }\end{array}$ & $\begin{array}{l}\text { Duboscq-Bidot (2009) } \\
\text { Moulik et al. (2009) }\end{array}$ & \\
\hline $\begin{array}{l}\text { Dilated cardiomyopathy related } \\
\text { to cardiac troponin I }\end{array}$ & 10.73 & $\mathrm{AD}$ & $\begin{array}{l}\text { CMD2A } \\
611880\end{array}$ & $19 \mathrm{q} 34$ & $\begin{array}{l}\text { TNNI3 } \\
191044\end{array}$ & cardiac troponin I & Carballo et al. (2009) & allelic to $\mathrm{CMH} 7$ and RCM1 \\
\hline $\begin{array}{l}\text { Dilated cardiomyopathy related } \\
\text { to GATADI }\end{array}$ & 10.74 & $\mathrm{AR}$ & $\begin{array}{l}\text { CMD2B } \\
614672\end{array}$ & $7 \mathrm{q} 21.3$ & $\begin{array}{l}\text { GATAD1 } \\
614518\end{array}$ & $\begin{array}{l}\text { GATA zinc finger } \\
\text { domain containing } \\
1\end{array}$ & Theis et al. (2011) & \\
\hline $\begin{array}{l}\text { Dilated cardiomyopathy related } \\
\text { to tafazzin }\end{array}$ & 10.75 & $\mathrm{XR}$ & $\begin{array}{l}\text { CMD3A } \\
300069\end{array}$ & $\mathrm{Xq} 28$ & $\begin{array}{l}\boldsymbol{T A Z} \\
300394\end{array}$ & tafazzin & Gedeon et al. (1995) & allelic to BTHS (group 10) \\
\hline $\begin{array}{l}\text { Dilated cardiomyopathy related } \\
\text { to dystrophin }\end{array}$ & 10.76 & $\mathrm{XR}$ & $\begin{array}{l}\text { CMD3B } \\
302045\end{array}$ & $\mathrm{Xp} 21.2$ & $\begin{array}{l}\text { DMD } \\
300377\end{array}$ & dystrophin & $\begin{array}{l}\text { Muntoni et al. (1993) } \\
\text { Milasin et al. (1996) }\end{array}$ & allelic to DMD (group 1) \\
\hline $\begin{array}{l}\text { Dilated cardiomyopathy related } \\
\text { to nesprin-1 }\end{array}$ & 10.77 & $\mathrm{AD}$ & & $6 \mathrm{q} 25$ & $\begin{array}{l}\text { SYNE1 } \\
608441\end{array}$ & $\begin{array}{l}\text { spectrin repeat } \\
\text { containing, nuclear } \\
\text { envelope } 1 \\
\text { (nesprin-1 }\end{array}$ & Puckelwartz et al. (2010) & $\begin{array}{l}\text { Allelic to EDMD with } \\
\text { nesprin-1 defect (group 1) } \\
\text { SCAR8 (group 13), dilated } \\
\text { APC with nesprin-1 defect } \\
\text { (group 16) }\end{array}$ \\
\hline $\begin{array}{l}\text { Dilated cardiomyopathy related } \\
\text { to } M U R C\end{array}$ & 10.78 & $\mathrm{AD}$ & & $9 \mathrm{q} 31.1$ & $\begin{array}{l}\text { MURC } \\
(C A V I N 4)\end{array}$ & $\begin{array}{l}\text { Muscle-restricted } \\
\text { colied-coil gene }\end{array}$ & Rodriguez et al. (2011) & \\
\hline $\begin{array}{l}\text { Dilated Cardiomyopathy related } \\
\text { to } D O L K\end{array}$ & 10.79 & $\mathrm{AR}$ & $\begin{array}{l}\text { CDGM1 } \\
610768\end{array}$ & $9 q 34.13$ & $\begin{array}{l}\text { DOLK } \\
610746\end{array}$ & Dolichol kinase & $\begin{array}{l}\text { Kranz et al. (2007) } \\
\text { Lefeber et al. (2011 }\end{array}$ & \\
\hline (c) Restrictive cardiomyopathies & & & & & & & & \\
\hline Restrictive cardiomyopathy, 1 & 10.80 & $\mathrm{AD}$ & $\begin{array}{l}\text { RCM1 } \\
115210\end{array}$ & $19 \mathrm{q} 34$ & $\begin{array}{l}\text { TTNI3 } \\
191044\end{array}$ & Cardiac troponin I & Mogensen et al. (2003) & allelic to $\mathrm{CMH7}$ (group 10) \\
\hline Restrictive cardiomyopathy, 2 & 10.81 & & $\begin{array}{l}\text { RCM2 } \\
609578\end{array}$ & 10 & $?$ & & Zhang et al. (2005) & \\
\hline \multicolumn{9}{|c|}{ (d) Other non arrhythmogenic hereditary cardiomyopathies } \\
\hline $\begin{array}{l}\text { Pompe disease Glycogenosis, } \\
\text { generalized, cardiac form (early } \\
\text { and late onset) also listed in } \\
\text { group } 9\end{array}$ & 10.82 & $\mathrm{AR}$ & $\begin{array}{l}\text { GSDII } \\
232300\end{array}$ & $17 \mathrm{q} 25$ & $\begin{array}{l}\boldsymbol{G A A} \\
606800\end{array}$ & $\begin{array}{l}\text { glucosidase, alpha; } \\
\text { acid }\end{array}$ & $\begin{array}{l}\text { Hers (1963) } \\
\text { Martiniuk et al. (1990) } \\
\text { Wokke et al. (1995) }\end{array}$ & allelic to GSDII (group 9) \\
\hline $\begin{array}{l}\text { Cardioskeletal myopathy with } \\
\text { neutropenia and abnormal } \\
\text { mitochondria (Barth syndrome) }\end{array}$ & 10.83 & $\mathrm{XR}$ & $\begin{array}{l}\text { BTHS } \\
302060\end{array}$ & $\mathrm{Xq} 28$ & $\begin{array}{l}\boldsymbol{T A Z} \\
300394\end{array}$ & tafazzin & $\begin{array}{l}\text { Bolhuis et al. (1991) } \\
\text { Bione et al. (1996) }\end{array}$ & allelic to CMD3A (group 10) \\
\hline Left ventricular noncompaction & 10.84 & $\mathrm{AD}$ & $\begin{array}{l}\text { LVNC } \\
604169\end{array}$ & $18 \mathrm{q} 12.1-\mathrm{q} 12.2$ & $\begin{array}{l}\text { DTNA } \\
601239\end{array}$ & dystrobrevin, alpha & Ichida et al. (2001) & \\
\hline $\begin{array}{l}\text { Cardiovalvular dysplasia, } \\
\text { X-linked (Myxomatous } \\
\text { valvular dystrophy) }\end{array}$ & 10.85 & $\mathrm{XR}$ & $\begin{array}{l}\text { XMVD } \\
314400\end{array}$ & $\mathrm{Xq} 28$ & $\begin{array}{l}\boldsymbol{F L N A} \\
300017\end{array}$ & $\begin{array}{l}\text { filamin A, alpha } \\
\text { (actin binding } \\
\text { protein 280) }\end{array}$ & $\begin{array}{l}\text { Kyndt et al. (1998) } \\
\text { Kyndt et al. (2007) }\end{array}$ & \\
\hline
\end{tabular}

10-B FOR ARRHYTHMOGENIC CARDIOMYOPATHIES AND RELATED SYNDROMES See online version of the gene table http://www.musclegenetable.fr

\begin{tabular}{|c|c|c|c|c|c|c|c|c|}
\hline \multirow{14}{*}{ Slow channel syndromes } & МY & THEN & YNDF & & & & & \\
\hline & 11.1 & $\mathrm{AD}$ & CMS1A & $2 q 24-q 32$ & CHRNA1 & Cholinergic & Sine et al. (1995) & Allelic to other entries in group \\
\hline & & & CMS1B & & 100690 & receptor, nicotinic, & Engel et al. (1996b) & 11 \\
\hline & & & 601462 & & & alpha 1 muscle & Croxen et al. (1997) & \\
\hline & 11.2 & $\mathrm{AD}$ & CMS2A & $17 \mathrm{p} 11-\mathrm{p} 12$ & CHRNB1 & Cholinergic & Engel et al. (1996b) & Allelic to other entries in group \\
\hline & & & $\begin{array}{l}\text { CMS2C } \\
616313\end{array}$ & & 100710 & $\begin{array}{l}\text { receptor, nicotinic, } \\
\text { beta } 1 \text { muscle }\end{array}$ & Gomez et al. (1996) & 11 \\
\hline & 11.3 & $\mathrm{AD}$ & CMS3A & $2 q 33-q 34$ & CHRND & Cholinergic & Gomez et al. (2002) & Allelic to other entries in group \\
\hline & & & CMS3B & & 100720 & receptor, nicotinic, & & 11 \\
\hline & & & $\mathrm{CMS} 3 \mathrm{C}$ & & & delta & & \\
\hline & & & 616321 & & & & & \\
\hline & 11.4 & $\mathrm{AD}, \mathrm{AR}$ & CMS4A & $17 \mathrm{p} 13$ & CHRNE & Cholinergic & Ohno et al. (1995) & Allelic to other entries in group \\
\hline & & & CMS4B & & 100725 & receptor, nicotinic, & Gomez et al. (1995) & 11 \\
\hline & & & CMS4C & & & epsilon & Engel et al. (1996b) & \\
\hline & & & 605809 & & & & Croxen et al. (2002) & \\
\hline \multirow[t]{5}{*}{ Fast channel syndromes } & 11.5 & AR & CMS1A & $2 q 24-q 32$ & CHRNA1 & Cholinergic & Wang et al. (1999) & Allelic to other entries in group \\
\hline & & & $\begin{array}{l}\text { CMS1B } \\
608930\end{array}$ & & 100690 & $\begin{array}{l}\text { receptor, nicotinic, } \\
\text { alpha } 1 \text { muscle }\end{array}$ & Shen et al. (2003) & 11 \\
\hline & 11.6 & $\mathrm{AR}$ & CMS3A, & $2 q 33-q 34$ & CHRND & Cholinergic & Brownlow et al. (2001) & Allelic to other entries in group \\
\hline & & & $\begin{array}{l}\text { CMS3B, } \\
\text { CMS3C }\end{array}$ & & 100720 & $\begin{array}{l}\text { receptor, nicotinic, } \\
\text { delta }\end{array}$ & & 11) \\
\hline & & & 616322 & & & & & \\
\hline
\end{tabular}




\begin{tabular}{|c|c|c|c|c|c|c|c|c|}
\hline DISEASE NAME & $\begin{array}{l}\text { Item } \\
\text { line } \\
\text { in this } \\
\text { group }\end{array}$ & Inheritance & $\begin{array}{l}\text { Locus or } \\
\text { disease } \\
\text { symbol and } \\
\text { OMIM } \\
\text { number }\end{array}$ & Chromosome & $\begin{array}{l}\text { Gene symbol } \\
\text { and OMIM } \\
\text { number }\end{array}$ & $\begin{array}{l}\text { Protein } \\
\text { (mitochondrial } \\
\text { proteins indicated } \\
\text { by symbol }[M] \text { ) }\end{array}$ & $\begin{array}{l}\text { Key } \\
\text { references }\end{array}$ & $\begin{array}{l}\text { Other allelic disease(s) } \\
\text { (group in this table) }\end{array}$ \\
\hline \multirow{4}{*}{$\begin{array}{l}\text { Acetylcholine receptor } \\
\text { deficiency }\end{array}$} & 11.7 & AR & $\begin{array}{l}\text { CMS4A, } \\
\text { CMS4B, } \\
\text { CMS4C } \\
616324\end{array}$ & $17 \mathrm{p} 13$ & $\begin{array}{l}\text { CHRNE } \\
100725\end{array}$ & $\begin{array}{l}\text { Cholinergic } \\
\text { receptor, nicotinic, } \\
\text { epsilon }\end{array}$ & Ohno et al. (1996) & $\begin{array}{l}\text { Allelic to other entries in group } \\
11\end{array}$ \\
\hline & 11.8 & $\mathrm{AR}$ & $\begin{array}{l}\text { CMS2A } \\
\text { CMS2C } \\
616314\end{array}$ & $17 \mathrm{p} 11-\mathrm{p} 12$ & $\begin{array}{l}\text { CHRNB1 } \\
100710\end{array}$ & $\begin{array}{l}\text { Cholinergic } \\
\text { receptor, nicotinic, } \\
\text { beta } 1 \text { muscle }\end{array}$ & Quiram et al. (1999) & $\begin{array}{l}\text { Allelic to other entries in group } \\
11\end{array}$ \\
\hline & 11.9 & AR & $\begin{array}{l}\text { CMS4A, } \\
\text { CMS4B, } \\
\text { CMS4C } \\
616323\end{array}$ & $2 q 33-q 34$ & $\begin{array}{l}\text { CHRND } \\
100720\end{array}$ & $\begin{array}{l}\text { Cholinergic } \\
\text { receptor, nicotinic, } \\
\text { delta }\end{array}$ & Shen et al. (2002) & $\begin{array}{l}\text { Allelic to other entries in group } \\
11\end{array}$ \\
\hline & 11.10 & $\mathrm{AR}$ & $\begin{array}{l}\text { CMS3A, } \\
\text { CMS3B, } \\
\text { CMS3C } \\
608931\end{array}$ & $17 \mathrm{p} 13$ & $\begin{array}{l}\text { CHRNE } \\
100725\end{array}$ & $\begin{array}{l}\text { Cholinergic } \\
\text { receptor, nicotinic, } \\
\text { epsilon }\end{array}$ & $\begin{array}{l}\text { Engel et al. (1996a) } \\
\text { Ohno et al. (1997) }\end{array}$ & $\begin{array}{l}\text { Allelic to other entries in group } \\
11\end{array}$ \\
\hline $\begin{array}{l}\text { Congenital myasthenic } \\
\text { syndrome related to end-plate } \\
\text { acetylcholinesterase }\end{array}$ & 11.11 & $\mathrm{AR}$ & $\begin{array}{l}\text { CMS5 } \\
603034\end{array}$ & $3 \mathrm{p} 24.2$ & $\begin{array}{l}\text { COLQ } \\
603033\end{array}$ & $\begin{array}{l}\text { C-like tail subunit } \\
\text { (single strand of } \\
\text { homotrimer) of } \\
\text { asymmetric } \\
\text { acetylcholinesterase }\end{array}$ & $\begin{array}{l}\text { Donger et al. (1998) } \\
\text { Ohno et al. }(1998,1999 \text {, } \\
2000)\end{array}$ & \\
\hline $\begin{array}{l}\text { Congenital myasthenic } \\
\text { syndrome related to choline } \\
\text { acetyltransferase }\end{array}$ & 11.12 & AR & $\begin{array}{l}\text { CMS6 } \\
254210\end{array}$ & $10 \mathrm{q} 11.2$ & $\begin{array}{l}\boldsymbol{C H} \boldsymbol{A T} \\
118490\end{array}$ & $\begin{array}{l}\text { Choline } \\
\text { acetyltransferase }\end{array}$ & $\begin{array}{l}\text { Ohno et al. (2001) } \\
\text { Maselli et al. (2003) }\end{array}$ & \\
\hline $\begin{array}{l}\text { Myasthenic syndrome, } \\
\text { presynaptic, congenital, with or } \\
\text { without motor neuropathy }\end{array}$ & 11.13 & $\mathrm{AD}$ & $\begin{array}{l}\text { CMS7 } \\
616040\end{array}$ & $1 \mathrm{q} 32.1$ & $\begin{array}{l}\text { SYT2 } \\
600104\end{array}$ & Synaptotagmin II & Herrmann et al. (2014) & \\
\hline $\begin{array}{l}\text { Familial limb girdle myasthenia } \\
\text { related to agrin }\end{array}$ & 11.14 & $\mathrm{AR}$ & $\begin{array}{l}\text { CMS8 } \\
615120\end{array}$ & $1 \mathrm{p} 36.33$ & $\begin{array}{l}A G R N \\
103320\end{array}$ & Agrin & Huzé et al. (2009) & \\
\hline $\begin{array}{l}\text { Congenital myasthenic } \\
\text { syndromerelated to MuSK }\end{array}$ & 11.15 & $\mathrm{AR}$ & $\begin{array}{l}\text { CMS9 } \\
616325\end{array}$ & $9 q 31-q 32$ & $\begin{array}{l}\text { MUSK } \\
601296\end{array}$ & $\begin{array}{l}\text { Muscle-specific } \\
\text { receptor tyrosine } \\
\text { kinase }\end{array}$ & Chevessier et al. (2004) & \\
\hline $\begin{array}{l}\text { Familial limb girdle myasthenia } \\
\text { related to } D O K 7\end{array}$ & 11.16 & $\mathrm{AR}$ & $\begin{array}{l}\text { CMS10 } \\
254300\end{array}$ & $4 \mathrm{p} 16.2$ & $\begin{array}{l}\text { DOK7 } \\
610285\end{array}$ & Docking protein 7 & $\begin{array}{l}\text { Beeson et al. (2006); Selcen } \\
\text { et al. (2008) }\end{array}$ & \\
\hline $\begin{array}{l}\text { Congenital myasthenic } \\
\text { syndrome related to rapsyn }\end{array}$ & 11.17 & $\mathrm{AR}$ & $\begin{array}{l}\text { CMS11 } \\
616326\end{array}$ & $11 \mathrm{p} 11$ & $\begin{array}{l}\text { RAPSN } \\
601592\end{array}$ & Rapsyn & $\begin{array}{l}\text { Ohno et al. (2002) } \\
\text { Ohno et al. (2003) } \\
\text { Dunne et al. (2003) }\end{array}$ & \\
\hline $\begin{array}{l}\text { Familial limb girdle myasthenia } \\
\text { with tubular aggregates related } \\
\text { to GFPTI }\end{array}$ & 11.18 & $\mathrm{AR}$ & $\begin{array}{l}\text { CMS12 } \\
610542\end{array}$ & $2 \mathrm{p} 12-\mathrm{p} 15$ & $\begin{array}{l}\text { GFPT1 } \\
138292\end{array}$ & $\begin{array}{l}\text { Glutamine-fructose-6- } \\
\text { phosphate } \\
\text { transaminase } 1\end{array}$ & Senderek et al. (2011) & \\
\hline $\begin{array}{l}\text { Familial limb-girdle myasthenia } \\
\text { with tubular aggregates related } \\
\text { to } D P A G T 1\end{array}$ & 11.19 & AR & $\begin{array}{l}\text { CMS13 } \\
614750\end{array}$ & $11 \mathrm{q} 23.3$ & $\begin{array}{l}\text { DPAGT1 } \\
191350\end{array}$ & $\begin{array}{l}\text { Dolichyl-phosphate } \\
\text { (UDP-N- } \\
\text { acetylglucosamine) } \\
\mathrm{N} \text {-acetylglucosamine } \\
\text { phosphotransferase } \\
1 \text { (GlcNAc-1-P } \\
\text { transferase) }\end{array}$ & Belaya et al. (2012) & \\
\hline $\begin{array}{l}\text { Congenital myasthenic } \\
\text { syndrome with tubular } \\
\text { aggregates }\end{array}$ & 11.20 & AR & $\begin{array}{l}\text { CMS14 } \\
616228\end{array}$ & $9 \mathrm{q} 31.1$ & $\begin{array}{l}\boldsymbol{A L G} \mathbf{2} \\
607905\end{array}$ & $\begin{array}{l}\text { alpha-1,3/1,6- } \\
\text { mannosyltransferase }\end{array}$ & Cossins et al (2013) & \\
\hline $\begin{array}{l}\text { Congenital myasthenic } \\
\text { syndrome related to } A L G 14\end{array}$ & 11.21 & $\mathrm{AR}$ & $\begin{array}{l}\text { CMS15 } \\
607227\end{array}$ & $1 \mathrm{p} 21.3$ & $\begin{array}{l}A L G 14 \\
612866\end{array}$ & $\begin{array}{l}\text { UDP-N- } \\
\text { acetylglucosami- } \\
\text { nyltransferase } \\
\text { subunit }\end{array}$ & Cossins et al (2013) & \\
\hline $\begin{array}{l}\text { Myasthenic syndrome, } \\
\text { acetazolamide-responsive }\end{array}$ & 11.22 & AR & $\begin{array}{l}\text { CMS16 } \\
614198\end{array}$ & $17 \mathrm{q} 23$ & $\begin{array}{l}S C N 4 A \\
603967\end{array}$ & $\begin{array}{l}\text { Sodium channel, } \\
\text { voltage-gated, type } \\
\text { IV, alpha }\end{array}$ & Tsujino et al. (2003) & $\begin{array}{l}\text { Allelic to HOKPP2 (group 7), } \\
\text { HYPP (group 7), PMC (group } \\
\text { 7), K-aggravated myotonia } \\
\text { (group 7) }\end{array}$ \\
\hline $\begin{array}{l}\text { Congenital myasthenic } \\
\text { syndrome }\end{array}$ & 11.23 & AR & $\begin{array}{l}\text { CMS17 } \\
616304\end{array}$ & $11 \mathrm{p} 11.2$ & $\begin{array}{l}\boldsymbol{L R P 4} \\
604270\end{array}$ & $\begin{array}{l}\text { LDL receptor } \\
\text { related protein } 4\end{array}$ & Ohkawara et al. (2014) & \\
\hline $\begin{array}{l}\text { Congenital myasthenic } \\
\text { syndrome with intellectual } \\
\text { disability and ataxia }\end{array}$ & 11.24 & $A D$ & $\begin{array}{l}\text { CMS18 } \\
616330\end{array}$ & $20 \mathrm{p} 12.2$ & $\begin{array}{l}\text { SNAP25 } \\
600322\end{array}$ & $\begin{array}{l}\text { synaptosome- } \\
\text { associated protein } \\
25\end{array}$ & Shen et al. (2014) & \\
\hline $\begin{array}{l}\text { Congenital myasthenic } \\
\text { syndrome type } 19\end{array}$ & 11.25 & AR & $\begin{array}{l}\text { CMS19 } \\
616720\end{array}$ & $10 \mathrm{q} 22.1$ & $\begin{array}{l}\text { COL13A1 } \\
120356\end{array}$ & $\begin{array}{l}\text { collagen type XIII } \\
\text { alpha } 1 \text { chain }\end{array}$ & Logan et al. (2015) & \\
\hline $\begin{array}{l}\text { Congenital myasthenic } \\
\text { syndrome with episodic apnea }\end{array}$ & 11.26 & AR & $\begin{array}{l}\text { CMS20 } \\
617143\end{array}$ & $2 \mathrm{q} 12.3$ & $\begin{array}{l}S L C 5 A 7 \\
608761\end{array}$ & $\begin{array}{l}\text { solute carrier } \\
\text { family } 5 \text { member } 7\end{array}$ & Bauche et al. (2016) & \\
\hline $\begin{array}{l}\text { Myasthenic Syndrome, } \\
\text { Congenital, 21, Presynaptic }\end{array}$ & 11.27 & $\mathrm{AR}$ & $\begin{array}{l}\text { CMS21 } \\
617239\end{array}$ & $10 \mathrm{q} 11.23$ & $\begin{array}{l}\text { SLC18A3 } \\
600336\end{array}$ & $\begin{array}{l}\text { Solute Carrier } \\
\text { Family } 18 \\
\text { (Vesicular } \\
\text { Acetylcholine), } \\
\text { Member } 3\end{array}$ & O’Grady et al. (2016) & \\
\hline
\end{tabular}




\begin{tabular}{|c|c|c|c|c|c|c|c|c|}
\hline DISEASE NAME & $\begin{array}{l}\text { Item } \\
\text { line } \\
\text { in this } \\
\text { group }\end{array}$ & Inheritance & $\begin{array}{l}\text { Locus or } \\
\text { disease } \\
\text { symbol and } \\
\text { OMIM } \\
\text { number }\end{array}$ & Chromosome & $\begin{array}{l}\text { Gene symbol } \\
\text { and OMIM } \\
\text { number }\end{array}$ & $\begin{array}{l}\text { Protein } \\
\text { (mitochondrial } \\
\text { proteins indicated } \\
\text { by symbol }[M] \text { ) }\end{array}$ & $\begin{array}{l}\text { Key } \\
\text { references }\end{array}$ & $\begin{array}{l}\text { Other allelic disease(s) } \\
\text { (group in this table) }\end{array}$ \\
\hline $\begin{array}{l}\text { Congenital myasthenic } \\
\text { syndrome related to PREPL } \\
\text { deficiency }\end{array}$ & 11.28 & $\mathrm{AR}$ & $\begin{array}{l}\text { CMS22 } \\
616224\end{array}$ & $2 \mathrm{p} 22.1$ & $\begin{array}{l}\text { PREPL } \\
609557\end{array}$ & $\begin{array}{l}\text { prolyl } \\
\text { endopeptidase-like }\end{array}$ & Regal et al. (2014) & \\
\hline $\begin{array}{l}\text { Congenital myasthenic } \\
\text { syndrome with nephrotic } \\
\text { syndrome }\end{array}$ & 11.29 & $\mathrm{AR}$ & $\begin{array}{l}\text { NPHS5 } \\
614199\end{array}$ & $3 \mathrm{p} 21$ & $\begin{array}{l}\mathbf{L A M B 2} \\
150325\end{array}$ & $\beta 2$-laminin & Maselli et al. (2009) & \\
\hline $\begin{array}{l}\text { Escobar syndrome (multiple } \\
\text { pterygium syndrome) }\end{array}$ & 11.30 & $\mathrm{AR}$ & $\begin{array}{l}\text { EVMPS } \\
265000\end{array}$ & $2 q 22-q 44$ & $\begin{array}{l}\text { CHRNG } \\
100730\end{array}$ & $\begin{array}{l}\text { Cholinergic } \\
\text { receptor, nicotinic, } \\
\text { gamma }\end{array}$ & $\begin{array}{l}\text { Hoffman et al. (2006) } \\
\text { Morgan et al. (2006) }\end{array}$ & \\
\hline $\begin{array}{l}\text { Myasthenic syndrome, with } \\
\text { plectin defect }\end{array}$ & 11.31 & $\mathrm{AR}$ & & 8q24-qter & $\begin{array}{l}\text { PLEC } \\
601282\end{array}$ & Plectin & $\begin{array}{l}\text { Banwell et al. (1999) } \\
\text { Forrest et al. (2010) } \\
\text { Selcen et al. (2011) }\end{array}$ & $\begin{array}{l}\text { Allelic to LGMD2Q (group 1) } \\
\text { MDEBS (group 5) }\end{array}$ \\
\hline Congenital Myasthenia & 11.32 & $\mathrm{AR}$ & & $15 \mathrm{q} 23$ & $\begin{array}{l}\text { МYO9A } \\
604875\end{array}$ & myosin IXA & O'Connor et al. (2016) & \\
\hline $\begin{array}{l}\text { Congenital Myasthenic } \\
\text { syndrome related to GMPPB }\end{array}$ & 11.33 & AR & & $3 \mathrm{q} 21.3$ & $\begin{array}{l}\boldsymbol{G M P P B} \\
615320\end{array}$ & $\begin{array}{l}\text { GDP-mannose } \\
\text { pyrophosphorylase } \\
\text { B }\end{array}$ & Belaya et al. (2015) & $\begin{array}{l}\text { allelic to MEB, MDDGB14 } \\
\text { (group 2), LGMD2T (group 1) }\end{array}$ \\
\hline $\begin{array}{l}\text { Presynaptic congenital } \\
\text { myasthenic syndrome }\end{array}$ & 11.34 & $\mathrm{AR}$ & & $12 \mathrm{p} 13.31$ & $\begin{array}{l}\text { VAMP1 } \\
185880\end{array}$ & $\begin{array}{l}\text { Vesicle-Associated } \\
\text { Membrane Protein } \\
1\end{array}$ & $\begin{array}{l}\text { Shen et al. (2017) } \\
\text { Salpietro et al. (2017) }\end{array}$ & allelic to SPAX1 (group 15) \\
\hline $\begin{array}{l}\text { Presynaptic congenital } \\
\text { myasthenic syndrome }\end{array}$ & 11.35 & $\mathrm{AR}$ & & $20 \mathrm{q} 13.33$ & $\begin{array}{l}L A M A 5 \\
601033\end{array}$ & Laminin, Alpha 5 & Maselli et al. (2017) & \\
\hline
\end{tabular}

\section{GROUP 12. SPINAL MUSCULAR ATROPHIES MOTONEURON DISEASES}

Spinal muscular atrophy related to SMN1

Spinal muscular atrophy, type 12.1 AR

I (Werdnig-Hoffman)
SMA1 5q11-q13 SMN1

$253300 \quad 600354$ survival of motor

neuron 1 , telomeric
Rodrigues et al. (1995)

Distal spinal muscular atrophy, recessive neuron 1 , telomeric

survival of motor

neuron 1 , telomeric

survival of motor

neuron 1 , telomeric survival of motor Li et al. (2015)
II (intermediate)

Spinal muscular atrophy, type $12.3 \quad$ AR

III (Kugelberg-Welander)

Spinal muscular atrophy, type $12.4 \quad \mathrm{AR}$

IV, adult form

Spinal muscular atrophy, distal $12.5 \quad$ AR

autosomal recessive 1 (with

respiratory distress)

Spinal muscular atrophy, distal $\quad 12.6 \quad$ AR

autosomal recessive 2

Spinal muscular atrophy, dista

autosomal recessive 3

autosomal recessive 4

$\begin{array}{lll}\text { SMA2 } & \text { 5q11-q13 } & \text { SMN1 } \\ 253550 & & 600354 \\ & & \\ \text { SMA3 } & 5 \mathrm{q} 11-\mathrm{q} 13 & \boldsymbol{S M N 1} \\ 253400 & & 600354 \\ & & \\ \text { SMA4 } & 5 \mathrm{q} 11-\mathrm{q} 13 & \boldsymbol{S M N 1} \\ 271150 & & 600354\end{array}$

(SMARD1)

604320

$\begin{array}{lll}\text { DSMA2 } & 9 \mathrm{p} 13.3 & \text { SIGMAR1 }\end{array}$

DSA3

DSMA

607088

DSMA4

611067

$1 \mathrm{p} 36$

p36

13

611101

Spinal muscular atrophy, distal $12.9 \quad$ AR

related to $D N A J B 2$

Spinal muscular atrophy with

congenital bone fractures

Spinal muscular atrophy with

congenital bone fractures 2

Spinal muscular atrophy with

progressive myoclonic epilepsy

Spinal muscular atrophy and

cerebellar hypoplasia

12.9 AR

614

616

12.12 AR

$12.13 \quad \mathrm{AR}$
Gilliam et al. (1990)

Melki et al. (1990a, 1994)

Lefebvre et al. (1995)

Bussaglia et al. (1995)

Roy et al. (1995)

Hahnen et al. (1997)

Matthijs et al. (1996),

Samilchuk (1996)
Brzustowicz et al. (1990)

Melki et al. (1990b)

Lefebvre et al. (1995)

Brahe et al. (1995)

Clermont et al. (1995) allelic to SMA2 (group 12), SMA3 (group 12), SMA4 (group 12)

allelic to SMA1 (group 12), SMA3 (group 12), SMA4 (group 12) allelic to SMA1 (group 12) SMA2 (group 12), SMA4 (group 12)

allelic to SMA1 (group 12), SMA2 (group 12), SMA3 (group 12)

Grohmann et al. (1999,

2001) mu-binding protein 2001)

2

Christodoulou et al. (2000) Allelic to ALS16 (group 12) intracellular receptor 1

Viollet et al. (2004)

Maystadt et al. $(2006 ; 2007)$

homology domain

containing, family

G (with RhoGef

domain) member 5

DnaJ (Hsp40)

homolog, subfamily

B, member 2

thyroid hormone

receptor interactor

4

activating signal

cointegrator 1

complex subunit 1

$\mathrm{N}$-acylsphingosine

amidohydrolase

(acid ceramidase) 1

Exosome

component 8
Blumen et al. (2012)

Knierim et al. (2016)

MDCDC (group 2)
Knierim et al. (2016)

Zhou et al. (2012)

Boczonadi et al. (2014) 


\begin{tabular}{|c|c|c|c|c|c|c|c|c|}
\hline DISEASE NAME & $\begin{array}{l}\text { Item } \\
\text { line } \\
\text { in this } \\
\text { group }\end{array}$ & Inheritance & $\begin{array}{l}\text { Locus or } \\
\text { disease } \\
\text { symbol and } \\
\text { OMIM } \\
\text { number }\end{array}$ & Chromosome & $\begin{array}{l}\text { Gene symbol } \\
\text { and OMIM } \\
\text { number }\end{array}$ & $\begin{array}{l}\text { Protein } \\
\text { (mitochondrial } \\
\text { proteins indicated } \\
\text { by symbol }[M] \text { ) }\end{array}$ & $\begin{array}{l}\text { Key } \\
\text { references }\end{array}$ & $\begin{array}{l}\text { Other allelic disease(s) } \\
\text { (group in this table) }\end{array}$ \\
\hline \multicolumn{9}{|c|}{ Distal spinal muscular atrophy, dominant } \\
\hline $\begin{array}{l}\text { Neuronopathy, distal hereditary } \\
\text { motor, type I }\end{array}$ & 12.14 & $\mathrm{AD}$ & $\begin{array}{l}\text { HMN1 } \\
182960\end{array}$ & $7 q 34-q 36$ & $?$ & & Gopinath et al. (2007) & \\
\hline $\begin{array}{l}\text { Neuronopathy, distal hereditary } \\
\text { motor, type I }\end{array}$ & 12.15 & $\mathrm{AD}$ & $\begin{array}{l}\text { HMN2A } \\
158590\end{array}$ & $12 \mathrm{q} 24$ & $\begin{array}{l}\text { HSPB8 } \\
608014\end{array}$ & $\begin{array}{l}\text { heat shock protein } \\
8\end{array}$ & $\begin{array}{l}\text { Timmerman et al.; Irobi } \\
\text { et al. (2004) }\end{array}$ & allelic to CMT2L (group 14) \\
\hline $\begin{array}{l}\text { Neuronopathy, distal hereditary } \\
\text { motor, type II, adult juvenile }\end{array}$ & 12.16 & $\mathrm{AD}$ & $\begin{array}{l}\text { HMN2B } \\
608634\end{array}$ & $7 \mathrm{q} 11.23$ & $\begin{array}{l}\text { HSPB1 } \\
602195\end{array}$ & $\begin{array}{l}\text { heat-shock } 27-\mathrm{kD} \\
\text { protein-1 }\end{array}$ & Evgrafov et al. (2004) & allelic to CMT2F (group 14) \\
\hline $\begin{array}{l}\text { Neuronopathy, distal hereditary } \\
\text { motor, type IIC }\end{array}$ & 12.17 & $\mathrm{AD}$ & $\begin{array}{l}\text { HMN2C } \\
613376\end{array}$ & $5 \mathrm{q} 11.2$ & $\begin{array}{l}\text { HSPB3 } \\
604624\end{array}$ & $\begin{array}{l}\text { heat shock } 27 \mathrm{kDa} \\
\text { protein } 3\end{array}$ & Kolb et al. (2010) & \\
\hline $\begin{array}{l}\text { Distal Spinal Muscular Atrophy } \\
\text { with Calf Predominance. }\end{array}$ & 12.18 & $\mathrm{AD}$ & $\begin{array}{l}\text { HMN2D } \\
615575\end{array}$ & $5 \mathrm{q} 32$ & $\begin{array}{l}\text { FВXO38 } \\
608533\end{array}$ & F-box protein 38 & Sumner et al. (2013) & \\
\hline $\begin{array}{l}\text { Distal spinal muscular atrophy, } \\
\text { distal with upper limb } \\
\text { predominance (type V) }\end{array}$ & 12.19 & $\mathrm{AD}$ & $\begin{array}{l}\text { HMN5A } \\
\text { (DSMAV) } \\
600794\end{array}$ & $7 \mathrm{p} 15$ & $\begin{array}{l}\boldsymbol{G} \boldsymbol{A R S} \\
600287\end{array}$ & $\begin{array}{l}\text { glycyl tRNA } \\
\text { synthetase }\end{array}$ & $\begin{array}{l}\text { Christodoulou et al. (1995), } \\
\text { Antonellis et al. (2003) }\end{array}$ & allelic to (CMT2D (group 14) \\
\hline $\begin{array}{l}\text { Distal spinal muscular atrophy } \\
\text { type V }\end{array}$ & 12.20 & $\mathrm{AD}$ & $\begin{array}{l}\text { HMN5A } \\
\text { (DSMAV) } \\
600794\end{array}$ & $11 \mathrm{q} 13$ & $\begin{array}{l}\text { BSCL2 } \\
606158\end{array}$ & seipin & Windpassinger et al. (2004) & allelic to SPG17 (group 15) \\
\hline $\begin{array}{l}\text { Distal spinal muscular atrophy, } \\
\text { type VB }\end{array}$ & 12.21 & $\mathrm{AD}$ & $\begin{array}{l}\text { HMNS5B } \\
\text { (DSMAVB) } \\
614751\end{array}$ & $2 \mathrm{p} 11.2$ & $\begin{array}{l}\text { REEP1 } \\
609139\end{array}$ & $\begin{array}{l}\text { Receptor accessory } \\
\text { protein } 1\end{array}$ & Beetz et al. (2012) & SPG 31 (group 15) \\
\hline $\begin{array}{l}\text { Dominant distal hereditary } \\
\text { motor neuropathy }\end{array}$ & 12.22 & $\mathrm{AD}$ & dHMN & $16 \mathrm{q} 22.1$ & $\begin{array}{l}\text { AARS } \\
601065\end{array}$ & $\begin{array}{l}\text { alanyl-tRNA } \\
\text { synthetase }\end{array}$ & Zhao et al. (2012) & Allelic to CMT2N (group 14) \\
\hline $\begin{array}{l}\text { Dominant distal hereditary } \\
\text { motor neuropathy }\end{array}$ & 12.23 & $\mathrm{AD}$ & dHMN & $14 \mathrm{q} 32.2$ & $\begin{array}{l}\text { WARS } \\
191050\end{array}$ & $\begin{array}{l}\text { tryptophanyl-tRNA } \\
\text { synthetase }\end{array}$ & Tsai et al. (2017) & \\
\hline $\begin{array}{l}\text { Spinal muscular atrophy, distal, } \\
\text { with vocal cord paralysis } \\
\text { (Harper-Young) }\end{array}$ & 12.24 & $\mathrm{AD}$ & $\begin{array}{l}\text { HMN7A } \\
158580\end{array}$ & $2 \mathrm{q} 12.31$ & $\begin{array}{l}S L C 5 A 7 \\
6008761\end{array}$ & $\begin{array}{l}\text { solute carrier } \\
\text { family } 5 \\
\text { (sodium/choline } \\
\text { cotransporter), } \\
\text { member } 7\end{array}$ & $\begin{array}{l}\text { McEntagart et al. (2001) } \\
\text { Barwick et al. (2012) }\end{array}$ & \\
\hline $\begin{array}{l}\text { Distal hereditary motor } \\
\text { neuronopathy type VIIB }\end{array}$ & 12.25 & $\mathrm{AD}$ & $\begin{array}{l}\text { HMN7B } \\
607641\end{array}$ & $2 \mathrm{p} 13$ & $\begin{array}{l}\text { DCTN1 } \\
601143\end{array}$ & dynactin 1 & Puls et al. (2003) & $\begin{array}{l}\text { Allelic to ALS related to } \\
\text { DNCT1 (group 12) }\end{array}$ \\
\hline $\begin{array}{l}\text { Hereditary motor and sensory } \\
\text { neuropathy } \mathrm{V}\end{array}$ & 12.26 & $\mathrm{AD}$ & $\begin{array}{l}\text { HMSN5 } \\
600361\end{array}$ & $4 q 34-q 35$ & $?$ & & Muglia et al. (2008) & \\
\hline $\begin{array}{l}\text { Spinal muscular atrophy } \\
\text { congenital non progressive of } \\
\text { lower limbs }\end{array}$ & 12.27 & $\mathrm{AD}$ & $\begin{array}{l}\text { SMAL } \\
600175\end{array}$ & $12 \mathrm{q} 24.1$ & $\begin{array}{l}\text { TRPV4 } \\
605427\end{array}$ & $\begin{array}{l}\text { transient receptor } \\
\text { potential cation } \\
\text { channel, subfamily } \\
\mathrm{V}, \text { member } 4\end{array}$ & $\begin{array}{l}\text { van der Vleuten et al. (1998) } \\
\text { Auer-Grumbach et al. (2010) } \\
\text { Deng et al. (2010) }\end{array}$ & $\begin{array}{l}\text { allelic to SPSMA (group 10) } \\
\text { allelic to CMT2C (group 14) }\end{array}$ \\
\hline Spinal motor neuropathy & 12.28 & & & $11 \mathrm{q} 23.2$ & $\begin{array}{l}\boldsymbol{R B M 7} \\
612413\end{array}$ & $\begin{array}{l}\text { RNA binding motif } \\
\text { protein } 7\end{array}$ & Giunta et al. (2016) & \\
\hline $\begin{array}{l}\text { Scapuloperoneal spinal } \\
\text { muscular atrophy }\end{array}$ & 12.29 & $\mathrm{AD}$ & $\begin{array}{l}\text { SPSMA } \\
181405\end{array}$ & $12 \mathrm{q} .24$ & $\begin{array}{l}\text { TRPV4 } \\
605427\end{array}$ & $\begin{array}{l}\text { transient receptor } \\
\text { potential cation } \\
\text { channel, subfamily } \\
\mathrm{V}, \text { member } 4\end{array}$ & $\begin{array}{l}\text { Isozumi et al. (1996) } \\
\text { Deng et al. (2010) }\end{array}$ & $\begin{array}{l}\text { allelic to SMAL (group 10), } \\
\text { CMT2C (group 14) }\end{array}$ \\
\hline $\begin{array}{l}\text { Spinal muscular atrophy, lower } \\
\text { extremity, autosomal dominant }\end{array}$ & 12.30 & $\mathrm{AD}$ & $\begin{array}{l}\text { SMALED } \\
158600\end{array}$ & $14 \mathrm{q} 32$ & $\begin{array}{l}\text { DYNC1H1 } \\
600112\end{array}$ & $\begin{array}{l}\text { dynein, cytoplasmic } \\
1 \text {, heavy chain } 1\end{array}$ & Harms et al. $(2010,2012)$ & $\mathrm{CMT} 2 \mathrm{O}$ \\
\hline $\begin{array}{l}\text { Spinal muscular atrophy, lower } \\
\text { extremity, autosomal dominant } \\
2\end{array}$ & 12.31 & $\mathrm{AD}$ & $\begin{array}{l}\text { SMALED2 } \\
615290\end{array}$ & $9 \mathrm{q} 22.31$ & $\begin{array}{l}\text { BICD2 } \\
609797\end{array}$ & $\begin{array}{l}\text { bicaudal D } \\
\text { homolog } 2 \\
\text { (Drosophila) }\end{array}$ & $\begin{array}{l}\text { Neveling et al. (2013) } \\
\text { Oates et al. (2013) } \\
\text { Peeters et al. (2013) }\end{array}$ & \\
\hline $\begin{array}{l}\text { Spinal muscular atrophy, } \\
\text { late-onset, Finkel type }\end{array}$ & 12.32 & $\mathrm{AD}$ & $\begin{array}{l}\text { SMAFK } \\
182980\end{array}$ & $20 \mathrm{q} 13$ & $\begin{array}{l}\text { VAP } \\
605704\end{array}$ & $\begin{array}{l}\text { vesicle-associated } \\
\text { membrane } \\
\text { protein-associated } \\
\text { protein B and C }\end{array}$ & Nishimura et al. (2004a) & See also ALS8 (group 12) \\
\hline $\begin{array}{l}\text { Late-onset spinal motor } \\
\text { neuronopathy, Jokela type }\end{array}$ & 12.33 & $\mathrm{AD}$ & $\begin{array}{l}\text { SMAJ } \\
615048\end{array}$ & $22 \mathrm{q} 11.2-\mathrm{q} 13.2$ & $\begin{array}{l}\text { CHCHD10 } \\
(=C 22 \text { orfl } 6) \\
615903\end{array}$ & $\begin{array}{l}\text { coiled-coil-helix-coil } \\
\text { coil-helix domain } \\
\text { containing } 10(\boldsymbol{M})\end{array}$ & $\begin{array}{l}\text { A-Muller et al. }(2014) \\
\text { Penttilä et al. }(2012,2015)\end{array}$ & $\begin{array}{l}\text { Allelic to FTDALS2 (group } \\
\text { 12) and Mitochondrial } \\
\text { myopathy (group 16) }\end{array}$ \\
\hline $\begin{array}{l}\text { Early onset spinal muscular } \\
\text { atrophy lower extremity, } \\
\text { autosomal dominant }\end{array}$ & 12.34 & $\mathrm{AD}$ & & $14 \mathrm{q}$ & $?$ & & Harms et al. 2010 & \\
\hline \multicolumn{9}{|c|}{ Distal spinal muscular atrophy, X-linked } \\
\hline $\begin{array}{l}\text { Spinal muscular atrophy, distal, } \\
\text { X-linked, related to UBAI }\end{array}$ & 12.35 & $\mathrm{XR}$ & $\begin{array}{l}\text { SMAX2 } \\
301830\end{array}$ & Xp11.23 & $\begin{array}{l}\boldsymbol{U B A 1} \\
(=U B E 1) \\
314370\end{array}$ & $\begin{array}{l}\text { ubiquitin-activating } \\
\text { enzyme } 1\end{array}$ & $\begin{array}{l}\text { Ramser et al. (2013) } \\
\text { Diamini et al. (2013) }\end{array}$ & \\
\hline $\begin{array}{l}\text { Spinal muscular atrophy, distal, } \\
\text { X-linked, related to ATPTA }\end{array}$ & 12.36 & $\mathrm{XR}$ & $\begin{array}{l}\text { SMAX3 } \\
300489\end{array}$ & $X q 13-q 21$ & $\begin{array}{r}A T P 7 A \\
300011\end{array}$ & $\begin{array}{l}\text { ATPase, } \mathrm{Cu}++ \\
\text { transporting, alpha } \\
\text { polypeptide }\end{array}$ & $\begin{array}{l}\text { Takata et al. (2004) } \\
\text { Kennerson et al. (2010) }\end{array}$ & \\
\hline \multicolumn{9}{|l|}{ Amyotrophic lateral sclerosis (ALS) } \\
\hline $\begin{array}{l}\text { Familial myotrophic lateral } \\
\text { sclerosis } 1 \text { (dominant) }\end{array}$ & 12.37 & $\mathrm{AD}$ & $\begin{array}{l}\text { ALS1 } \\
105400\end{array}$ & $21 \mathrm{q} 22$ & $\begin{array}{l}\text { SOD1 } \\
147450\end{array}$ & $\begin{array}{l}\mathrm{Cu} / \mathrm{Zn} \text { superoxide } \\
\text { dismutase }\end{array}$ & $\begin{array}{l}\text { Siddique et al. (1991, 1996) } \\
\text { Rosen et al. (1993) }\end{array}$ & \\
\hline $\begin{array}{l}\text { Familial amyotrophic lateral } \\
\text { sclerosis } 1 \text { (recessive) }\end{array}$ & 12.38 & AR & $\begin{array}{l}\text { ALS1 } \\
105400\end{array}$ & $21 \mathrm{q} 22$ & $\begin{array}{l}\text { SOD1 } \\
147450\end{array}$ & $\begin{array}{l}\mathrm{Cu} / \mathrm{Zn} \text { superoxide } \\
\text { dismutase }\end{array}$ & Andersen et al. (1995) & Allelic to IAHSP (group 15) \\
\hline
\end{tabular}




\begin{tabular}{|c|c|c|c|c|c|c|c|c|}
\hline DISEASE NAME & $\begin{array}{l}\text { Item } \\
\text { line } \\
\text { in this } \\
\text { group }\end{array}$ & Inheritance & $\begin{array}{l}\text { Locus or } \\
\text { disease } \\
\text { symbol and } \\
\text { OMIM } \\
\text { number } \\
\end{array}$ & Chromosome & $\begin{array}{l}\text { Gene symbol } \\
\text { and OMIM } \\
\text { number }\end{array}$ & $\begin{array}{l}\text { Protein } \\
\text { (mitochondrial } \\
\text { proteins indicated } \\
\text { by symbol }[M] \text { ) }\end{array}$ & $\begin{array}{l}\text { Key } \\
\text { references }\end{array}$ & $\begin{array}{l}\text { Other allelic disease(s) } \\
\text { (group in this table) }\end{array}$ \\
\hline $\begin{array}{l}\text { Amyotrophic lateral sclerosis } 2 \\
\text { juvenile }\end{array}$ & 12.39 & AR & $\begin{array}{l}\text { ALS2 } \\
205100\end{array}$ & $2 \mathrm{q} 33$ & $\begin{array}{l}A L S 2 \\
606352\end{array}$ & alsin & $\begin{array}{l}\text { Hentati et al. (1994a) } \\
\text { Yang et al. (2001) } \\
\text { Hadano et al. (2001) }\end{array}$ & \\
\hline Amyotrophic lateral sclerosis 3 & 12.40 & AR & $\begin{array}{l}\text { ALS3 } \\
606640\end{array}$ & $18 \mathrm{q} 21$ & $?$ & & Hand et al. (2002) & \\
\hline Amyotrophic lateral sclerosis 4 & 12.41 & $\mathrm{AD}$ & $\begin{array}{l}\text { ALS4 } \\
602433\end{array}$ & $9 \mathrm{q} 34$ & $\begin{array}{l}\text { SETX } \\
608465\end{array}$ & senataxin & $\begin{array}{l}\text { Chance et al. (1998) } \\
\text { Chen et al. (2004) } \\
\text { Moreira et al. (2004) }\end{array}$ & Allelic to AOA2 (group 13) \\
\hline Amyotrophic lateral sclerosis 5 & 12.42 & $\mathrm{AD}$ & $\begin{array}{l}\text { ALS5 } \\
602099\end{array}$ & $15 q 15-q 21$ & $?$ & & Hentati et al. (1998) & \\
\hline Amyotrophic lateral sclerosis 5 & 12.43 & AR & $\begin{array}{l}\text { ALS5 } \\
602099\end{array}$ & $5 \mathrm{q} 21.1$ & $\begin{array}{l}\text { SPG11 } \\
610844\end{array}$ & Spatacsin & Orlacchio et al. (2010) & $\begin{array}{l}\text { allelic to CMT2X (group 14), } \\
\text { SPG11 (group 15) }\end{array}$ \\
\hline Amyotrophic lateral sclerosis 6 & 12.44 & $\mathrm{AD}$ & $\begin{array}{l}\text { ALS6 } \\
608030\end{array}$ & $16 \mathrm{p} 11.2$ & $\begin{array}{l}\boldsymbol{F U S} \\
137070\end{array}$ & $\begin{array}{l}\text { fusion (involved in } \\
\mathrm{t}(12 ; 16) \text { in } \\
\text { malignant } \\
\text { liposarcoma) }\end{array}$ & $\begin{array}{l}\text { Sapp et al. (2003) } \\
\text { Abalkhail et al. (2003), } \\
\text { Kwiatkowski et al. (2009), } \\
\text { Vance et al. (2009) }\end{array}$ & \\
\hline Amyotrophic lateral sclerosis 7 & 12.45 & $\mathrm{AD}$ & $\begin{array}{l}\text { ALS7 } \\
608031\end{array}$ & $20 \mathrm{p} 13$ & $?$ & & Sapp et al. (2003) & \\
\hline Amyotrophic lateral sclerosis 8 & 12.46 & $\mathrm{AD}$ & $\begin{array}{l}\text { ALS8 } \\
608627\end{array}$ & $20 \mathrm{q} 13$ & $\begin{array}{l}\boldsymbol{V A P B} \\
605704\end{array}$ & $\begin{array}{l}\text { vesicle-associated } \\
\text { membrane } \\
\text { protein-associated } \\
\text { protein B and C }\end{array}$ & $\begin{array}{l}\text { Nishimura et al. (2004a, } \\
\text { 2004b) }\end{array}$ & \\
\hline Amyotrophic lateral sclerosis 9 & 12.47 & $\mathrm{AD}$ & $\begin{array}{l}\text { ALS9 } \\
611895\end{array}$ & $14 \mathrm{q} 11.2$ & $\begin{array}{l}A N G \\
105850\end{array}$ & angiogenin & $\begin{array}{l}\text { Greenway et al. (2006) } \\
\text { Wu et al. (2007) }\end{array}$ & \\
\hline $\begin{array}{l}\text { Amyotrophic lateral sclerosis } \\
10, \text { with or without } \\
\text { frontotemporal dementia }\end{array}$ & 12.48 & $\mathrm{AD}$ & $\begin{array}{l}\text { ALS10 } \\
612069\end{array}$ & $1 \mathrm{p} 36.2$ & $\begin{array}{l}\text { TARDBP } \\
605078\end{array}$ & $\begin{array}{l}\text { TAR DNA-binding } \\
\text { protein }\end{array}$ & Sreedharan et al. (2008) & \\
\hline $\begin{array}{l}\text { Amyotrophic lateral sclerosis } \\
11\end{array}$ & 12.49 & $\mathrm{AD}$ & $\begin{array}{l}\text { ALS11 } \\
612577\end{array}$ & $6 \mathrm{q} 21$ & $\begin{array}{l}\text { FIG4 } \\
(\boldsymbol{K I A A 0 2 7 4 )} \\
609390\end{array}$ & $\begin{array}{l}\text { Sac } \\
\text { domain-containing } \\
\text { inositol } \\
\text { phosphatase } 3\end{array}$ & Chow et al. (2009) & Allelic to CMT4J (group 14) \\
\hline $\begin{array}{l}\text { Amyotrophic lateral sclerosis } \\
12\end{array}$ & 12.50 & $\mathrm{AD} A \mathrm{AR}$ & $\begin{array}{l}\text { ALS12 } \\
613435\end{array}$ & $10 \mathrm{p} 14$ & $\begin{array}{l}\text { OPTN } \\
602432\end{array}$ & Optineurin & Maruyama et al. (2010) & \\
\hline $\begin{array}{l}\text { Amyotrophic lateral sclerosis } \\
13\end{array}$ & 12.51 & $\mathrm{AD}$ & $\begin{array}{l}\text { ALS13 } \\
183090\end{array}$ & $12 \mathrm{q} 24.12$ & $\begin{array}{l}A T X N 2 \\
601517\end{array}$ & Ataxin 2 & $\begin{array}{l}\text { Elden et al. (2010) } \\
\text { Daoud et al. (2011) } \\
\text { Van Damme et al. (2011) }\end{array}$ & $\begin{array}{l}\text { Allelic to spinocellular ataxia } \\
\text { (group 13) }\end{array}$ \\
\hline $\begin{array}{l}\text { Amyotrophic lateral sclerosis } \\
14 \text {, with or without } \\
\text { frontotemporal dementia }\end{array}$ & 12.52 & $\mathrm{AD}$ & $\begin{array}{l}\text { ALS14 } \\
613954\end{array}$ & $9 \mathrm{p} 13.3$ & $\begin{array}{l}\text { VCP } \\
601023\end{array}$ & $\begin{array}{l}\text { Valosin-containing } \\
\text { protein }\end{array}$ & Johnson et al. (2011) & $\begin{array}{l}\text { Allelic to \#1.42 and IBMPFD } \\
(\# 4.17, \# 5.22)\end{array}$ \\
\hline $\begin{array}{l}\text { Amyotrophic lateral sclerosis } \\
15 \text {, with or without } \\
\text { frontotemporal dementia }\end{array}$ & 12.53 & $\mathrm{XD}$ & $\begin{array}{l}\text { ALS15 } \\
300857\end{array}$ & Xp11.21 & $\begin{array}{l}\text { UBQLN2 } \\
300264\end{array}$ & Ubiquilin 2 & Deng et al. (2011) & \\
\hline $\begin{array}{l}\text { Amyotrophic lateral sclerosis } \\
16 \text {, juvenile }\end{array}$ & 12.54 & $\mathrm{AR}$ & $\begin{array}{l}\text { ALS16 } \\
614373\end{array}$ & $9 \mathrm{p} 13.3$ & $\begin{array}{l}\text { SIGMARI } \\
601978\end{array}$ & $\begin{array}{l}\text { sigma non-opioid } \\
\text { intracellular } \\
\text { receptor } 1\end{array}$ & Al-Saif et al. (2011) & Allelic to DSMA2 (group 12) \\
\hline $\begin{array}{l}\text { Amyotrophic lateral sclerosis } \\
17\end{array}$ & 12.55 & $\mathrm{AD}$ & $\begin{array}{l}\text { ALS17 } \\
614696\end{array}$ & $3 \mathrm{p} 11.2$ & $\begin{array}{l}\text { СНМР2B } \\
609512\end{array}$ & $\begin{array}{l}\text { charged } \\
\text { multivesicular body } \\
\text { protein 2B }\end{array}$ & $\begin{array}{l}\text { Parkinson et al. (2006) } \\
\text { Cox et al. (20010) }\end{array}$ & \\
\hline $\begin{array}{l}\text { Amyotrophic lateral sclerosis } \\
18\end{array}$ & 12.56 & $\mathrm{AD}$ & $\begin{array}{l}\text { ALS18 } \\
614808\end{array}$ & $17 \mathrm{p} 13.2$ & $\begin{array}{l}\text { PFN1 } \\
176610\end{array}$ & Profilin 1 & Wu et al. (2012) & \\
\hline $\begin{array}{l}\text { Amyotrophic lateral sclerosis } \\
19\end{array}$ & 12.57 & $\mathrm{AD}$ & $\begin{array}{l}\text { ALS19 } \\
615515\end{array}$ & $2 \mathrm{q} 34$ & $\begin{array}{l}\text { ERBB4 } \\
600543\end{array}$ & $\begin{array}{l}\text { V-ERB-B2 Avian } \\
\text { Erythroblastic } \\
\text { Leukemia Viral } \\
\text { Oncogene Homolog } \\
4\end{array}$ & Takahashi et al. (2013) & \\
\hline $\begin{array}{l}\text { Amyotrophic lateral sclerosis } \\
20\end{array}$ & 12.58 & $\mathrm{AD}$ & $\begin{array}{l}\text { ALS20 } \\
615426\end{array}$ & $12 \mathrm{q} 13.13$ & $\begin{array}{l}\text { HNRPA1 } \\
164017\end{array}$ & $\begin{array}{l}\text { heterogeneous } \\
\text { nuclear } \\
\text { ribonucleoprotein } \\
\text { A1 }\end{array}$ & Kim et al. (2013) & IBMPFD3 (group 3) \\
\hline $\begin{array}{l}\text { Familial amyotrophic lateral } \\
\text { sclerosis. }\end{array}$ & 12.59 & $\mathrm{AD}$ & $\begin{array}{l}\text { ALS21 } \\
606070\end{array}$ & $5 \mathrm{q} 31$ & $\begin{array}{l}\text { MATR3 } \\
164015\end{array}$ & Matrin 3 & Johnson et al. (2014) & Allelic to VCPDM (group 4) \\
\hline Amyotrophic lateral sclerosis 22 & 12.60 & $\mathrm{AD}$ & $\begin{array}{l}\text { ALS22 } \\
616208\end{array}$ & $2 q 35$ & $\begin{array}{l}\text { TUBA4A } \\
191110\end{array}$ & Tubulin, Alpha-4A & Smith et al. (2014) & \\
\hline $\begin{array}{l}\text { Susceptibility to amyotrophic } \\
\text { lateral sclerosis related to } \\
\text { NEFH }\end{array}$ & 12.61 & $\mathrm{AD}$ & $\begin{array}{l}\text { ALS1 } \\
105400\end{array}$ & $22 \mathrm{q} 12.2$ & $\begin{array}{l}\text { NEFH } \\
162230\end{array}$ & $\begin{array}{l}\text { Neurofilament, } \\
\text { heavy polypeptide }\end{array}$ & Al-Chalabie et al. (1999) & \\
\hline $\begin{array}{l}\text { Susceptibility to amyotrophic } \\
\text { lateral sclerosis related to } \\
\text { peripherin }\end{array}$ & 12.62 & $\mathrm{AD}$ & $\begin{array}{l}\text { ALS1 } \\
105400\end{array}$ & $12 \mathrm{q} 13.12$ & $\begin{array}{l}\text { PRPH } \\
170710\end{array}$ & Peripherin & $\begin{array}{l}\text { Gros-Louis et al. (2004), } \\
\text { Leung et al. (2004) }\end{array}$ & \\
\hline $\begin{array}{l}\text { Susceptibility to amyotrophic } \\
\text { lateral sclerosis related to } \\
\text { dynactin } 1\end{array}$ & 12.63 & $\mathrm{AD}$ & $\begin{array}{l}\text { ALS1 } \\
105400\end{array}$ & $2 \mathrm{p} 13.1$ & $\begin{array}{l}\text { DCTN1 } \\
601143\end{array}$ & Dynactin 1 & Munch et al. (2005) & Allelic to HMN7B (group 12) \\
\hline
\end{tabular}




\begin{tabular}{|c|c|c|c|c|c|c|c|c|}
\hline DISEASE NAME & $\begin{array}{l}\text { Item } \\
\text { line } \\
\text { in this } \\
\text { group }\end{array}$ & Inheritance & $\begin{array}{l}\text { Locus or } \\
\text { disease } \\
\text { symbol and } \\
\text { OMIM } \\
\text { number }\end{array}$ & Chromosome & $\begin{array}{l}\text { Gene symbol } \\
\text { and OMIM } \\
\text { number }\end{array}$ & $\begin{array}{l}\text { Protein } \\
\text { (mitochondrial } \\
\text { proteins indicated } \\
\text { by symbol }[M] \text { ) }\end{array}$ & $\begin{array}{l}\text { Key } \\
\text { references }\end{array}$ & $\begin{array}{l}\text { Other allelic disease(s) } \\
\text { (group in this table) }\end{array}$ \\
\hline $\begin{array}{l}\text { Amyotrophic lateral sclerosis } \\
\text { and/or frontotemporal dementia }\end{array}$ & 12.64 & $\mathrm{AD}$ & $\begin{array}{l}\text { FTDALS1 } \\
\text { (ALSFTD) } \\
105550\end{array}$ & $9 \mathrm{p} 21.2$ & $\begin{array}{l}\text { C9orf72 } \\
614260\end{array}$ & $\begin{array}{l}\text { chromosome } 9 \\
\text { open reading frame } \\
72\end{array}$ & $\begin{array}{l}\text { Morita et al. (2006) } \\
\text { DeJesus-Hernandez (2011) }\end{array}$ & \\
\hline $\begin{array}{l}\text { Amyotrophic lateral sclerosis } \\
\text { and/or frontotemporal dementia }\end{array}$ & 12.65 & $\mathrm{AD}$ & $\begin{array}{l}\text { FTDALS2 } \\
615911\end{array}$ & $22 \mathrm{q} 11$ & $\begin{array}{l}\text { CHCHD10 } \\
(=C 22 \text { orf16) } \\
615903\end{array}$ & $\begin{array}{l}\text { Coiled-coil-helix } \\
\text {-coiled-coil-helix } \\
\text { domain containing } \\
10(M)\end{array}$ & Bannwarth et al. (2014) & $\begin{array}{l}\text { Allelic to mitochondrial } \\
\text { myopathy (group 16) }\end{array}$ \\
\hline $\begin{array}{l}\text { Amyotrophic lateral sclerosis } \\
\text { and/or frontotemporal dementia }\end{array}$ & 12.66 & $\mathrm{AD}$ & $\begin{array}{l}\text { FTDALS3 } \\
66437\end{array}$ & $5 \mathrm{q} 35.3$ & $\begin{array}{l}\text { SQSTM1 } \\
601539\end{array}$ & Sequestosome 1 & Fecto et al. (2011) & \\
\hline \multicolumn{9}{|l|}{ Others } \\
\hline Kennedy disease & 12.67 & XR & $\begin{array}{l}\text { SBMA } \\
313200\end{array}$ & $\mathrm{Xq13}$ & $\begin{array}{l}\boldsymbol{A R} \\
313700\end{array}$ & androgen receptor & $\begin{array}{l}\text { Fishbeck et al. (1986) } \\
\text { La Spada et al. (1991) }\end{array}$ & \\
\hline $\begin{array}{l}\text { Lethal Congenital Contracture } \\
\text { Syndrome } 1\end{array}$ & 12.68 & AR & $\begin{array}{l}\text { LCCS1 } \\
253310\end{array}$ & $9 q 34$ & $\begin{array}{l}\text { GLE1 } \\
603371\end{array}$ & $\begin{array}{l}\text { GLE1 RNA export } \\
\text { mediator homolog } \\
\text { (yeast) }\end{array}$ & $\begin{array}{l}\text { Makela-Bengs et al. (1998) } \\
\text { Nousiainen et al. (2008) }\end{array}$ & \\
\hline $\begin{array}{l}\text { Lethal Congenital Contracture } \\
\text { Syndrome } 2\end{array}$ & 12.69 & AR & $\begin{array}{l}\text { LCCS2 } \\
607598\end{array}$ & $12 \mathrm{q} 13$ & $\begin{array}{l}\text { ERBB3 } \\
190151\end{array}$ & $\begin{array}{l}\text { v-erb-b2 } \\
\text { erythroblastic } \\
\text { leukemia viral } \\
\text { oncogene homolog } \\
3 \text { (avian) }\end{array}$ & Narkis et al. (2007) & \\
\hline $\begin{array}{l}\text { Lethal Congenital Contracture } \\
\text { Syndrome } 3\end{array}$ & 12.70 & AR & $\begin{array}{l}\text { LCCS3 } \\
611359\end{array}$ & $19 \mathrm{p} 13$ & $\begin{array}{l}\text { PIP5K1C } \\
606102\end{array}$ & $\begin{array}{l}\text { phosphatidylinositol- } \\
\text { 4-phosphate } \\
\text { 5-kinase, type I, } \\
\text { gamma }\end{array}$ & Narkis et al. (2007) & \\
\hline $\begin{array}{l}\text { Spinal muscular atrophy with } \\
\text { pontocerebellar hypoplasia, } \\
\text { type } 1 \mathrm{~b}\end{array}$ & 12.71 & AR & $\begin{array}{l}\text { PCH1B } \\
614678\end{array}$ & $9 \mathrm{p} 13.2$ & $\begin{array}{l}\text { EXOSC3 } \\
606489\end{array}$ & $\begin{array}{l}\text { exosome } \\
\text { component } 3\end{array}$ & $\begin{array}{l}\text { Rudnik-Schöneborn et al. } \\
\text { (2013) }\end{array}$ & \\
\hline $\begin{array}{l}\text { Spinal muscular atrophy with } \\
\text { or without pontocerebellar } \\
\text { hypoplasia }\end{array}$ & 12.72 & AR & $\begin{array}{l}\text { PCH1 } \\
607596\end{array}$ & $14 \mathrm{q} 32$ & $\begin{array}{l}\text { VRK1 } \\
602168\end{array}$ & $\begin{array}{l}\text { Vaccinia-related } \\
\text { kinase } 1\end{array}$ & $\begin{array}{l}\text { Renbaum et al. (2009) } \\
\text { Stoll et al. (2016) }\end{array}$ & \\
\hline $\begin{array}{l}\text { Pontocerebellar hypoplasia with } \\
\text { spinal muscular atrophy }\end{array}$ & 12.73 & AR & $\begin{array}{l}\text { HSMN6B } \\
616505\end{array}$ & $5 \mathrm{q} 22.1$ & $\begin{array}{l}\text { SLC25A46 } \\
610826\end{array}$ & $\begin{array}{l}\text { Solute Carrier Family } \\
25 \text {, Member } 46\end{array}$ & van Dijk et al. (2017) & \\
\hline $\begin{array}{l}\text { Brown-Vialetto-van Laere } \\
\text { syndrome } 1\end{array}$ & 12.74 & AR & $\begin{array}{l}\text { BVVLS1 } \\
211530\end{array}$ & $20 \mathrm{p} 13$ & $\begin{array}{l}\text { SLC52A3 } \\
613350\end{array}$ & $\begin{array}{l}\text { Solute carrier } \\
\text { family } 52 \text {, riboflavin } \\
\text { transporter, member } \\
3\end{array}$ & $\begin{array}{l}\text { Green et al. (2010) } \\
\text { Bosch et al. (2011) } \\
\text { Johnson et al. (2010) }\end{array}$ & \\
\hline $\begin{array}{l}\text { Brown-Vialetto-van Laere } \\
\text { syndrome } 2\end{array}$ & 12.75 & AR & $\begin{array}{l}\text { BVVLS2 } \\
614707\end{array}$ & $8 \mathrm{q} 24$ & $\begin{array}{l}S L C 52 A 2 \\
607882\end{array}$ & $\begin{array}{l}\text { Solute carrier } \\
\text { family } 52 \text {, riboflavin } \\
\text { transporter, member } \\
2\end{array}$ & $\begin{array}{l}\text { Green et al. (2010) } \\
\text { Bosch et al. (2011) } \\
\text { Johnson et al. (2012) }\end{array}$ & \\
\hline $\begin{array}{l}\text { Late onset spinal muscular } \\
\text { atrophy related to } H E X B\end{array}$ & 12.76 & $\mathrm{AD}$ & & $5 \mathrm{q} 13.3$ & $\begin{array}{l}\text { HEXB } \\
606873\end{array}$ & hexosaminidase B & Rattay et al. (2013) & $\begin{array}{l}\text { Sandhoff disease, adult type } \\
\text { (OMIM \#268800) }\end{array}$ \\
\hline
\end{tabular}

GROUP 13. HEREDITARY ATAXIAS See online version of the gene table at $\mathrm{http}: / /$ musclegenetable.fr

\section{GROUP 14. HEREDITARY MOTOR SENSORY NEUROPATHIES (HMSN)}

A. Charcot-Marie-Tooth neuropathy, type I (demyelinating)

Autosomal dominant (AD-CMT1)

Type $1 \mathrm{~A}$

CMT1A

$17 \mathrm{p} 11.2$

PMP22

601097

Type 1B

CMT1B

118200

$1 \mathrm{q} 22$

$M P Z$

159440

Type $1 \mathrm{C}$

Type 1D

14.3 AD

14.4 $\mathrm{AD}$

CMT1C

601098

CMT1D

$16 \mathrm{p} 13$

LITAF

607678

$10 \mathrm{q} 21.1$

603795

Type 1E (with deafness)

Hereditary Neuropathy with

$14.5 \quad \mathrm{AD}$

CMT1E

118300

HNPP

$17 \mathrm{p} 11.2$

PMP22

14.6 $\mathrm{AD}$

162500

$\begin{array}{ll}17 \mathrm{p} 11.2 & 601097 \\ & \text { PMP22 }\end{array}$

Liability to Pressure Palsies

601097 peripheral myelin

protein 22

Vance et al. (1989)

Patel et al. (1992)

Matsunami et al. (1992);

Timmerman et al. (1990,

1992); Valentijn et al. (1992)

Roa et al. (1993a)

Bird et al. (1982)

Guiloff et al. (1982)

Hayasaka et al. (1993a)

Kulkens et al. (1993)

Street et al. $(2002,2003)$

Warner et al. (1998), Street

induced TNF factor

early growth

response 2 (Krox-20

homolog)

peripheral myelin

protein 22

peripheral myelin

protein P22 et al. (2003)

Kovach et al. (1999);

Boerkoel et al. (2002)

Chance et al. (1993)

Nicholson et al. (1994)

Mariman et al. (1994) allelic to CMT1E (group14), HNPP (group14), DSS (group14)

allelic to CMT2I (group14), CMT2J (group14), DSS (group14), CMT4E (group14)

allelic to CMT4E (group 14), DSS (group 14)

allelic to CMT1A (group 14), DSS (group14) allelic to CMT1A (group 14)

CMT1E (group 14), HNPP (group 14), DSS (group 14) (continued on next page) 


\begin{tabular}{|c|c|c|c|c|c|c|c|c|}
\hline DISEASE NAME & $\begin{array}{l}\text { Item } \\
\text { line } \\
\text { in this } \\
\text { group }\end{array}$ & Inheritance & $\begin{array}{l}\text { Locus or } \\
\text { disease } \\
\text { symbol and } \\
\text { OMIM } \\
\text { number }\end{array}$ & Chromosome & $\begin{array}{l}\text { Gene symbol } \\
\text { and OMIM } \\
\text { number }\end{array}$ & $\begin{array}{l}\text { Protein } \\
\text { (mitochondrial } \\
\text { proteins indicated } \\
\text { by symbol }[M] \text { ) }\end{array}$ & $\begin{array}{l}\text { Key } \\
\text { references }\end{array}$ & $\begin{array}{l}\text { Other allelic disease(s) } \\
\text { (group in this table) }\end{array}$ \\
\hline Type 1F & 14.7 & $\mathrm{AD}$ & $\begin{array}{l}\text { CMT1F } \\
607734\end{array}$ & $8 \mathrm{p} 21$ & $\begin{array}{l}\text { NEFL } \\
162280\end{array}$ & $\begin{array}{l}\text { neurofilament, light } \\
\text { polypeptide } 68 \mathrm{kDa}\end{array}$ & Jordanova et al. (2003) & allelic to CMT2E (group14) \\
\hline $\begin{array}{l}\text { CMT with congenital vertical } \\
\text { talus }\end{array}$ & 14.8 & $\mathrm{AD}$ & $\begin{array}{l}\text { CVT } \\
192950\end{array}$ & $2 q 31-q 32$ & $\begin{array}{l}\text { HOXD10 } \\
(H O X 4) \\
142984\end{array}$ & homeobox D10 & Shrimpton et al. (2004) & \\
\hline $\begin{array}{l}\text { Slowed nerve conduction } \\
\text { velocity }\end{array}$ & 14.9 & $\mathrm{AD}$ & $\begin{array}{l}\text { NCV } \\
608236\end{array}$ & $8 \mathrm{p} 23$ & $\begin{array}{l}\text { ARHGEF10 } \\
608136\end{array}$ & $\begin{array}{l}\text { Rho } \\
\text { guanine-nucleotide } \\
\text { exchange factor-10 }\end{array}$ & $\begin{array}{l}\text { De Jonghe, et al. (1999) } \\
\text { Verhoeven, et al. (2003) }\end{array}$ & \\
\hline $\begin{array}{l}\text { Neuropathy, hereditary, with or } \\
\text { without age-related macular } \\
\text { degeneration }\end{array}$ & 14.10 & $\mathrm{AD}$ & $\begin{array}{l}\text { HNARMD } \\
608895\end{array}$ & $14 \mathrm{q} 32.12$ & $\begin{array}{l}\text { FBLN5 } \\
604580\end{array}$ & Fibulin 5 & Auer-Grumbach et al. (2011) & \\
\hline CMT1 related to $P M P 2$ & 14.11 & $\mathrm{AD}$ & CMTDI & $8 \mathrm{q} 21.13$ & $\begin{array}{l}P M P 2 \\
170715\end{array}$ & $\begin{array}{l}\text { Peripheral Myelin } \\
\text { Protein } 2\end{array}$ & Hong et al. (2016) & \\
\hline \multicolumn{9}{|l|}{ Dominant intermediate (CMTDI) } \\
\hline Type A & 14.12 & $\mathrm{AD}$ & $\begin{array}{l}\text { CMTDIA } \\
606483\end{array}$ & $10 \mathrm{q} 24.1-\mathrm{q} 25.1$ & $?$ & & Verhoeven et al. (2001) & \\
\hline Type B & 14.13 & $\mathrm{AD}$ & $\begin{array}{l}\text { CMTDIB } \\
606482\end{array}$ & $19 \mathrm{p} 12-13.2$ & $\begin{array}{l}\text { DNM2 } \\
602378\end{array}$ & dynamin 2 & Zuchner et al. (2005) & $\begin{array}{l}\text { allelic to CNM (group 3) and } \\
\mathrm{CM} \text { (group 2) }\end{array}$ \\
\hline Type C & 14.14 & $\mathrm{AD}$ & $\begin{array}{l}\text { CMTDIC } \\
608323\end{array}$ & $1 \mathrm{p} 35$ & $\begin{array}{l}\text { YARS } \\
603623\end{array}$ & $\begin{array}{l}\text { tyrosyl-tRNA } \\
\text { synthetase }\end{array}$ & $\begin{array}{l}\text { Jordanova et al. (2003, } \\
2006)\end{array}$ & \\
\hline Type D & 14.15 & $\mathrm{AD}$ & $\begin{array}{l}\text { CMTDID } \\
607791\end{array}$ & $1 \mathrm{q} 22$ & $\begin{array}{l}M P Z \\
159440\end{array}$ & myelin protein zero & Mastaglia et al. (1999) & $\begin{array}{l}\text { allelic to CMT1B, CMT4E, } \\
\text { CMT2I, CMT2J, DSS (group } \\
\text { 14) }\end{array}$ \\
\hline Type E with glomerulopathy & 14.16 & $\mathrm{AD}$ & $\begin{array}{l}\text { CMTDIE } \\
614455\end{array}$ & $14 q 32-33$ & $\begin{array}{l}\text { INF2 } \\
610982\end{array}$ & Inverted formin 2 & Boyer et al. (2011) & \\
\hline Type F & 14.17 & $\mathrm{AD}$ & $\begin{array}{l}\text { CMTDIF } \\
615185\end{array}$ & $3 q 28-q 29$ & $\begin{array}{l}\boldsymbol{G N B 4} \\
610863\end{array}$ & $\begin{array}{l}\text { guanine } \\
\text { nucleotide-binding } \\
\text { protein, beta-4 }\end{array}$ & Soong et al. (2013) & \\
\hline \multicolumn{9}{|c|}{ Autosomal recessive (AR-CMT1 or CMT4) } \\
\hline CMT, type $4 \mathrm{~A}$ & 14.18 & AR & $\begin{array}{l}\text { CMT4A } \\
(=\mathrm{CMT} 2 \mathrm{H}) \\
214400\end{array}$ & $8 \mathrm{q} 13-\mathrm{q} 21$ & $\begin{array}{l}\boldsymbol{G D A P 1} \\
606598\end{array}$ & $\begin{array}{l}\text { ganglioside induced } \\
\text { differentiation } \\
\text { associated protein } 1 \\
\text { (connexin 32) }\end{array}$ & $\begin{array}{l}\text { Ben Othmane et al. (1993b) } \\
\text { Baxter et al. (2002) } \\
\text { Cuesta et al. (2002) } \\
\text { Nelis et al. (2002) }\end{array}$ & $\begin{array}{l}\text { allelic to CMT2K and } \\
\text { Autosomal recessive CMT2C } \\
\text { (group 14) }\end{array}$ \\
\hline CMT, type 4B1 & 14.19 & AR & $\begin{array}{l}\text { CMT4B1 } \\
601382\end{array}$ & $11 \mathrm{q} 22$ & $\begin{array}{l}\text { MTMR2 } \\
603557\end{array}$ & $\begin{array}{l}\text { myotubularin-related } \\
\text { protein-2 }\end{array}$ & $\begin{array}{l}\text { Bolino et al. }(1996,2000) \\
\text { Previtali et al. }(2003)\end{array}$ & \\
\hline CMT, type 4B2 & 14.20 & AR & $\begin{array}{l}\text { CMT4B2 } \\
604563\end{array}$ & $11 \mathrm{p} 15$ & $\begin{array}{l}\text { SBF2 } \\
(=\mathrm{MTMR} 13) \\
607697\end{array}$ & $\begin{array}{l}\text { SET binding factor } \\
2\end{array}$ & $\begin{array}{l}\text { Azzedine et al (2003); } \\
\text { Senderek et al. (2004) }\end{array}$ & \\
\hline CMT, type 4B3 & 14.21 & AR & $\begin{array}{l}\text { CMT4B3 } \\
615284\end{array}$ & $22 \mathrm{q} 13.33$ & $\begin{array}{l}\text { SBF1 } \\
(=\text { MTMR5) } \\
603560\end{array}$ & $\begin{array}{l}\text { SET binding factor } \\
1\end{array}$ & Nakhro et al. (2013) & \\
\hline CMT, type $4 \mathrm{C}$ & 14.22 & AR & $\begin{array}{l}\text { CMT4C } \\
601596\end{array}$ & $5 q 32$ & $\begin{array}{l}\text { SH3TC2 } \\
608206 \\
(\text { ex-KIAA1985) }\end{array}$ & $\begin{array}{l}\mathrm{SH} 3 \text { domain and } \\
\text { tetratricopeptide } \\
\text { repeats } 2\end{array}$ & $\begin{array}{l}\text { LeGuern et al. (1996), } \\
\text { Senderek et al. (2003) }\end{array}$ & \\
\hline CMT, type 4D & 14.23 & AR & $\begin{array}{l}\text { CMT4D } \\
\text { (HMNSL) } \\
601455\end{array}$ & $8 \mathrm{q} 24$ & $\begin{array}{l}\text { NDRG1 } \\
605262\end{array}$ & $\begin{array}{l}\text { Nmyc downstream } \\
\text { regulated gene } 1\end{array}$ & $\begin{array}{l}\text { Kalaydjieva et al. (1996, } \\
2000) \\
\text { Hunter et al. (2003) }\end{array}$ & Allelic to HMNSL (group 14) \\
\hline $\begin{array}{l}\text { CMT, type } 4 \mathrm{E} \text { (congenital } \\
\text { hypomyelinating myopathy) }\end{array}$ & 14.24 & $\mathrm{AR}$ & $\begin{array}{l}\text { CMT4E } \\
605253\end{array}$ & $10 \mathrm{q} 21.1$ & $\begin{array}{l}\text { EGR2 } \\
129010\end{array}$ & $\begin{array}{l}\text { early growth } \\
\text { response } 2 \\
\text { (Krox-20 homolog) }\end{array}$ & Warner et al. (1998) & allelic to CMT1D (group 14) \\
\hline $\begin{array}{l}\text { CMT, type } 4 \mathrm{E} \text { (congenital } \\
\text { hypomyelinating myopathy) }\end{array}$ & 14.25 & AR & $\begin{array}{l}\text { CMT4E } \\
605253\end{array}$ & $1 \mathrm{q} 22$ & $\begin{array}{l}M P Z \\
159440\end{array}$ & myelin protein zero & Warner et al. (1996) & $\begin{array}{l}\text { allelic to CMT1B (group 14), } \\
\text { CMT2I (group 14), CMT2J } \\
\text { (group 14), DSS (group 14) }\end{array}$ \\
\hline CMT, type $4 \mathrm{~F}$ & 14.26 & AR & $\begin{array}{l}\text { CMT4F } \\
145900\end{array}$ & $19 q 13$ & $\begin{array}{l}P R X \\
605725\end{array}$ & periaxin & $\begin{array}{l}\text { Delague et al. (2000) } \\
\text { Guilbot et al. (2001) }\end{array}$ & allelic to DSSE (group14) \\
\hline CMT, type 4G (type Russe) & 14.27 & $\mathrm{AR}$ & $\begin{array}{l}\text { CMT4G } \\
605285\end{array}$ & $10 \mathrm{q} 22$ & $\begin{array}{l}\text { HK1 } \\
142600\end{array}$ & Hexokinase 1 & $\begin{array}{l}\text { Rogers et al. (2000) } \\
\text { Thomas et al. (2001) } \\
\text { Hantke et al. (2009) } \\
\text { Sevilla et al. (2013) }\end{array}$ & \\
\hline CMT, type $4 \mathrm{H}$ & 14.28 & $\mathrm{AR}$ & $\begin{array}{l}\text { CMT4H } \\
609311\end{array}$ & $12 \mathrm{p} 11.21$ & $\begin{array}{l}\text { FGD4 } \\
611104\end{array}$ & frabin & $\begin{array}{l}\text { De Sandre-Giovannoli et al. } \\
\text { (2005) } \\
\text { Delague et al. (2007) } \\
\text { Stendel et al. (2007) }\end{array}$ & \\
\hline CMT, type 4J & 14.29 & AR & $\begin{array}{l}\text { CMT4J } \\
611228\end{array}$ & $6 \mathrm{q} 21$ & $\begin{array}{l}\text { FIG4 } \\
(=\text { KIAA0274) } \\
609390\end{array}$ & $\begin{array}{l}\text { Sac } \\
\text { domain-containing } \\
\text { inositol } \\
\text { phosphatase } 3\end{array}$ & Chow et al. (2007) & Allelic to ALS 11 (group 12) \\
\hline CMT, type $4 \mathrm{~K}$ & 14.30 & AR & CMT4K & $9 \mathrm{q} 34.2$ & $\begin{array}{l}\text { SURF1 } \\
185620\end{array}$ & surfeit $1[\mathbf{M}]$ & Echaniz-Laguna et al. (2013) & \\
\hline
\end{tabular}




\begin{tabular}{|c|c|c|c|c|c|c|c|c|}
\hline DISEASE NAME & $\begin{array}{l}\text { Item } \\
\text { line } \\
\text { in this } \\
\text { group }\end{array}$ & Inheritance & $\begin{array}{l}\text { Locus or } \\
\text { disease } \\
\text { symbol and } \\
\text { OMIM } \\
\text { number }\end{array}$ & Chromosome & $\begin{array}{l}\text { Gene symbol } \\
\text { and OMIM } \\
\text { number }\end{array}$ & $\begin{array}{l}\text { Protein } \\
\text { (mitochondrial } \\
\text { proteins indicated } \\
\text { by symbol }[M] \text { ) }\end{array}$ & $\begin{array}{l}\text { Key } \\
\text { references }\end{array}$ & $\begin{array}{l}\text { Other allelic disease(s) } \\
\text { (group in this table) }\end{array}$ \\
\hline \multicolumn{9}{|l|}{ X-linked CMT1 } \\
\hline CMT1, X-linked 1 & 14.31 & $\mathrm{XD}$ & $\begin{array}{l}\text { CMTX1 } \\
302800\end{array}$ & $\mathrm{Xq13}$ & $\begin{array}{l}\text { GJB1 } \\
304040\end{array}$ & $\begin{array}{l}\text { gap junction } \\
\text { protein, beta } 1 \text {, } \\
32 \mathrm{kDa} \text { (connexin } \\
\text { 32) }\end{array}$ & $\begin{array}{l}\text { Bergoffen et al. (1993) } \\
\text { Bone et al. (1995) }\end{array}$ & allelic to DSS (group 14) \\
\hline CMT1, X-linked 2 & 14.32 & $\mathrm{XR}$ & $\begin{array}{l}\text { СMTX2 } \\
302801\end{array}$ & $\mathrm{Xp} 22.2$ & $?$ & & Ionasecu et al. (1992) & \\
\hline CMT1, X-linked 3 & 14.33 & $\mathrm{XR}$ & $\begin{array}{l}\text { CMTX3 } \\
302802\end{array}$ & $\mathrm{Xq} 26$ & $\begin{array}{l}78 \text { kb Chro8 } \\
\text { insertion }\end{array}$ & $\begin{array}{l}78 \mathrm{~kb} \\
\text { inter-chromosomal } \\
\text { insertion (from } \\
\text { chro } 8 \mathrm{q} 24.3 \text { ) }\end{array}$ & $\begin{array}{l}\text { Ionasecu et al. (1992) } \\
\text { Huttner et al. (2006) } \\
\text { Brewer et al. (2016) }\end{array}$ & \\
\hline $\begin{array}{l}\text { CMT1, X-linked } 4 \text { (Cowchock } \\
\text { syndrome) }\end{array}$ & 14.34 & $\mathrm{XR}$ & $\begin{array}{l}\text { CMTX4 } \\
310490\end{array}$ & $\mathrm{Xq} 24-\mathrm{q} 26$ & $\begin{array}{l}\text { AIFM1 } \\
300169\end{array}$ & $\begin{array}{l}\text { Apoptosis-inducing } \\
\text { factor, } \\
\text { mitochondrion- } \\
\text { associated, } 1 \text { [M] }\end{array}$ & $\begin{array}{l}\text { Priest et al. (1995) } \\
\text { Rinaldi et al. (2012) }\end{array}$ & \\
\hline $\begin{array}{l}\text { CMT1, X-linked } 5 \text { (with } \\
\text { hearing loss and optic } \\
\text { neuropathy) }\end{array}$ & 14.35 & $\mathrm{XR}$ & $\begin{array}{l}\text { CMTX5 } \\
311070\end{array}$ & $\mathrm{Xq} 22-\mathrm{q} 24$ & $\begin{array}{l}\text { PRPS1 } \\
311850\end{array}$ & $\begin{array}{l}\text { phosphoribosyl } \\
\text { pyrophosphate } \\
\text { synthetase } 1\end{array}$ & Kim et al (2007) & \\
\hline CMT1, X-linked 6 & 14.36 & $\mathrm{XD}$ & $\begin{array}{l}\text { CMTX6 } \\
300905\end{array}$ & $\mathrm{Xp} 22.11$ & $\begin{array}{l}\text { PDK3 } \\
300906\end{array}$ & $\begin{array}{l}\text { Pyruvate } \\
\text { dehydrogenase } \\
\text { kinase, isoenzyme } \\
3\end{array}$ & Kennerson et al. (2013) & \\
\hline \multicolumn{9}{|c|}{ Dejerine-Sottas syndrome (DSS or CMT3) } \\
\hline $\begin{array}{l}\text { Dejerine-Sottas hypertrophic } \\
\text { neuropathy, dominant }\end{array}$ & 14.37 & $\mathrm{AD}$ & $\begin{array}{l}\text { DSSA } \\
145900\end{array}$ & $17 \mathrm{p} 11.2$ & $\begin{array}{l}P M P 22 \\
601097\end{array}$ & $\begin{array}{l}\text { peripheral myelin } \\
\text { protein } 22\end{array}$ & Roa et al. (1993b) & $\begin{array}{l}\text { allelic to CMT1A (group 14) } \\
\text { CMT1E (group 14), HNPP } \\
\text { (group 14) }\end{array}$ \\
\hline $\begin{array}{l}\text { Dejerine-Sottas hypertrophic } \\
\text { neuropathy, dominant }\end{array}$ & 14.38 & $\mathrm{AD}$ & $\begin{array}{l}\text { DSSB } \\
145900\end{array}$ & $1 \mathrm{q} 21-\mathrm{q} 23$ & $\begin{array}{l}M P Z \\
159440\end{array}$ & myelin protein zero & Hayasaka et al. (1993b) & $\begin{array}{l}\text { allelic to CMT1B (group 14), } \\
\text { CMT2I (group 14), CMT2J } \\
\text { (group 14), CMT4E (group 14) }\end{array}$ \\
\hline $\begin{array}{l}\text { Dejerine-Sottas hypertrophic } \\
\text { neuropathy, dominant }\end{array}$ & 14.39 & $\begin{array}{l}\mathrm{AD} \\
\text { (digenic) }\end{array}$ & $\begin{array}{l}\text { DSSC } \\
145900\end{array}$ & $\begin{array}{l}10 \mathrm{q} 21 . \\
\mathrm{Xq} 13\end{array}$ & $\begin{array}{l}\text { EGR2 } \\
129010 \\
\text { and } \\
\text { GJB1 } \\
304040\end{array}$ & $\begin{array}{l}\text { early growth } \\
\text { response } 2 \\
\text { (Krox-20 homolog) } \\
\text { and gap junction } \\
\text { protein, beta 1, 32k } \\
\text { Da (connexin 32) }\end{array}$ & Chung et al. (2005) & allelic to CMTX1 (group 14) \\
\hline $\begin{array}{l}\text { Dejerine-Sottas hypertrophic } \\
\text { neuropathy, recessive }\end{array}$ & 14.40 & AR & $\begin{array}{l}\begin{array}{l}\text { DSSE } \\
(=\mathrm{CMT} 4 \mathrm{~F})\end{array} \\
145900\end{array}$ & $19 \mathrm{q} 13$ & $\begin{array}{l}\boldsymbol{P R X} \\
605725\end{array}$ & periaxin & $\begin{array}{l}\text { Delague et al. (2000); } \\
\text { Boerkoel et al. (2001) }\end{array}$ & allelic to CMT4F (group 14) \\
\hline \multicolumn{9}{|c|}{ B. Charcot-Marie-Tooth neuropathy, type 2 (axonal) $=C M T 2$ autosomal dominant } \\
\hline Type $2 \mathrm{~A} 1$ & 14.41 & $\mathrm{AD}$ & $\begin{array}{l}\text { CMT2A1 } \\
118210\end{array}$ & $1 \mathrm{p} 36.2$ & $\begin{array}{l}\text { KIF1B } \\
605995\end{array}$ & $\begin{array}{l}\text { kinesin family } \\
\text { member } 1 \mathrm{~B}\end{array}$ & Zhao, C. et al. (2001a) & \\
\hline Type $2 \mathrm{~A} 2$ & 14.42 & $\mathrm{AD}$ & $\begin{array}{l}\text { CMT2A2A } \\
609260\end{array}$ & $1 \mathrm{p} 36.2$ & $\begin{array}{l}\text { MFN2 } \\
608507\end{array}$ & mitofusin 2 & $\begin{array}{l}\text { Ben Othmane et al. (1993a) } \\
\text { Züchner, et al. (2004) }\end{array}$ & \\
\hline Type 2B & 14.43 & $\mathrm{AD}$ & $\begin{array}{l}\text { СMT2B } \\
600882\end{array}$ & $3 q 21$ & $\begin{array}{l}\boldsymbol{R A B 7} \\
602298\end{array}$ & $\begin{array}{l}\text { RAB7, member of } \\
\text { RAS oncogene } \\
\text { family) }\end{array}$ & $\begin{array}{l}\text { Kwon et al. (1995) } \\
\text { Pericak-Vance et al. (1997) } \\
\text { Kok et al. (2003) }\end{array}$ & \\
\hline Type $2 \mathrm{C}$ & 14.44 & $\mathrm{AD}$ & $\begin{array}{l}\text { СМT2C } \\
606071\end{array}$ & $12 \mathrm{q} 23-\mathrm{q} 24$ & $\begin{array}{l}\text { TRPV4 } \\
600175\end{array}$ & $\begin{array}{l}\text { transient receptor } \\
\text { potential cation } \\
\text { channel, subfamily } \\
\mathrm{V} \text {, member } 4\end{array}$ & $\begin{array}{l}\text { Klein et al. (2003) } \\
\text { McEntagart et al. (2005) } \\
\text { Auer-Grumbach et al. (2010) } \\
\text { Deng et al. (2010) } \\
\text { Landoure et al. (2010) }\end{array}$ & \\
\hline Type 2D & 14.45 & $\mathrm{AD}$ & $\begin{array}{l}\text { CMT2D } \\
601472\end{array}$ & $7 \mathrm{p} 15$ & $\begin{array}{l}\text { GARS } \\
600287\end{array}$ & $\begin{array}{l}\text { glycyl tRNA } \\
\text { synthetase }\end{array}$ & $\begin{array}{l}\text { Ionasescu et al. (1996) } \\
\text { Antonellis et al. (2003) }\end{array}$ & allelic to DSMAV (group12) \\
\hline Type $2 \mathrm{E}$ & 14.46 & $\mathrm{AD}$ & $\begin{array}{l}\text { CMT2E } \\
607684\end{array}$ & $8 \mathrm{p} 21$ & $\begin{array}{l}\text { NEFL } \\
162280\end{array}$ & $\begin{array}{l}\text { neurofilament, light } \\
\text { polypeptide } 68 \mathrm{kDa}\end{array}$ & $\begin{array}{l}\text { Birouk et al. (2003) } \\
\text { Claramunt et al. (2005) }\end{array}$ & $\begin{array}{l}\text { allelic to SMAL and SPSMA } \\
\text { (group 12) }\end{array}$ \\
\hline Type $2 \mathrm{~F}$ & 14.47 & $\mathrm{AD}$ & $\begin{array}{l}\text { CMT2F } \\
606595\end{array}$ & $7 q 11-q 21$ & $\begin{array}{l}\boldsymbol{H S P B 1} \\
602195\end{array}$ & $\begin{array}{l}\text { heat-shock } 27-\mathrm{kD} \\
\text { protein-1 }\end{array}$ & $\begin{array}{l}\text { Ismailov et al. (2001) } \\
\text { Evgrafov et al. (2004) }\end{array}$ & \\
\hline Type $2 \mathrm{G}$ & 14.48 & $\mathrm{AD}$ & $\begin{array}{l}\text { CMT2G } \\
608591\end{array}$ & $12 \mathrm{q} 12-\mathrm{q} 13$ & $?$ & $?$ & Nelis et al. (2004) & \\
\hline Type $2 \mathrm{H}$ & 14.49 & $\mathrm{AD}$ & $\begin{array}{l}\text { СMT2H } \\
607731\end{array}$ & $8 \mathrm{q} 21.3$ & $?$ & $?$ & Barhoumi et al. (2001) & $\begin{array}{l}\text { maybe allelic to CMT4A } \\
\text { (group14) }\end{array}$ \\
\hline Type 2I (late onset) & 14.50 & $\mathrm{AD}$ & $\begin{array}{l}\text { CMT2I } \\
607677\end{array}$ & $1 \mathrm{q} 22$ & $\begin{array}{l}M P Z \\
159440\end{array}$ & myelin protein zero & Auer-Grumbach et al. (2003) & $\begin{array}{l}\text { allelic to CMT1B (group 1), } \\
\text { CMT2J (group 14), DSS } \\
\text { (group 14), CMT4E (group 14) }\end{array}$ \\
\hline $\begin{array}{l}\text { Type } 2 \mathrm{~J} \text { (with hearing loss and } \\
\text { pupillary abnormality) }\end{array}$ & 14.51 & $\mathrm{AD}$ & $\begin{array}{l}\text { CMT2J } \\
607736\end{array}$ & $1 \mathrm{q} 22$ & $\begin{array}{l}M P Z \\
159440\end{array}$ & myelin protein zero & $\begin{array}{l}\text { De Jonghe et al. (1999) } \\
\text { Chapon et al. (1999) }\end{array}$ & $\begin{array}{l}\text { allelic to CMT1B (group 14), } \\
\text { CMT2J (group 14), DSS } \\
\text { (group 14), CMT4E (group 14) }\end{array}$ \\
\hline Type $2 \mathrm{~K}$ & 14.52 & $\mathrm{AD}, \mathrm{AR}$ & $\begin{array}{l}\text { СМТ2K } \\
607831\end{array}$ & $8 \mathrm{q} 13-\mathrm{q} 21$ & $\begin{array}{l}\boldsymbol{G D A P 1} \\
606598\end{array}$ & $\begin{array}{l}\text { ganglioside-induced } \\
\text { differentiation- } \\
\text { associated protein } 1\end{array}$ & $\begin{array}{l}\text { Nelis et al. (2002) } \\
\text { Birouk et al. (2003) } \\
\text { Claramunt et al. (2005) }\end{array}$ & $\begin{array}{l}\text { allelic to CMT4A and } \\
\text { ARCMT2C (group 14) }\end{array}$ \\
\hline
\end{tabular}




\begin{tabular}{|c|c|c|c|c|c|c|c|c|}
\hline DISEASE NAME & $\begin{array}{l}\text { Item } \\
\text { line } \\
\text { in this } \\
\text { group }\end{array}$ & Inheritance & $\begin{array}{l}\text { Locus or } \\
\text { disease } \\
\text { symbol and } \\
\text { OMIM } \\
\text { number }\end{array}$ & Chromosome & $\begin{array}{l}\text { Gene symbol } \\
\text { and OMIM } \\
\text { number }\end{array}$ & $\begin{array}{l}\text { Protein } \\
\text { (mitochondrial } \\
\text { proteins indicated } \\
\text { by symbol }[M] \text { ) }\end{array}$ & $\begin{array}{l}\text { Key } \\
\text { references }\end{array}$ & $\begin{array}{l}\text { Other allelic disease(s) } \\
\text { (group in this table) }\end{array}$ \\
\hline Type 2L & 14.53 & $\mathrm{AD}$ & $\begin{array}{l}\text { CMT2L } \\
608673\end{array}$ & $12 \mathrm{q} 24$ & $\begin{array}{l}\text { HSPB8 } \\
608014\end{array}$ & $\begin{array}{l}\text { heat shock protein } \\
8\end{array}$ & Tang et al. $(2004,2005)$ & allelic to HMN2A (group 12) \\
\hline Type $2 \mathrm{~N}$ & 14.54 & $\mathrm{AD}$ & $\begin{array}{l}\text { CMT2N } \\
613287\end{array}$ & $16 \mathrm{q} 22.1$ & $\begin{array}{l}\text { AARS } \\
601065\end{array}$ & $\begin{array}{l}\text { AARS alanyl-tRNA } \\
\text { synthetase }\end{array}$ & Latour et al. (2010) & \\
\hline Type $2 \mathrm{O}$ & 14.55 & $\mathrm{AD}$ & $\begin{array}{l}\text { CMT2O } \\
614228\end{array}$ & $14 \mathrm{q} 32.31$ & $\begin{array}{l}\text { DYNC1H1 } \\
600112\end{array}$ & $\begin{array}{l}\text { dynein, cytoplasmic } \\
1 \text {, heavy chain } 1\end{array}$ & Weedon et al. (2011) & \\
\hline Type 2P & 14.56 & $\mathrm{AD}$ & $\begin{array}{l}\text { CMT2P } \\
614436\end{array}$ & $9 \mathrm{q} 33.3$ & $\begin{array}{l}\text { LRSAM1 } \\
610933\end{array}$ & $\begin{array}{l}\text { leucine rich repeat } \\
\text { and sterile alpha } \\
\text { motif containing } 1\end{array}$ & $\begin{array}{l}\text { Guernsey et al. (2010) } \\
\text { Weterman et al. (2012) } \\
\text { Nicolaou et al. (2012) }\end{array}$ & \\
\hline Type 2Q & 14.57 & $\mathrm{AD}$ & $\begin{array}{l}\text { CMT2Q } \\
615025\end{array}$ & $10 \mathrm{p} 14$ & $\begin{array}{l}\text { DHTKD1 } \\
614984\end{array}$ & $\begin{array}{l}\text { dehydrogenase E1 } \\
\text { and transketolase } \\
\text { domain containing } \\
1\end{array}$ & Xu et al. (2012) & \\
\hline Type $2 \mathrm{U}$ & 14.58 & $\mathrm{AD}$ & $\begin{array}{l}\text { CMT2U } \\
616280\end{array}$ & $12 \mathrm{q} 13.3$ & $\begin{array}{l}\text { MARS } \\
156560\end{array}$ & $\begin{array}{l}\text { methionyl-tRNA } \\
\text { synthetase }\end{array}$ & Gonzalez et al. (2013) & \\
\hline Type $2 \mathrm{~V}$ & 14.59 & $\mathrm{AD}$ & $\begin{array}{l}\text { CMT2V } \\
616491\end{array}$ & $17 \mathrm{q} 21.2$ & $\begin{array}{l}\text { NAGLU } \\
609701\end{array}$ & $\begin{array}{l}\text { N-acetyl-alpha- } \\
\text { glucosaminidase }\end{array}$ & Tetreault et al. (2015) & \\
\hline Type $2 \mathrm{~W}$ & 14.60 & $\mathrm{AD}$ & $\begin{array}{l}\text { CMT2W } \\
616625\end{array}$ & $5 \mathrm{q} 31.3$ & $\begin{array}{l}\text { HARS } \\
142810\end{array}$ & $\begin{array}{l}\text { histidyl-tRNA } \\
\text { synthetase }\end{array}$ & $\begin{array}{l}\text { Vester et al. (2013) } \\
\text { Safka-Brozkova (2015) }\end{array}$ & \\
\hline Type $2 \mathrm{Y}$ & 14.61 & $\mathrm{AD}$ & $\begin{array}{l}\text { CMT2Y } \\
616687\end{array}$ & $9 \mathrm{p} 13.3$ & $\begin{array}{l}\text { VCP } \\
601023\end{array}$ & $\begin{array}{l}\text { Valosin-containing } \\
\text { protein }\end{array}$ & Gonsalez et al. (2014) & $\begin{array}{l}\text { Allelic to 1.48, IBMPFD } \\
\text { (groups } 4 \text { and 5), ALS14 } \\
\text { (group 12) }\end{array}$ \\
\hline Type $2 Z$ & 14.62 & $\mathrm{AD}$ & $\begin{array}{l}\text { CMT2Z } \\
616688\end{array}$ & $2 q 12.2$ & $\begin{array}{l}\text { MORC2 } \\
616661\end{array}$ & $\begin{array}{l}\text { MORC family } \\
\text { CW-type zinc } \\
\text { finger } 2\end{array}$ & $\begin{array}{l}\text { Albulym et al. (2015) } \\
\text { Sevilla et al. (2016) }\end{array}$ & \\
\hline $\begin{array}{l}\text { Hereditary motor and sensory } \\
\text { neuropathy, Okinawa type }\end{array}$ & 14.63 & $\mathrm{AD}$ & $\begin{array}{l}\text { HMSN0/ } \\
\text { HMNSP } \\
604484\end{array}$ & $3 q 13$ & $\begin{array}{l}\boldsymbol{T F G} \\
602498\end{array}$ & TRK-fused gene & $\begin{array}{l}\text { Takeshima et al. (1997, } \\
\text { 1999) } \\
\text { Maeda et al. (2007) } \\
\text { Ishiura et al. (2012) }\end{array}$ & \\
\hline CMT2 related to KIF5A & 14.64 & $\mathrm{AD}$ & & $12 \mathrm{q} 13.13$ & $\begin{array}{l}\text { KIF5A } \\
602821\end{array}$ & $\begin{array}{l}\text { kinesin family } \\
\text { member } 5 \mathrm{~A}\end{array}$ & Liu et al. (2014) & Allelic to SPG10 (group 15) \\
\hline $\begin{array}{l}\text { Early onset axonal neuropathy } \\
\text { with sensory ataxia }\end{array}$ & 14.65 & $\mathrm{AD}$ & CMT2 & $1 \mathrm{q} 13.3$ & $\begin{array}{l}D G A T 2 \\
606983\end{array}$ & $\begin{array}{l}\text { diacylglycerol } \\
\text { O-acyltransferase } 2\end{array}$ & Hong et al. (2016) & \\
\hline $\begin{array}{l}\text { Charcot-Marie-Tooth disease, } \\
\text { axonal, type } 2 \mathrm{CC}\end{array}$ & 14.66 & $\mathrm{AD}$ & $\begin{array}{l}\text { CMT2CC } \\
616924\end{array}$ & $22 \mathrm{q} 11.2$ & $\begin{array}{l}\text { NEFH } \\
162230\end{array}$ & $\begin{array}{l}\text { Neurofilament } \\
\text { Protein, Heavy } \\
\text { Polypeptide }\end{array}$ & Rebelo et al. (2016) & \\
\hline $\begin{array}{l}\text { Charcot-Marie-Tooth disease, } \\
\text { axonal, related to BAG3 }\end{array}$ & 14.67 & $\mathrm{AD}$ & & $10 \mathrm{q} 25-\mathrm{q} 26$ & $\begin{array}{l}\text { BAG3 } \\
603883\end{array}$ & $\begin{array}{l}\text { BCL2-associated } \\
\text { athanogene } 3\end{array}$ & Noury et al. (2017) & $\begin{array}{l}\text { Allelic to MFM6 (group 5) and } \\
\text { to CMH1HH (group 10A) }\end{array}$ \\
\hline \multicolumn{9}{|l|}{ CMT2 Autosomal recessive } \\
\hline AR-CMT2A & 14.68 & $\mathrm{AR}$ & $\begin{array}{l}\text { СMT2B1 } \\
605588\end{array}$ & $1 \mathrm{q} 21.2$ & $\begin{array}{l}\boldsymbol{L M N A} \\
150330\end{array}$ & $\operatorname{lamin} \mathrm{A} / \mathrm{C}$ & $\begin{array}{l}\text { Bouhouch et al. (1999) } \\
\text { De Sandre et al. (2002) } \\
\text { Worman and Bonne (2007) }\end{array}$ & $\begin{array}{l}\text { allelic to EDMD2 (group 1), } \\
\text { EDMD3 (group 1), LGMD1B } \\
\text { (group 1), [+ FPLD2/151660, } \\
\text { HGPS/176670, restrictive } \\
\text { dermopathy/275210, not in this } \\
\text { table] }\end{array}$ \\
\hline AR-CMT2B & 14.69 & $\mathrm{AR}$ & $\begin{array}{l}\text { СМТ2B2 } \\
605589\end{array}$ & $19 \mathrm{q} 13$ & $\begin{array}{l}\text { MED25 } \\
610697\end{array}$ & $\begin{array}{l}\text { mediator complex } \\
\text { subunit } 25\end{array}$ & Leal et al. $(2001,2009)$ & $\begin{array}{l}\text { allelic to CMT4A, and CMT2K } \\
\text { (group 14) }\end{array}$ \\
\hline AR-CMT2 related to $D N A J B 2$ & 14.70 & AR & & $2 q 35$ & $\begin{array}{l}\text { DNAJB2 } \\
\text { (=HSJ1) } \\
604139\end{array}$ & $\begin{array}{l}\text { DnaJ (Hsp40) } \\
\text { homolog, subfamily } \\
\text { B, member } 2\end{array}$ & Gesse et al. (2014) & Allelic to SMA (group 12) \\
\hline $\begin{array}{l}\text { Axonal neuropathy with } \\
\text { neuromyotonia }\end{array}$ & 14.71 & $\mathrm{AR}$ & $\begin{array}{l}\text { NMAN } \\
137200\end{array}$ & $5 \mathrm{q} 23.3$ & $\begin{array}{l}\text { HINT1 } \\
601314\end{array}$ & $\begin{array}{l}\text { histidine triad } \\
\text { nucleotide binding } \\
\text { protein } 1\end{array}$ & Zimon et al. (2012) & \\
\hline $\begin{array}{l}\text { Axonal neuropathy } \\
\text { intermediate recessive B }\end{array}$ & 14.72 & $\mathrm{AR}$ & $\begin{array}{l}\text { CMTRIB } \\
613641\end{array}$ & $16 \mathrm{q} 23.1$ & $\begin{array}{l}\boldsymbol{K A R S} \\
601421\end{array}$ & $\begin{array}{l}\text { Lysyl-tRNA } \\
\text { synthetase }\end{array}$ & McLaughlin et al. (2010) & \\
\hline $\begin{array}{l}\text { Axonal neuropathy } \\
\text { intermediate recessive } \mathrm{C}\end{array}$ & 14.73 & $\mathrm{AR}$ & $\begin{array}{l}\text { CMTRIC } \\
615376\end{array}$ & $1 \mathrm{p} 36$ & $\begin{array}{l}\text { PLEKHG5 } \\
611101\end{array}$ & $\begin{array}{l}\text { Pleckstrin } \\
\text { homology domain } \\
\text { containing, family } \\
\text { G (with RhoGef } \\
\text { domain) member } 5\end{array}$ & $\begin{array}{l}\text { Azzedine et al. (2013) } \\
\text { Kim et al. (2013) }\end{array}$ & Allelic to DSMA4 (group 12) \\
\hline CMT recessive intermediate D & 14.74 & AR & $\begin{array}{l}\text { CMTRID } \\
616039\end{array}$ & $12 \mathrm{q} 24.31$ & $\begin{array}{l}\text { COX6A1 } \\
602072\end{array}$ & $\begin{array}{l}\text { cytochrome c } \\
\text { oxidase subunit VIa } \\
\text { polypeptide } 1[\mathbf{M}]\end{array}$ & Tamiya et al. (2014) & \\
\hline Type $2 \mathrm{R}$ & 14.75 & $\mathrm{AR}$ & $\begin{array}{l}\text { CMT2R } \\
615490\end{array}$ & $4 \mathrm{q} 31.3$ & $\begin{array}{l}\text { TRIM2 } \\
614141\end{array}$ & $\begin{array}{l}\text { tripartite motif } \\
\text { containing } 2\end{array}$ & $\begin{array}{l}\text { Ylikallio et al. (2013) } \\
\text { Pehlivan et al. (2015) }\end{array}$ & \\
\hline $\begin{array}{l}\text { Autosomal recessive CMT } \\
\text { axonal type } 2 \mathrm{~S}\end{array}$ & 14.76 & $\mathrm{AR}$ & $\begin{array}{l}\text { CMT2S } \\
616155\end{array}$ & $11 \mathrm{q} 13.3$ & $\begin{array}{l}\text { IGHMBP2 } \\
600502\end{array}$ & $\begin{array}{l}\text { immunoglobulin } \\
\text { mu binding protein } \\
2\end{array}$ & $\begin{array}{l}\text { Cottenie et al. (2014) } \\
\text { Schottmann et al. (2015) }\end{array}$ & Allelic to DSMA1 (group 12) \\
\hline Type 2T & 14.77 & $\mathrm{AR}$ & $\begin{array}{l}\text { CMT2T } \\
617017\end{array}$ & $3 \mathrm{q} 25.2$ & $\begin{array}{l}\text { MME } \\
120520\end{array}$ & $\begin{array}{l}\text { membrane } \\
\text { metalloendopeptidase }\end{array}$ & Higuchi et al. (2016) & \\
\hline
\end{tabular}




\begin{tabular}{|c|c|c|c|c|c|c|c|c|}
\hline DISEASE NAME & $\begin{array}{l}\text { Item } \\
\text { line } \\
\text { in this } \\
\text { group }\end{array}$ & Inheritance & $\begin{array}{l}\text { Locus or } \\
\text { disease } \\
\text { symbol and } \\
\text { OMIM } \\
\text { number }\end{array}$ & Chromosome & $\begin{array}{l}\text { Gene symbol } \\
\text { and OMIM } \\
\text { number }\end{array}$ & $\begin{array}{l}\text { Protein } \\
\text { (mitochondrial } \\
\text { proteins indicated } \\
\text { by symbol }[M] \text { ) }\end{array}$ & $\begin{array}{l}\text { Key } \\
\text { references }\end{array}$ & $\begin{array}{l}\text { Other allelic disease(s) } \\
\text { (group in this table) }\end{array}$ \\
\hline Type $2 \mathrm{X}$ & 14.78 & $\mathrm{AR}$ & $\begin{array}{l}\text { CMT2X } \\
616668\end{array}$ & $15 \mathrm{q} 21.1$ & $\begin{array}{l}\text { SPG11 } \\
610844\end{array}$ & Spatacsin & Montecchiani et al. (2015) & $\begin{array}{l}\text { ALS5 (group 12), SPG11 } \\
\text { (group 15) }\end{array}$ \\
\hline $\begin{array}{l}\text { Early-onset axonal } \\
\text { Charcot-Marie-Tooth with } \\
\text { ataxia }\end{array}$ & 14.79 & AR & $\begin{array}{l}\text { AOA4 } \\
616267\end{array}$ & $19 \mathrm{q} 13.33$ & $\begin{array}{l}\text { PNKP } \\
605610\end{array}$ & $\begin{array}{l}\text { polynucleotide } \\
\text { kinase } \\
\text { 3'-phosphatase }\end{array}$ & Pedroso et al. (2015) & \\
\hline $\begin{array}{l}\text { Charcot-Marie-Tooth disease, } \\
\text { axonal }\end{array}$ & 14.80 & AR & & $10 \mathrm{q} 22.1$ & $\begin{array}{l}\text { SGPL1 } \\
603729\end{array}$ & $\begin{array}{l}\text { Sphingosine-1- } \\
\text { Phosphate Lyase } 1\end{array}$ & Atkinson et al. (2017) & $\begin{array}{l}\text { allelic to Nephrotic Syndrome } \\
14 \text { (\# 617575) }\end{array}$ \\
\hline \multicolumn{9}{|c|}{$\begin{array}{l}\text { C. CMT Distal = Distal hereditary motor neuropathies (dHMN) = spinal CMT or distal spinal muscular atrophy (DSMA) See Under MOTOR NEURONE DISEASES (Group 12) } \\
\text { D. Other HSMN syndromes }\end{array}$} \\
\hline $\begin{array}{l}\text { Hereditary sensory and } \\
\text { autonomic neuropathy type I }\end{array}$ & 14.81 & $\mathrm{AD}$ & $\begin{array}{l}\text { HSAN1 } \\
162400\end{array}$ & $9 \mathrm{q} 22.1-\mathrm{q} 22.3$ & $\begin{array}{l}\text { SPTLC1 } \\
605712\end{array}$ & $\begin{array}{l}\text { serine } \\
\text { palmitoyltransferase } \\
\text { long chain base } \\
\text { subunit } 1\end{array}$ & $\begin{array}{l}\text { Nicholson et al. (1996) } \\
\text { Bejaoui et al. (2001) } \\
\text { Dawkins et al. (2001) }\end{array}$ & \\
\hline $\begin{array}{l}\text { Hereditary sensory and } \\
\text { autonomic neuropathy type IB } \\
\text { with cough and } \\
\text { gastroesophageal reflux }\end{array}$ & 14.82 & $\mathrm{AD}$ & $\begin{array}{l}\text { HSAN1B } \\
608088\end{array}$ & $3 \mathrm{p} 24-\mathrm{p} 22$ & $?$ & & Kok et al. (2004) & \\
\hline $\begin{array}{l}\text { Hereditary sensory and } \\
\text { autonomic neuropathy type I }\end{array}$ & 14.83 & $\mathrm{AD}$ & $\begin{array}{l}\text { HSN IC } \\
613640\end{array}$ & $14 \mathrm{q} 24.3$ & $\begin{array}{l}\text { SPTLC2 } \\
605713\end{array}$ & $\begin{array}{l}\text { serine } \\
\text { palmitoyltransferase } \\
\text { long chain base } \\
\text { subunit } 2\end{array}$ & Rotthier et al. (2010) & \\
\hline $\begin{array}{l}\text { Hereditary sensory neuropathy } \\
\text { type I.D }\end{array}$ & 14.84 & $\mathrm{AD}$ & $\begin{array}{l}\text { HSN ID } \\
613708\end{array}$ & $14 \mathrm{q} 22.1$ & $\begin{array}{l}\text { ATL1 } \\
606439\end{array}$ & atllastin GTPase 1 & Guelly et al. (2011) & $\begin{array}{l}\text { Allelic to SPG3A } \\
\text { (group 15) }\end{array}$ \\
\hline $\begin{array}{l}\text { Neuropathy, hereditary sensory, } \\
\text { type IF }\end{array}$ & 14.85 & $\mathrm{AD}$ & $\begin{array}{l}\text { HSN IF } \\
615632\end{array}$ & $11 \mathrm{q} 13.1$ & $\begin{array}{l}\text { ATL3 } \\
609369\end{array}$ & atllastin GTPase 3 & Kornak et al. (2014) & \\
\hline $\begin{array}{l}\text { Hereditary sensory and } \\
\text { autonomic neuropathy type II }\end{array}$ & 14.86 & AR & $\begin{array}{l}\text { HSAN2 } \\
201300\end{array}$ & 12 p. 13 & $\begin{array}{l}\text { WNK1 } \\
605232\end{array}$ & $\begin{array}{l}\text { WNK lysine } \\
\text { deficient protein } \\
\text { kinase } 1\end{array}$ & $\begin{array}{l}\text { Lafreniere et al. (2004) } \\
\text { Shekarabi et al. (2008) }\end{array}$ & \\
\hline $\begin{array}{l}\text { Hereditary sensory and } \\
\text { autonomic neuropath type IIB }\end{array}$ & 14.87 & AR & $\begin{array}{l}\text { HSAN2B } \\
613115\end{array}$ & $5 \mathrm{p} 15.1$ & $\begin{array}{l}\text { FAM134B } \\
613114\end{array}$ & $\begin{array}{l}\text { family with } \\
\text { sequence similarity } \\
134 \text { member B }\end{array}$ & Kurth et al. (2009) & \\
\hline $\begin{array}{l}\text { Hereditary sensory neuropathy, } \\
\text { type IIC }\end{array}$ & 14.88 & $\mathrm{AD}$ & $\begin{array}{l}\text { HSN IIC } \\
614213\end{array}$ & $2 \mathrm{q} 37.3$ & $\begin{array}{l}\boldsymbol{K I F I A} \\
601255\end{array}$ & $\begin{array}{l}\text { kinesin family } \\
\text { member } 1 \mathrm{~A}\end{array}$ & Riviere et al. (2011) & Allelic to SPG30 (group 15) \\
\hline $\begin{array}{l}\text { Neuropathy, hereditary sensory } \\
\text { and autonomic, type IId, }\end{array}$ & 14.89 & AR & $\begin{array}{l}\text { HSAN2D } \\
24300\end{array}$ & $2 \mathrm{q} 24.3$ & $\begin{array}{l}S C N 9 A \\
603415\end{array}$ & $\begin{array}{l}\text { sodium } \\
\text { voltage-gated } \\
\text { channel alpha } \\
\text { subunit } 9\end{array}$ & Yuan et al. (2013) & \\
\hline $\begin{array}{l}\text { Hereditary sensory and } \\
\text { autonomic neuropathy type III } \\
\text { (Familial dysautonomia, } \\
\text { Riley-Day syndrome) }\end{array}$ & 14.90 & $\mathrm{AR}$ & $\begin{array}{l}\text { HSAN3 } \\
223900\end{array}$ & $9 \mathrm{q} 31$ & $\begin{array}{l}\text { IKBKAP } \\
603722\end{array}$ & $\begin{array}{l}\text { inhibitor of kappaB } \\
\text { kinase complex } \\
\text { associated protein }\end{array}$ & $\begin{array}{l}\text { Blumenfeld et al. (1993) } \\
\text { Anderson et al. (2001) } \\
\text { Slaugenhaupt et al. (2001) }\end{array}$ & \\
\hline $\begin{array}{l}\text { Hereditary sensory and } \\
\text { autonomic neuropathy type IV }\end{array}$ & 14.91 & AR & $\begin{array}{l}\text { HSAN4 } \\
\text { (CIPA) } \\
256800\end{array}$ & 1biq23.1 & $\begin{array}{l}\text { NTRK1 } \\
191315\end{array}$ & $\begin{array}{l}\text { neurotrophic } \\
\text { receptor tyrosine } \\
\text { kinase } 1\end{array}$ & Indo et al. (1996) & \\
\hline $\begin{array}{l}\text { Hereditary sensory and } \\
\text { autonomic neuropathy type } \mathrm{V}\end{array}$ & 14.92 & AR & HSAN5 & $1 \mathrm{p} 13.1$ & $\begin{array}{l}\text { NGFB } \\
162030\end{array}$ & $\begin{array}{l}\text { nerve growth factor } \\
\text { (beta polypeptide) }\end{array}$ & Einarsdottir et al. (2004) & \\
\hline $\begin{array}{l}\text { Hereditary sensory and } \\
\text { autonomic neuropathy type VI }\end{array}$ & 14.93 & AR & $\begin{array}{l}\text { HSAN6 } \\
614653\end{array}$ & $6 \mathrm{p} 12.1$ & $\begin{array}{l}\text { DST } \\
113810\end{array}$ & dystonin & Edvardson et al. (2012) & \\
\hline $\begin{array}{l}\text { Neuropathy, hereditary sensory } \\
\text { and autonomic, type VII }\end{array}$ & 14.94 & $\mathrm{AD}$ & $\begin{array}{l}\text { HSAN7 } \\
615548\end{array}$ & $3 \mathrm{p} 22.2$ & $\begin{array}{l}\text { SCN11A } \\
604385\end{array}$ & $\begin{array}{l}\text { sodium } \\
\text { voltage-gated } \\
\text { channel alpha } \\
\text { subunit } 11\end{array}$ & Leipold et al. (2013) & \\
\hline $\begin{array}{l}\text { Hereditary sensory and } \\
\text { autonomic neuropathy type } \\
\text { VIII }\end{array}$ & 14.95 & $\mathrm{AR}$ & $\begin{array}{l}\text { HSAN8 } \\
616488\end{array}$ & $9 \mathrm{q} 34.12$ & PRDM12 & $\begin{array}{l}\text { PR/SET domain } 12 \\
\text { (positive regulatory } \\
\text { domain zinc finger } \\
\text { protein } 12 \text { ) }\end{array}$ & Chen et al. (2015) & \\
\hline $\begin{array}{l}\text { Hereditary motor and sensory } \\
\text { neuropathy-Lom (with } \\
\text { deafness) }\end{array}$ & 14.96 & $\mathrm{AR}$ & $\begin{array}{l}\text { HMNSL } \\
601455\end{array}$ & $8 \mathrm{q} 24$ & $\begin{array}{l}\text { NDRG1 } \\
605262\end{array}$ & $\begin{array}{l}\text { Nmyc downstream } \\
\text { regulated gene } 1\end{array}$ & $\begin{array}{l}\text { Kalaydjieva et al. (1996, } \\
2000) \\
\text { Hunter et al. (2003) }\end{array}$ & Allelic to CMT4D (group14) \\
\hline $\begin{array}{l}\text { Hereditary sensory neuropathy } \\
\text { with dementia and hearing loss. }\end{array}$ & 14.97 & $\mathrm{AD}$ & $\begin{array}{l}\text { HSN1E } \\
614116\end{array}$ & $19 \mathrm{p} 13.2$ & $\begin{array}{l}\text { DNMT1 } \\
126375\end{array}$ & $\begin{array}{l}\text { DNA (cytosine-5)- } \\
\text { methyltransferase } 1\end{array}$ & Klein et al. (2011) & \\
\hline $\begin{array}{l}\text { Peripheral neuropathy and } \\
\text { agenesis of the corpus } \\
\text { callosum (Charlevoix disease) }\end{array}$ & 14.98 & AR & $\begin{array}{l}\text { ACCPN } \\
218000\end{array}$ & $15 \mathrm{q} 13-\mathrm{q} 14$ & $\begin{array}{l}\text { SLC12A6 } \\
\text { (KCC3) } \\
604878\end{array}$ & $\begin{array}{l}\text { solute carrier } \\
\text { family } 12 \\
\text { (potassium chloride } \\
\text { cotransporter) }\end{array}$ & $\begin{array}{l}\text { Casaubon et al. (1996) } \\
\text { Howard et al. (2002a, } \\
2002 b)\end{array}$ & \\
\hline $\begin{array}{l}\text { Peripheral neuropathy and } \\
\text { deafness, autosomal dominant }\end{array}$ & 14.99 & $\mathrm{AD}$ & & $1 \mathrm{p} 34.3$ & $\begin{array}{l}\text { GJB3 } \\
603324\end{array}$ & $\begin{array}{l}\text { Gap junction } \\
\text { protein, beta } 3 \text {, } \\
31 \mathrm{kDa} \\
(=\text { connexin } 31)\end{array}$ & Lopez-Bigas et al. (2001) & \\
\hline
\end{tabular}




\begin{tabular}{|c|c|c|c|c|c|c|c|c|}
\hline DISEASE NAME & $\begin{array}{l}\text { Item } \\
\text { line } \\
\text { in this } \\
\text { group }\end{array}$ & Inheritance & $\begin{array}{l}\text { Locus or } \\
\text { disease } \\
\text { symbol and } \\
\text { OMIM } \\
\text { number }\end{array}$ & Chromosome & $\begin{array}{l}\text { Gene symbol } \\
\text { and OMIM } \\
\text { number }\end{array}$ & $\begin{array}{l}\text { Protein } \\
\text { (mitochondrial } \\
\text { proteins indicated } \\
\text { by symbol }[M] \text { ) }\end{array}$ & $\begin{array}{l}\text { Key } \\
\text { references }\end{array}$ & $\begin{array}{l}\text { Other allelic disease(s) } \\
\text { (group in this table) }\end{array}$ \\
\hline $\begin{array}{l}\text { Hereditary neuralgic } \\
\text { amyotrophy (familial brachial } \\
\text { plexus neuropathy) }\end{array}$ & 14.100 & $\mathrm{AD}$ & $\begin{array}{l}\text { HNA } \\
162100\end{array}$ & $17 \mathrm{q} 25$ & $\begin{array}{l}\text { SEPT9 } \\
604061\end{array}$ & septin 9 & $\begin{array}{l}\text { Pellegrino et al. (1996) } \\
\text { Kuhlenbaumer et al. (2005) }\end{array}$ & \\
\hline Giant axonal neuropathy & 14.101 & $\mathrm{AR}$ & $\begin{array}{l}\text { GAN } \\
256850\end{array}$ & $16 \mathrm{q} 24.1$ & $\begin{array}{l}\boldsymbol{G A N 1} \\
605379\end{array}$ & gigaxonin & $\begin{array}{l}\text { Ben Hamida et al. (1997) } \\
\text { Bomont et al. (2000) }\end{array}$ & \\
\hline Giant axonal neuropathy 2 & 14.102 & $\mathrm{AD}$ & $\begin{array}{l}\text { GAN2 } \\
610100\end{array}$ & $1 \mathrm{q} 23.2$ & $\begin{array}{l}\boldsymbol{D C A F 8} \\
615820\end{array}$ & $\begin{array}{l}\text { DDB1 and CUL4 } \\
\text { associated factor } 8\end{array}$ & Klein et al. (2014) & \\
\hline $\begin{array}{l}\text { Congenital cataracts, facial } \\
\text { dysmorphism and neuropathy }\end{array}$ & 14.103 & AR & $\begin{array}{l}\text { CCFDN } \\
604168\end{array}$ & $18 \mathrm{p} 23$ & $\begin{array}{l}\text { CTDP1 } \\
604927\end{array}$ & $\begin{array}{l}\text { CTD phosphatase } \\
\text { subunit } 1\end{array}$ & Varon et al. (2003) & \\
\hline $\begin{array}{l}\text { Complex motor and sensory } \\
\text { axonal neuropathy plus } \\
\text { microcephaly and cerebral } \\
\text { dysgenesis }\end{array}$ & 14.104 & $\mathrm{AR}$ & & $14 \mathrm{q} 32.2$ & $\begin{array}{l}\text { VRK1 } \\
602168\end{array}$ & $\begin{array}{l}\text { Vaccinia-related } \\
\text { kinase } 1\end{array}$ & $\begin{array}{l}\text { Gonzaga-Jauregui et al. } \\
(2013)\end{array}$ & \\
\hline $\begin{array}{l}\text { Neuropathy, hereditary sensory, } \\
\text { with spastic paraplegia, } \\
\text { autosomal recessive }\end{array}$ & 14.105 & $\mathrm{AR}$ & 256840 & $5 \mathrm{p} 15.2$ & $\begin{array}{l}\text { CCT5 } \\
610150\end{array}$ & $\begin{array}{l}\text { chaperonin-containing } \\
\text { TCP1 subunit } 5\end{array}$ & $\begin{array}{l}\text { Bouhouche et al. (2006a; } \\
\text { 2006b) }\end{array}$ & \\
\hline
\end{tabular}

GROUP 15. HEREDITARY PARAPLEGIAS See online version of the gene table at http://www.musclegenetable.fr

\begin{tabular}{|c|c|c|c|c|c|c|c|c|}
\hline Torsion dystonia, early onset & 16.1 & $\mathrm{AD}$ & $\begin{array}{l}\text { EOTD } \\
128100\end{array}$ & $9 q 34$ & $\begin{array}{l}\text { TOR1A } \\
\text { (DYT1) } \\
605204\end{array}$ & Torsin A & $\begin{array}{l}\text { Ozelius et al. (1997) } \\
\text { Ikeuchi et al. (1999) }\end{array}$ & \\
\hline Myoclonus-dystonia syndrome & 16.2 & $\mathrm{AD}$ & $\begin{array}{l}\text { DYT11 } \\
159900\end{array}$ & $7 \mathrm{q} 21$ & $\begin{array}{l}\text { SGCE } \\
604149\end{array}$ & Epsilon-sarcoglycan & $\begin{array}{l}\text { Klein et al. (2000), Zimprich } \\
\text { et al. (2001), Tezenas du } \\
\text { Montcel et al. (2006) }\end{array}$ & \\
\hline $\begin{array}{l}\text { Familial dysautonomia } \\
\text { (Riley-Day syndrome) }\end{array}$ & 16.3 & $\mathrm{AR}$ & $\begin{array}{l}\text { HSAN3 } \\
223900\end{array}$ & $9 \mathrm{q} 31$ & $\begin{array}{l}\text { IKBKAP } \\
603722\end{array}$ & $\begin{array}{l}\text { Inhibitor of kappab } \\
\text { kinase complex } \\
\text { associated protein }\end{array}$ & $\begin{array}{l}\text { Blumenfeld et al. (1993), } \\
\text { Anderson et al. (2001), } \\
\text { Slaugenhaupt et al. (2001) }\end{array}$ & \\
\hline Familial amyloid neuropathy & 16.4 & $\mathrm{AD}$ & & $18 \mathrm{q} 12.1$ & $\begin{array}{l}\text { TTR } \\
176300\end{array}$ & $\begin{array}{l}\text { Transthyretin } \\
\text { (prealbumin) }\end{array}$ & $\begin{array}{l}\text { Costa et al. (1978) } \\
\text { Tawara et al. (1983), Saraiva } \\
\text { et al. (1995) }\end{array}$ & \\
\hline $\begin{array}{l}\text { Congenital fibrosis of the } \\
\text { extraocular muscles }\end{array}$ & 16.5 & $\mathrm{AD}$ & $\begin{array}{l}\text { CFEOM1 } \\
135700\end{array}$ & $12 \mathrm{q} 12$ & $\begin{array}{l}\text { KIF 21A } \\
608283\end{array}$ & $\begin{array}{l}\text { Kinesin family } \\
\text { member } 21 \mathrm{a}\end{array}$ & $\begin{array}{l}\text { Engle et al. (1994), Yamada } \\
\text { et al. (2003), Tiab et al. } \\
(2004)\end{array}$ & \\
\hline $\begin{array}{l}\text { Congenital fibrosis of the } \\
\text { extraocular muscles }\end{array}$ & 16.6 & $\mathrm{AD}$ & $\begin{array}{l}\text { CFEOM2 } \\
602078\end{array}$ & $11 \mathrm{q} 13$ & $\begin{array}{l}\text { PHOX2A } \\
\text { (ARIX) } \\
602753\end{array}$ & $\begin{array}{l}\text { Paired-like } \\
\text { aristaless } \\
\text { homeobox protein } \\
\text { 2a) }\end{array}$ & $\begin{array}{l}\text { Wang et al. (1998) } \\
\text { Nakano et al. (2001) }\end{array}$ & \\
\hline $\begin{array}{l}\text { Congenital fibrosis of the } \\
\text { extraocular muscles }\end{array}$ & 16.7 & $\mathrm{AD}$ & $\begin{array}{l}\text { CFEOM3 } \\
600638\end{array}$ & $16 \mathrm{q} 24$ & $\begin{array}{l}\text { TUBB3 } \\
602661\end{array}$ & Tubulin, beta 3 & $\begin{array}{l}\text { Doherty et al. (1999), } \\
\text { Tischfield et al. (2010) }\end{array}$ & \\
\hline Distal arthrogryposis type 1 & 16.8 & $\mathrm{AD}$ & $\begin{array}{l}\text { DA1 } \\
108120\end{array}$ & $9 \mathrm{p} 13$ & $\begin{array}{l}\text { TPM2 } \\
190990\end{array}$ & $\begin{array}{l}\text { Tropomyosin } 2, \mathrm{~b} \\
\text { tropomyosin }\end{array}$ & Sung et al. (2003a) & $\begin{array}{l}\text { Allelic to NEM } 4 \text { (group 3), } \\
\text { CAP disease (group 3.), DA2B } \\
\text { (group 16) }\end{array}$ \\
\hline $\begin{array}{l}\text { Distal arthrogryposis type } 2 \mathrm{a}, \\
\text { Freeman-Sheldon syndrome }\end{array}$ & 16.9 & $\mathrm{AD}$ & $\begin{array}{l}\text { DA2A } \\
193700\end{array}$ & $17 \mathrm{p} 13$ & $\begin{array}{l}\text { МУН3 } \\
160720\end{array}$ & $\begin{array}{l}\text { Myosin heavy } \\
\text { chain 3, skeletal } \\
\text { muscle, embryonic }\end{array}$ & Toydemir et al. (2006) & \\
\hline $\begin{array}{l}\text { Distal arthrogryposis type } 2 b \text {, } \\
\text { Sheldon-Hall syndrome }\end{array}$ & 16.10 & $\mathrm{AD}$ & $\begin{array}{l}\text { DA2B, } \\
601680\end{array}$ & $11 \mathrm{p} 15$ & $\begin{array}{l}\text { TNNI2 } \\
191043\end{array}$ & $\begin{array}{l}\text { Troponin i, } \\
\text { fast-twich skeletal } \\
\text { muscle isoform }\end{array}$ & $\begin{array}{l}\text { Sung et al. (2003a); Kimber } \\
\text { et al. (2006) }\end{array}$ & \\
\hline $\begin{array}{l}\text { Distal arthrogryposis type } 2 b \text {, } \\
\text { Sheldon-Hall syndrome }\end{array}$ & 16.11 & $\mathrm{AD}$ & $\begin{array}{l}\text { DA2B, } \\
601680\end{array}$ & $11 \mathrm{p} 15$ & $\begin{array}{l}T N N T 3 \\
600692\end{array}$ & $\begin{array}{l}\text { Troponin } \mathrm{t} 3 \text {, fast } \\
\text { skeletal }\end{array}$ & Sung et al. (2003b) & \\
\hline $\begin{array}{l}\text { Distal arthrogryposis type } 2 b \text {, } \\
\text { Sheldon-Hall syndrome }\end{array}$ & 16.12 & $\mathrm{AD}$ & $\begin{array}{l}\text { DA2B, } \\
601680\end{array}$ & $17 \mathrm{p} 13$ & $\begin{array}{l}\text { МYH3 } \\
160720\end{array}$ & $\begin{array}{l}\text { Myosin heavy } \\
\text { chain 3, skeletal } \\
\text { muscle, embryonic }\end{array}$ & Toydemir et al. (2006a) & \\
\hline $\begin{array}{l}\text { Distal arthrogryposis type } 2 b \text {, } \\
\text { Sheldon-Hall syndrome }\end{array}$ & 16.13 & $\mathrm{AD}$ & $\begin{array}{l}\text { DA2B, } \\
601680\end{array}$ & $9 \mathrm{p} 13$ & $\begin{array}{l}\text { TPM2 } \\
190990\end{array}$ & $\begin{array}{l}\text { Tropomyosin } 2 \\
\text { (beta) }\end{array}$ & $\begin{array}{l}\text { Tajsharghi et al. (2007c); } \\
\text { Ochala et al. (2007) }\end{array}$ & $\begin{array}{l}\text { NEM4 (group 3), CAP disease } \\
\text { (group 3), DA1 (group 16) }\end{array}$ \\
\hline $\begin{array}{l}\text { Arthrogryposis multiplex } \\
\text { congenita with nesprin-1 defect }\end{array}$ & 16.14 & $\mathrm{AR}$ & $\mathrm{AMC}$ & $6 q 25$ & $\begin{array}{l}\text { SYNE1 } \\
608441\end{array}$ & $\begin{array}{l}\text { Spectrin repeat } \\
\text { containing, nuclear } \\
\text { envelope } 1 \\
\text { (nesprin-1) }\end{array}$ & Attali et al. (2009) & \\
\hline $\begin{array}{l}\text { Arthrogryposis multiplex } \\
\text { congenita with cerebral and } \\
\text { cerebellar atrophy }\end{array}$ & 16.15 & $\mathrm{AR}$ & $\begin{array}{l}\text { LCCS7 } \\
616286\end{array}$ & $17 \mathrm{q} 21.2$ & $\begin{array}{l}\text { CNTNAP1 } \\
602346\end{array}$ & $\begin{array}{l}\text { Contactin-Associated } \\
\text { Protein } 1\end{array}$ & Laquérriere et al. (2014) & \\
\hline Trismus-pseudocamptodactyly & 16.16 & $\mathrm{AD}$ & 608837 & $17 \mathrm{p} 13$ & $\begin{array}{l}\text { МYH8 } \\
160741\end{array}$ & $\begin{array}{l}\text { Myosin heavy } \\
\text { chain, } 8 \text {, skeletal } \\
\text { muscle, perinatal }\end{array}$ & $\begin{array}{l}\text { Veugelers et al. (2004); } \\
\text { Toydemir et al. (2006b) }\end{array}$ & \\
\hline $\begin{array}{l}\text { Progressive external } \\
\text { ophthalmoplegia with } \\
\text { mitochondrial DNA deletions, }\end{array}$ & 16.17 & $\mathrm{AD}$ & $\begin{array}{l}\text { PEOA1 } \\
157640\end{array}$ & $15 \mathrm{q} 25$ & $\begin{array}{l}\text { POLG } \\
174763\end{array}$ & $\begin{array}{l}\text { Polymerase, DNA, } \\
\text { gamma (M) }\end{array}$ & Van Goethem et al. (2001) & \\
\hline
\end{tabular}




\begin{tabular}{|c|c|c|c|c|c|c|c|c|}
\hline DISEASE NAME & $\begin{array}{l}\text { Item } \\
\text { line } \\
\text { in this } \\
\text { group }\end{array}$ & Inheritance & $\begin{array}{l}\text { Locus or } \\
\text { disease } \\
\text { symbol and } \\
\text { OMIM } \\
\text { number }\end{array}$ & Chromosome & $\begin{array}{l}\text { Gene symbol } \\
\text { and OMIM } \\
\text { number }\end{array}$ & $\begin{array}{l}\text { Protein } \\
\text { (mitochondrial } \\
\text { proteins indicated } \\
\text { by symbol }[M] \text { ) }\end{array}$ & $\begin{array}{l}\text { Key } \\
\text { references }\end{array}$ & $\begin{array}{l}\text { Other allelic disease(s) } \\
\text { (group in this table) }\end{array}$ \\
\hline $\begin{array}{l}\text { Progressive external } \\
\text { ophthalmoplegia with } \\
\text { mitochondrial DNA deletions, } \\
\text { autosomal dominant, } 2 \text {; }\end{array}$ & 16.18 & $\mathrm{AD}$ & $\begin{array}{l}\text { PEOA2 } \\
609283\end{array}$ & $4 q 35$ & $\begin{array}{l}\text { ANT1 } \\
103220\end{array}$ & $\begin{array}{l}\text { Mitochondrial } \\
\text { carrier, adenine } \\
\text { nucleotide } \\
\text { translocator. ant1 } \\
\text { (M)] }\end{array}$ & Kaukonen et al. (2000) & \\
\hline $\begin{array}{l}\text { Progressive external } \\
\text { ophthalmoplegia with } \\
\text { mitochondrial DNA deletions, } \\
\text { autosomal dominant, } 3\end{array}$ & 16.19 & $\mathrm{AD}$ & $\begin{array}{l}\text { PEOA3 } \\
609286\end{array}$ & $10 \mathrm{q} 24$ & $\begin{array}{l}\text { PEO1 } \\
\text { (C10ORF2) } \\
606075\end{array}$ & $\begin{array}{l}\text { Twinkle, } \mathrm{t} 7 \text { gene } \\
\text { 4-like protein with } \\
\text { intramitochondrial } \\
\text { nucleoid } \\
\text { localization (M) }\end{array}$ & $\begin{array}{l}\text { Suomalinen et al. (1997) } \\
\text { Spelbrink et al. (2001) }\end{array}$ & Allelic to IOSCA (group 13) \\
\hline $\begin{array}{l}\text { Progressive external } \\
\text { ophthalmoplegia with } \\
\text { mitochondrial DNA deletions, } \\
\text { autosomal dominant, } 4\end{array}$ & 16.20 & $\mathrm{AD}$ & $\begin{array}{l}\text { PEOA4 } \\
610131\end{array}$ & $10 \mathrm{q} 24$ & $\begin{array}{l}\text { POLG2 } \\
604983\end{array}$ & $\begin{array}{l}\text { Polymerase (DNA } \\
\text { directed), gamma 2, } \\
\text { accessory subunit } \\
\text { (M) }\end{array}$ & Longley et al. (2006) & \\
\hline $\begin{array}{l}\text { Progressive external } \\
\text { ophthalmoplegia with } \\
\text { mitochondrial DNA deletions, } \\
\text { autosomal dominant, } 5\end{array}$ & 16.21 & $\mathrm{AD}$ & $\begin{array}{l}\text { PEOA5 } \\
613077\end{array}$ & $8 \mathrm{q} 23$ & $\begin{array}{l}\boldsymbol{R R M 2} \\
604712\end{array}$ & $\begin{array}{l}\text { Ribonucleotide } \\
\text { reductase M2 B } \\
\text { (M) }\end{array}$ & Tyynismaa et al., 2009 & Allelic to MTDP8B (group 16) \\
\hline $\begin{array}{l}\text { Mitochondrial DNA depletion } \\
\text { myopathy }\end{array}$ & 16.22 & $\mathrm{AR}$ & $\begin{array}{l}\text { MTDPS3 } \\
609560\end{array}$ & $16 \mathrm{q} 22$ & $\begin{array}{l}\text { TK2 } \\
188250\end{array}$ & $\begin{array}{l}\text { Thymidine kinase, } \\
\text { mitochondrial (M) }\end{array}$ & Saada et al. (2001) & \\
\hline $\begin{array}{l}\text { Mitochondrial DNA depletion } \\
\text { myopathy, encephalomyopathic } \\
\text { form }\end{array}$ & 16.23 & $\mathrm{AR}$ & $\begin{array}{l}\text { MTDPS5 } \\
612073\end{array}$ & $13 q 12-q 13$ & $\begin{array}{l}\text { SUCLA2 } \\
603921\end{array}$ & $\begin{array}{l}\text { Succinate-CoA } \\
\text { ligase, adp-forming, } \\
\text { beta subunit (M) }\end{array}$ & Elpeleg et al. (2005) & \\
\hline $\begin{array}{l}\text { Mitochondrial DNA depletion } \\
\text { myopathy }\end{array}$ & 16.24 & $\mathrm{AR}$ & $\begin{array}{l}\text { MTDP8B } \\
612075\end{array}$ & $8 \mathrm{q} 23$ & $\begin{array}{l}\boldsymbol{R R M} 2 \boldsymbol{B} \\
604712\end{array}$ & $\begin{array}{l}\text { Ribonucleotide } \\
\text { reductase, M2B } \\
\text { (M) }\end{array}$ & Bourdon et al. (2007) & Allelic to PËOA5 (group 16) \\
\hline Mitochondrial myopathy & 16.25 & $\mathrm{AR}$ & & $19 \mathrm{p} 13.11$ & $\begin{array}{l}S L C 25 A 42 \\
610823\end{array}$ & $\begin{array}{l}\text { solute carrier } \\
\text { family } 25 \text { member } \\
42 \text { (M) }\end{array}$ & Shamseldin et al. (2015) & \\
\hline $\begin{array}{l}\text { Progressive external } \\
\text { ophthalmoplegia with optic } \\
\text { atrophy, optic atrophy } 1 \text { with } \\
\text { deafness }\end{array}$ & 16.26 & Ad & 125250 & $3 q 28-q 29$ & $\begin{array}{l}\text { OPA1 } \\
605290\end{array}$ & $\begin{array}{l}\text { Opa1 protein, } \\
\text { dynamin related } \\
\text { gtpase }(\mathbf{M})\end{array}$ & $\begin{array}{l}\text { Amati-Bonneau et al. (2008) } \\
\text { Hudson et al. (2008) }\end{array}$ & \\
\hline Tubular aggregate myopathy 1 & 16.27 & $\mathrm{AD}$ & $\begin{array}{l}\text { TAM1 } \\
160565\end{array}$ & $11 \mathrm{p} 15.4$ & $\begin{array}{l}\text { STIM1 } \\
605921\end{array}$ & $\begin{array}{l}\text { Stromal interaction } \\
\text { molecule } 1\end{array}$ & $\begin{array}{l}\text { Bohm et al. (2013) } \\
\text { Hedberg et al. (2014) } \\
\text { Nesin et al. (2014), }\end{array}$ & \\
\hline Tubular aggregate myopathy 2 & 16.28 & $\mathrm{AD}$ & $\begin{array}{l}\text { TAM2 } \\
615883\end{array}$ & $12 \mathrm{q} 24.31$ & $\begin{array}{l}\text { ORAI1 } \\
610277\end{array}$ & $\begin{array}{l}\text { ORAI calcium } \\
\text { release-activated } \\
\text { calcium modulator } \\
1\end{array}$ & Nesin et al. (2014) & \\
\hline $\begin{array}{l}\text { Mitochondrial myopathy and } \\
\text { sideroblastic anemia } 1\end{array}$ & 16.29 & AR & $\begin{array}{l}\text { MLASA1 } \\
600462\end{array}$ & $12 \mathrm{q} 24.33$ & $\begin{array}{l}\text { PUS1 } \\
608109\end{array}$ & $\begin{array}{l}\text { Pseudouridylate } \\
\text { synthase } 1 \text { (M) }\end{array}$ & $\begin{array}{l}\text { Bykhovskaya et al. (2004) } \\
\text { Fernandez-Vizarra (2007) }\end{array}$ & \\
\hline Mitochondrial myopathy & 16.30 & $\mathrm{AD}$ & & $22 \mathrm{q} 11$ & $\begin{array}{l}\text { CHCHD10 } \\
(=C 22 \text { ORF16) } \\
615903\end{array}$ & $\begin{array}{l}\text { Coiled-coil-helix } \\
\text {-coiled-coil-helix } \\
\text { domain containing } \\
10(\mathbf{M})\end{array}$ & Ajroud-Driss et al. (2014) & $\begin{array}{l}\text { allelic to FTDALS2 and SMAJ } \\
\text { (group 12) }\end{array}$ \\
\hline $\begin{array}{l}\text { Vacuolar myopathy with } \\
\text { accumulation of sarcoplasmic } \\
\text { reticulum protein aggregates }\end{array}$ & 16.31 & $?$ & $\begin{array}{l}\text { VMCQA } \\
616231\end{array}$ & $1 \mathrm{q} 21$ & $\begin{array}{l}C A S Q 1 \\
114250\end{array}$ & $\begin{array}{l}\text { Calsequestrin } 1 \\
\text { (fast-twitch, } \\
\text { skeletal muscle) } \\
\text { (M) }\end{array}$ & Rossi et al. (2014) & \\
\hline $\begin{array}{l}\text { Myopathy, lactic acidosis, and } \\
\text { sideroblastic anemia-2 }\end{array}$ & 16.32 & AR & $\begin{array}{l}\text { MLASA2 } \\
613561\end{array}$ & $12 \mathrm{p} 11.21$ & $\begin{array}{l}\text { YARS2 } \\
610957\end{array}$ & $\begin{array}{l}\text { Tyrosyl-tRNA } \\
\text { synthetase 2, } \\
\text { mitochondrial (M) }\end{array}$ & Riley et al. (2010) & \\
\hline $\begin{array}{l}\text { poikiloderma, hereditary } \\
\text { fibrosing, with tendon } \\
\text { contractures, myopathy, and } \\
\text { pulmonary fibrosis }\end{array}$ & 16.33 & $\mathrm{AD}$ & $\begin{array}{l}\text { POIKTMP } \\
615704\end{array}$ & $11 \mathrm{q} 12.1$ & $\begin{array}{l}\text { FAM111B } \\
615584\end{array}$ & $\begin{array}{l}\text { Family With } \\
\text { Sequence Similarity } \\
111, \text { Member B }\end{array}$ & Mercier et al. (2015) & \\
\hline $\begin{array}{l}\text { Combined Oxidative } \\
\text { phosphorylation Deficiency 6; }\end{array}$ & 16.34 & $\mathrm{XL}$ & $\begin{array}{l}\text { COXPD6 } \\
300816\end{array}$ & $\mathrm{Xq} 26.1$ & $\begin{array}{l}\text { AIFM1 } \\
300169\end{array}$ & $\begin{array}{l}\text { Apoptosis-Inducing } \\
\text { Factor, } \\
\text { Mitochondria- } \\
\text { Associated, } 1 \text { (M) }\end{array}$ & Morton et al. (2017) & \\
\hline $\begin{array}{l}\text { Mitochondrial myopathy with } \\
\text { severe neurological } \\
\text { manifestations }\end{array}$ & 16.35 & $\mathrm{AR}$ & & $8 \mathrm{q} 24.13$ & $\begin{array}{l}\text { TMEM65 } \\
616609\end{array}$ & $\begin{array}{l}\text { Transmembrane } \\
\text { Protein } 65\end{array}$ & Nasli et al. (2017) & \\
\hline MELAS-like syndrome & 16.36 & $\mathrm{AR}$ & 220110 & $2 \mathrm{q} 33.3$ & $\begin{array}{l}\text { FASTKD2 } \\
612322\end{array}$ & $\begin{array}{l}\text { Fast Kinase } \\
\text { Domains } 2\end{array}$ & Yoo et al. (2017) & \\
\hline $\begin{array}{l}\text { Infantile-onset multisystem } \\
\text { disease with progressive } \\
\text { muscle weakness }\end{array}$ & 16.37 & $\mathrm{AR}$ & $\begin{array}{l}\text { IMNEPD } \\
616263\end{array}$ & $17 q 23.1$ & $\begin{array}{l}\text { PTRH2 } \\
608625\end{array}$ & $\begin{array}{l}\text { Peptidyl-tRNA } \\
\text { Hydrolase } 2\end{array}$ & Hu et al. (2014) & \\
\hline
\end{tabular}




\section{NEW REFERENCES}

\section{GROUP 1. MUSCULAR DYSTROPHIES}

Servian-Morilla E., Takeuchi H., Lee T.V., Clarimon J., Mavillard F., Area-Gómez E., et al. A POGLUT1 mutation causes a muscular dystrophy with reduced Notch signaling and satellite cell loss. EMBO Molec. Med. 8: 1289-1309, 2016. PMID: 27807076. [Item \#1.46]

\section{GROUP 2. CONGENITAL MUSCULAR DYSTROPHIES}

Geis T., Marquard K., Rödl T., Reihle C., Schirmer S., von Kalle T., et al. Homozygous dystroglycan mutation associated with a novel muscle-eye-brain disease-like phenotype with multicystic leucodystrophy. Neurogenetics 14: 205-213, 2013. PMID: 24052401. [Item \#2.37]

Osborn D.P.S., Pond H.L., Mazaheri N., Dejardin J., Munn C.J., Mushref K., et al. Mutations in INPP5K cause a form of congenital muscular dystrophy overlapping Marinesco-Sjögren syndrome and dystroglycanopathy. Am. J. Hum. Genet. 100: 537-545, 2017. PMID: 28190459. [Item \#2.49]

Wiessner M., Roos A., Munn C.J., Viswanathan R., Whyte T., Cox D., et al. Mutations in INPP5K, encoding a phosphoinositide 5-phosphatase, cause congenital muscular dystrophy with cataracts and mild cognitive impairment. Am. J. Hum. Genet. 100: 523-536, 2017. PMID: 28190456. [Item \#2.49]

\section{GROUP 3. CONGENITAL MYOPATHIES}

Di Gioia S.A., Connors S., Matsunami N., Cannavino J., Rose M.F., Gilette N.M., et al. A defect in myoblast fusion underlies Carey-Fineman-Ziter syndrome. Nature Commun. 8:16077, 2017. PMID: 28681861. [Item \#3.51]

Knierim E., Gill E., Seifert F., Morales-Gonzalez S., Unudurthi S.D., Hund T.J., et al. A recessive mutation in betaIV-spectrin (SPTBN4) associates with congenital myopathy, neuropathy, and central deafness. Hum. Genet. 136: 903-910, 2017. PMID: 28540413. [Item \#3.47]

Lornage X., Malfatti E., Chéraud C., Schneider R., Biancalana V., Cuisset J.M., et al. Recessive MYPN mutations cause cap myopathy with occasional nemaline rods. Ann Neurol. 2017 Mar;81(3):467-473. PMID: 28220527. [Item \#3.11]

Malfatti E., Böhm J., Lacène E., Beuvin M., Romero N.B., Laporte J. A Premature Stop Codon in MYO18B is Associated with Severe Nemaline Myopathy with Cardiomyopathy. Journal of Neuromuscular Diseases 2 (2015) 219-227 PMID: 27858739. [Item \#3.49]

Miyatake S., Mitsuhashi S., Hayashi Y.K., Purejiav E., Nishikawa A., Koshimizu E., et al. Biallelic mutations in MYPN, encoding myopalladin, are associated with childhoodonset, slowly progressive nemaline myopathy. Am. J. Hum. Genet. 100: 169-178, 2017. PMID: 28017374. [Item \#3.11]

Quélin C., Loget P., Rozel C., D'Hervé D., Fradin M., Demurger F., et al. Fetal costello syndrome with neuromuscular spindles excess and p.Gly12Val HRAS mutation. Eur J Med Genet. 2017 Jul;60(7):395-398. PMID: 28455154. [Item $\# 3.50]$
Vasli N., Harris E., Karamchandani J., Bareke E., Majewski J., Romero N.B., et al. Recessive mutations in the kinase ZAK cause a congenital myopathy with fibre type disproportion. Brain. 2017 Jan;140(Pt 1):37-48 PMID: 27816943. [Item \#3.48]

\section{GROUP 9. METABOLIC MYOPATHIES}

Taylor R.W., Pyle A., Griffin H., Blakely E.L., Duff J., He L., et al. Use of whole-exome sequencing to determine the genetic basis of multiple mitochondrial respiratory chain complex deficiencies. JAMA 312: 68-77, 2014. PMID: 25058219. [Item \#9.30]

\section{GROUP 10-A HEREDITARY CARDIOMYOPATHIES (NON-ARRHYTHMOGENIC)}

Arndt A.K., Schafer S., Drenckhahn J.D., Sabeh M.K., Plovie E.R., Caliebe A., et al. Fine mapping of the 1p36 deletion syndrome identifies mutation of PRDM16 as a cause of cardiomyopathy. Am. J. Hum. Genet. 93: 67-77, 2013. PMID: 23768516. [Item \#10.68]

Chiu C., Tebo M., Ingles J., Yeates L., Arthur J.W., Lind J.M., et al. Genetic screening of calcium regulation genes in familial hypertrophic cardiomyopathy. J. Molec. Cell. Cardiol. 43: 337343, 2007. PMID: 17655857. [Item \#10.20]

Dhandapany P.S., Razzaque M.A., Muthusami U., Kunnoth S., Edwards J.J., Mulero-Navarro S., et al. RAF1 mutations in childhood-onset dilated cardiomyopathy. Nature Genet. 46: 635-639, 2014. PMID: 24777450. [Item \#10.70]

Hayashi T., Arimura T., Itoh-Satoh M., Ueda K., Hohda S., Inagaki $\mathrm{N}$., et al. Tcap gene mutations in hypertrophic cardiomyopathy and dilated cardiomyopathy. J. Am. Coll. Cardiol. 44: 2192-2201, 2004. PMID: 15582318. [Item $\# 10.26]$

Norton N., Li D., Rieder M.J., Siegfried J.D., Rampersaud E., Züchner S., et al. Genome-wide studies of copy number variation and exome sequencing identify rare variants in BAG3 as a cause of dilated cardiomyopathy. Am. J. Hum. Genet. 88: 273-282, 2011. PMID: 21353195. [Item \#10.64]

Posch M.G., Posch M.J., Geier C., Erdmann B., Mueller W., Richter A., et al. A missense variant in desmoglein-2 predisposes to dilated cardiomyopathy. Mol. Genet. Metab. 95: 74-80, 2008. PMID: 18678517. [Item \#10.59]

Purevjav E., Arimura T., Augustin S., Huby A.C., Takagi K., Nunoda S., et al. Molecular basis for clinical heterogeneity in inherited cardiomyopathies due to myopalladin mutations. Hum. Molec. Genet. 21: 2039-2053, 2012. PMID: 22286171. [Item \#10.23]

Theis J.L., Bos J.M., Bartleson V.B., Will M.L., Binder J., Vatta M., et al. Echocardiographic-determined septal morphology in Z-disc hypertrophic cardiomyopathy. Biochem. Biophys. Res. Commun. 351: 896-902, 2006. PMID: 17097056. [Item \#10.25]

\section{GROUP 11. CONGENITAL MYASTHENIC SYNDROMES}

Maselli R.A., Arredondo J., Vázquez J., Chong J.X., Bamshad M.J., Nickerson D.A., et al. Presynaptic congenital 
myasthenic syndrome with a homozygous sequence variant in LAMA5 combines myopia, facial tics, and failure of neuromuscular transmission. Am J Med Genet A. 2017 Aug;173(8):2240-2245. PMID: 28544784 [Item \#11.35]

O'Grady G.L., Verschuuren C., Yuen M., Webster R., Menezes M., Fock J.M., et al. Variants in SLC18A3, vesicular acetylcholine transporter, cause congenital myasthenic syndrome. Neurology 87: 1442-1448, 2016. PMID: 27590285. [Item \#11.27]

Salpietro V., Lin W., Delle Vedove A., Storbeck M., Liu Y., Efthymiou S., et al. Homozygous mutations in VAMP1 cause a presynaptic congenital myasthenic syndrome. Ann Neurol. 2017 Apr;81(4):597-603. doi: 10.1002/ana.24905. Epub 2017 Mar 29. [Item \#11.34]

Shen X.M., Scola R.H., Lorenzoni P.J., Kay C.S., Werneck L.C., Brengman J., et al. Novel synaptobrevin-1 mutation causes fatal congenital myasthenic syndrome. Ann Clin Transl Neurol. 2017 Jan 16;4(2):130-138. doi: 10.1002/acn3.387. eCollection 2017. PMID 28168212 [Item \#11.34]

\section{GROUP 12. MOTOR NEURON DISEASES}

Li X., Hu Z., Xie Y., Zhan Y., Zi X., Wang J., et al. A SIGMAR1 splice-site mutation causes distal hereditary motor neuropathy. Neurology 84: 2430-2437, 2015. PMID: 26078401. [Item \#12.6]

Smith B.N., Ticozzi N., Fallini C., Gkazi A.S., Topp S., Kenna K.P., et al. Exome-wide rare variant analysis identifies TUBA4A mutations associated with familial ALS. Neuron 84: 324-331, 2014. PMID: 25374358. [Item \#12.60]

Stoll M., Teoh H., Lee J., Reddel S., Zhu Y., Buckley M., et al. Novel motor phenotypes in patients with VRK1 mutations without pontocerebellar hypoplasia. Neurology. 2016 Jul 5;87(1):65-70. PMID 27281532. [Item 12.72]

Takahashi Y., Fukuda Y., Yoshimura J., Toyoda A., Kurppa $\mathrm{K}$., Moritoyo T., et al. ERBB4 mutations that disrupt the neuregulin-ErbB4 pathway cause amyotrophic lateral sclerosis type 19. Am. J. Hum. Genet. 93: 900-905, 2013. PMID: 24119685. [Item \#12.57]

Tsai P.C., Soong B.W., Mademan I., Huang Y.H., Liu C.R., Hsiao C.T., et al. A recurrent WARS mutation is a novel cause of autosomal dominant distal hereditary motor neuropathy. Brain. 2017 Mar 22. PMID: 28369220. [Item \#12.23]

van Dijk T., Rudnick-Schöneborn S., Senderek J., Haimousa G., Mei H., Dusl M., et al. Pontocerebellar hypoplasia with spinal muscular atrophy (PCH1): identification of SLC25A46 mutations in the original Dutch PCH1 family. Brain. 2017 Aug 1;140(8):e46. PMID: 28637197. [Item \#12.73]

\section{GROUP 14. HEREDITARY MOTOR SENSORY NEUROPATHIES (HMSN)}

Atkinson D., Nikodinovic Glumac J., Asselbergh B., Ermanoska B., Blocquel D., Steiner R., et al. Sphingosine 1-phosphate lyase deficiency causes Charcot-Marie-Tooth neuropathy. Neurology. 2017 Feb 7;88(6):533-542. PMID: 28077491. [Item \#14.80]

Brewer M.H, .Chaudhry R., Qi J., Kidambi A., Drew A.P., Menezes M.P., et al. Whole Genome Sequencing Identifies a 78 $\mathrm{kb}$ Insertion from Chromosome 8 as the Cause of CharcotMarie-Tooth Neuropathy CMTX3. PLoS Genet. 2016 Jul 20;12(7):e1006177. PMID: 27438001. [Item \#14.33]

Gonzalez M.A., Feely S.M., Speziani F., Strickland A.V., Danzi M., Bacon C., et al. A novel mutation in VCP causes Charcot-Marie-Tooth type 2 disease. Brain 137: 2897-2902, 2014. PMID: 25125609. [Item \#14.61]

Noury J.B., Maisonobe T., Richard P., Delague V., Malfatti E., Stojkovic T. Rigid spine syndrome associated with sensorymotor axonal neuropathy resembling Charcot-Marie-Tooth disease is characteristic of $\mathrm{Bcl}-2$-associated athanogene-3 gene mutations even without cardiac involvement. Muscle Nerve. 2017 Feb 22. doi: 10.1002/mus.25631. PMID: 28224639. [Item \#14.67]

Rebelo A.P., Abrams A.J., Cottenie E., Horga A., Gonzalez M., Bis D.M., et al. Cryptic Amyloidogenic Elements in the 3' UTRs of Neurofilament Genes Trigger Axonal Neuropathy. Am J Hum Genet. 2016 Apr 7;98(4):597-614 PMID: 27040688. [Item \#14.66]

\section{GROUP 16. OTHER NEUROMUSCULAR DISORDERS}

Hu H., Matter M.L., Issa-Jahns L., Jijiwa M., Kraemer N., Musante L., et al. Mutations in PTRH2 cause novel infantileonset multisystem disease with intellectual disability, microcephaly, progressive ataxia, and muscle weakness. Ann. Clin. Transl. Neurol. 1: 1024-1035, 2014. PMID: 25574476. [Item \#16.37]

Laquérriere A., Maluenda J., Camus A., Fontenas L., Dieterich K., Nolent F., et al. Mutations in CNTNAP1 and ADCY6 are responsible for severe arthrogryposis multiplex congenita with axoglial defects. Hum. Molec. Genet. 23: 22792289, 2014. PMID: 24319099. [Item \#16.15]

Morton S.U., Prabhu S.P., Lidov H.G.W., Shi J., Anselm I., Brownstein C.A., et al. AIFM1 mutation presenting with fatal encephalomyopathy and mitochondrial disease in an infant. Cold Spring Harb Mol Case Stud. 2017 Mar;3(2): a001560. doi: 10.1101/mcs.a001560. PMID:28299359. [Item \#16.34]

Nazli A., Safdar A., Saleem A., Akhtar M., Brady L.I., Schwartzentruber J., et al. A mutation in the TMEM65 gene results in mitochondrial myopathy with severe neurological manifestations. Eur J Hum Genet. 2017 Jun;25(6):744-751. doi: 10.1038/ejhg.2017.20. Epub 2017 Mar 15. PMID:28295037. [Item \#16.35]

Yoo D.H., Choi Y.C., Nam D.E., Choi S.S., Kim J.W., Choi B.O., et al. Identification of FASTKD2 compound heterozygous mutations as the underlying cause of autosomal recessive MELAS-like syndrome. Mitochondrion. 2017 Jul;35:54-58. doi: 10.1016/j.mito.2017.05.005. Epub 2017 May 9. PMID:28499982. [Item \#16.36] 